\title{
I DIRITTI SOCIALI E L'UNIONE EUROPEA
}

O DIREITO SOCIAL NA UNIÃO EUROPEA

Silvio Gambino

Università della Calabria - UNICAL - Arcavacata di Rende - Itália

\section{I diritti sociali fondamentali (fra Costituzioni e legislazione):} \section{l'esperienza dei Paesi europei in un'ottica comparatistica}

Se può ancora affermarsi che il deficit democratico e le stesse derive tecnocratiche rendono il sistema costituzionale europeo ancora poco idoneo ad ampliare gli orizzonti della democrazia (almeno di quella costituzionale, individuata nella bisecolare evoluzione successiva alla Déclaration des droits de l'homme et du citoyen), appare ancora più evidente che il suo costituzionalismo, con la relativa frammentarietà, non induce a prefigurare un processo lineare di inequivocabile $e$ progressiva riproduzione dei canoni costituzionalistici del XX secolo, appena trascorso ${ }^{1}$. II costituzionalismo europeo se, da un lato, assorbe con gradualità crescente i poteri e le competenze degli Stati nazionali, erodendo l'essenza stessa delle loro Costituzioni, dall'altro, ha evitato di ricalcarne le forme, di rifletterne i princìi e di riecheggiarne i valori, dispiegando al nuovo secolo una gracile trama istituzionale su cui appare difficile tessere, con l'ordito di una cittadinanza che "integra" ma non "supplisce" quella nazionale, una nuova e più "progressiva" epoca dei diritti e delle libertà.

\footnotetext{
${ }^{1}$ Sulle problematiche costituzionali poste dal 'Trattato che istituisce una Costituzione per l'Europa' (il cui iter, come è noto, fu bloccato a seguito della bocciatura referendaria della Francia e dell'Olanda, nel mentre era stato già ratificato da 18 Paesi, fra cui l'Italia), nell'ampia bibliografia, cfr. anche i nostri "Diritti fondamentali, costituzioni nazionali e trattati comunitari" nonché "La protezione dei diritti fondamentali fra Trattato costituzionale europeo e costituzioni nazionali. Prefazione", ambedue in S. Gambino (a cura di), Trattato che adotta una Costituzione per l'Europa, costituzioni nazionali, diritti fondamentali, Milano, 2006), nonché "Diritti fondamentali europei e Trattato costituzionale", in M. Scudiero, II trattato costituzionale nel processo di integrazione europea, Napoli, 2005.
} 
In tale quadro, il "diritto costituzionale europeo"2 - da tempo in via di lenta formazione, - evidenzia due fondamentali e distinte componenti. La prima - più immediata da cogliere - è data dal diritto dell'Unione che, tenuto conto della giurisprudenza intervenuta sui principi generali, penetra in tutti i diritti positivi nazionali, e la cui diretta applicabilità ${ }^{3}$ e prevalenza ${ }^{4}$ risultano da tempo consolidati dai decisa della Corte di Giustizia, salva l'eventuale confliggenza con i diritti fondamentali (soprattutto sociali) costituzionalmente garantiti dai singoli Stati ${ }^{5}$. Sulla seconda ci soffermeremo più a lungo in seguito, sottolineando luci e ombre della tutela dei diritti fondamentali a livello di Unione, esaminata fra prospettive di una giurisprudenza di tipo pretorio e incertezze del processo di positivizzazione normativa degli stessi diritti fondamentali, il cui approdo (prima nel Trattato costituzionale e ora nei nuovi trattati, riformati a Lisbona) è costituito dalla Carta dei diritti fondamentali dell'Unione europea (proclamata a Nizza, il 7 dicembre 2000 e nuovamente proclamata, in modo solenne, il 12 dicembre 2007, nell'Aula del Parlamento europeo di Strasburgo), un documento politico che diviene - a seguito della ratifica dei nuovi trattati - strumento giuridico di tutela effettiva degli stessi e, al contempo, vero e proprio Bill of rights materiale del costituzionalismo europeo ${ }^{6}$.

\subsection{Diritti fondamentali e forma di Stato: dal costituzionalismo liberale a} quello sociale

Anche al fine di ricostruire il dibattito culturale che ha approfondito la significativa svolta giurisprudenziale a proposito delle 'tradizioni costituzionali comuni

\footnotetext{
${ }^{2}$ Nell'ampia bibliografia sul tema, cfr. anche il nostro "La Carta e le corti costituzionali. Controlimiti e protezione equivalente", in G. Bronzini - V. Piccone (a cura di), La Carta e le corti, Taranto, 2007.

${ }^{3}$ Sentenza Van Gend en Loos (Causa 26/62, sentenza 5 febbraio 1963).

${ }^{4}$ Sentenza Costa c. Enel (Causa 6/64, sentenza 15 luglio 1964).

${ }^{5}$ Cfr. anche AA.VV. (a cura di S. Gambino), Costituzione italiana e diritto comunitario, Milano, 2002.

${ }^{6}$ Fra gli altri cfr. C. Pinelli, II momento della scrittura, Bologna, 2002; S. Rodotà, "La Carta come atto politico e documento giuridico", in AA.VV. (A. Manzella - P. Melograni - E. Paciotti - S. Rodotà), Riscrivere $i$ diritti in Europa, Bologna, 2001; R. Bifulco - M. Cartabia - A. Celotto, Commento alla Carta dei diritti fondamentali dell'UE, Bologna, 2001; L.S. Rossi, “'Constitutionnalisation' de l'Unione européenne et des droits fondamentaux", in R.T.D.E., 2002, 1, nonché Carta dei diritti fondamentali e Costituzione dell'Unione europea, Milano, 2002; A. Pace, "A che serve la Carta dei diritti fondamentali dell'Unione Europea? Appunti preliminari", in Giur. cost., 2001; A. Barbera, "La Carta dei diritti dell'Unione europea", Relazione al Convegno in memoria di Paolo Barile, ora in http://www.paolobarile.unifi.it/progr.htm.
} 
ai Paesi membri', invocate a supporto dell'individuazione, all'interno della nozione dei principi generali (essa stessa di creazione giurisprudenziale), dei diritti fondamentali dell'Unione, di cui la Corte di Giustizia si è riconosciuta garante, nonché per cogliere la stessa intensità del dibattito interno alla 'Convenzione"7, a mò di premessa (sia pure essenziale), s'impone di analizzare lo statuto giuridico dei diritti fondamentali sociali nei Paesi membri dell'Unione europea. Si tratta di individuarne la natura, la tipologia e la stessa intensità del loro riconoscimento da parte del legislatore ordinario e di quello costituzionale, nonché le forme e l'effettività della relativa protezione giurisdizionale, in una parola l'inventario di tali diritti nell'ambito delle Costituzioni degli Stati membri dell'U.E. ${ }^{8}$.

Sia pure con formule differenziate e di diversa intensità ed estensione nel riconoscimento e nella protezione delle singole e specifiche situazioni giuridiche, dopo la breve e significativa esperienza in materia costituita dalla Costituzione di

\footnotetext{
${ }^{7}$ Istituita - nel giugno del 1999, un mese dopo l'entrata in vigore del Trattato di Amsterdam - dal Consiglio europeo, a Colonia, al fine di elaborare una Carta dei diritti fondamentali che rendesse "più manifesti i diritti fondamentali vigenti nell'Unione". Per cogliere le sfide interne alla negoziazione svolta nella Convenzione, basta mettere a confronto le diverse versioni della Carta, da quella elaborata nel maggio (consilium.eu.int Charte 4316/00, CONVENT 34) a quella di giugno (consilium.eu.int Charte 4423/00 CONVENT 46), fino a quella di settembre (consilium.eu.int Charte 4487/00, CONVENT 50). Fra gli altri, sul punto, cfr. E. Paciotti, "La Carta: i contenuti, gli attori", in AA.VV., Riscrivere i diritti in Europa, Bologna, 2001.

${ }^{8}$ Cfr. J. Iliopoulos Strangas (ed.), La protection des droits sociaux fondamentaux dans les Etats membres de I'Union européenne, Athènes-Bruxelles-Baden-Baden, 2000; F.-F. Flauss, J.F. Flauss (dir.), Droits sociaux et droit européen. Bilan et perspectives de la protection normative, Bruxelles, 2002; AA.VV. (Actes Conférecnce organiseée par le Secrétariat de la Charte sociale européenne, Sofia, Bulgarie, $5 / 7$ juillet 2000), La protection des droits sociaux fondamentaux en Europe par la Charte sociale européenne, Strasbourg, 2001; B. Veneziani, "Nel nome di Erasmo di Rotterdam. La faticosa marcia dei diritti sociali fondamentali nel'ordinamento comunitario", in Riv. giur. lav. e previd. sociale, 2000; I.J. Baquero Cruz, "La protecion de los derechos sociales en la Comunidad europe tras el Tratado de Amsterdam", in Revista de derecho comunitario europeo, 1998, 4; S. Sciarra, "La costituzionalizzazione dell'Europa sociale. Diritti fondamentali e procedure di soft law", IWP (Università di Catania), 2003, n. 16; R. Greco, "Il modello sociale della Carta di Nizza", in G. Bronzini V. Piccone (a cura di), La Carta e le Corti ... cit.; M.M. Mutarelli, "Il ruolo potenziale dei diritti sociali fondamentali nel Trattato costituzionale dell'Unione Europea", IWP (Università di Catania), 2007, n. 54; C. Di Turi, La protezione dei diritti sociali fondamentali a livello internazionale ed europeo", in S. Gambino (a cura di), Costituzione italiana e diritto comunitario ... cit.; S. Giubboni, Diritti sociali e mercato. La dimensione sociale dell'integrazione europea, Bologna, 2003; S. Giubboni, "I diritti sociali fondamentali nell'ordinamento comunitario. Una rilettura alla luce della Carta di Nizza", in II diritto dell'U.E., 2003, nn. 2-3; C. Salazar, "I diritti sociali nella Carta dei diriti fondamentali dell'U.E.: un 'viaggio al termine della notte'?", in G. Ferrari (a cura di), I diritti fondamentali dopo la Carta di Nizza. II costituzionalismo dei diritti, Milano, 2001; G. Zagrebelsky, Diritti e Costituzione nell'U.E., Roma-Bari, 2003; G. Bronzini, "Il modello sociale europeo", in F. Bassanini - G. Tiberi, Le nuove istituzioni europee. Commento al nuovo Trattato europeo, Bologna, 2008.
} 
Weimar (1919), si può affermare che, nel costituzionalismo europeo del secondo dopo-guerra, risulta ormai positivizzato uno stretto rapporto fra concezione (avanzata, 'progressiva') della democrazia, modello di Stato e diritti fondamentali. Diversamente da quanto veniva sancito nel costituzionalismo liberale originario, tale rapporto si fonda sull'ampliamento delle situazioni giuridiche costituzionalmente protette e su una nuova concezione del concetto di libertà, ora strettamente integrato con quello di eguaglianza: non più solo l'eguaglianza che proviene dalla tradizione classica, che vede come intollerabili le discriminazioni fondate sulle differenze di sesso, di religione e di razza, bensì un concetto di eguaglianza che ritiene inaccettabili le differenze che si fondano sul rapporto economico e sociale, ritenendo intollerabili le differenze fondate sulla capacità di reddito ${ }^{9}$. Unitamente a quelli classici di libertà, in tale concezione, i diritti sociali sono assunti come condizioni 'costitutive', indefettibili, del principio costituzionale di eguaglianza (art. 3 Cost.) e, al contempo, del valore della persona (art. 2 Cost.).

Dei diritti sociali, come è noto, la dottrina costituzionalistica parla inizialmente come di norme dirette a destinatari speciali, in particolare di diritti condizionati o imperfetti, in quanto fondati su norme che presuppongono l'esercizio della discrezionalità legislativa. Una parte della dottrina, tuttavia, ha già colto come tale discrezionalità non concerna tanto l'an e il quid, cioè il contenuto sostanziale del diritto, bensì solo il quando e il quomodo e, comunque, come bene osserva Mortati, "non in modo tale da comprimere il contenuto minimo necessario a non rendere illusoria la soddisfazione dell'interesse protetto" ${ }^{10}$.

Sulla base di tale approccio dottrinario, che valorizza il profilo programmatico delle disposizioni costituzionali in materia di diritti sociali e la natura - più che

\footnotetext{
${ }^{9}$ Nell'ampia bibliografia, sul punto cfr., almeno, A. Cerri, "Uguaglianza (principio costituzionale di)", in Enciclopledia Giuridica Treccani, e da ultimo AA.VV. (Atti Convegno in ricordo di Livio Paladin, Padova 2 aprile 2001), Corte costituzionale e principio di eguaglianza, Padova, 2002; R. Greco, "Diritti sociali, logiche di mercato e ruolo della Corte costituzionale", in Questioni Giustizia, 1994, n. 2-3; A. Di Giovine - M. Dogliani, "Dalla democrazia emancipante alla democrazia senza qualità?", in Questione Giustizia, 1993; E. Cheli, "Classificazione e protezione dei diritti economici e sociali nella Costituzione italiana", in Scritti in onore di L. Mengoni. Le ragioni del diritto, Milano, 1995; P. Caretti, I diritti fondamentali. Libertà e diritti sociali, Torino, 2002; B. Pezzini, La decisione sui diritti sociali, Milano, 2002; C. Salazar, Dal riconoscimento alla garanzia dei diritti sociali, Torino, 2000.

${ }^{10} \mathrm{Cfr}$. C. Mortati "Appunti per uno studio sui rimedi giurisdizionali contro comportamenti omissivi del legislatore", in Foro italiano, 1970.
} 
costituzionale - 'legale' che li regola, a partire dagli anni '70, la dottrina costituzionale propone letture e tipologie più articolate, tra cui rileva, in particolare, quella che distingue fra diritti sociali 'condizionati' (artt. 38; 34; 32; 38, III co.; 46 Cost.) e diritti sociali 'incondizionati' (artt. 36, I, II e III commi; 32, II co.; 37; 29; 30; 4 Cost.). I primi presuppongono un intervento del legislatore, del potere politico, sul quando, sul quomodo e sull'an; gli altri, invece, hanno una struttura e una natura tale per cui non occorrono ulteriori interventi per realizzarli.

Tuttavia, nell'esperienza costituzionale dei Paesi membri dell'Unione europea, non sempre è dato cogliere una positivizzazione dei diritti sociali fondamentali come situazioni giuridiche costituzionalmente riconosciute e protette in modo comparabile alle libertà c.d. negative. I diritti civili e politici, in tal senso, vengono riconosciuti da tutte le Costituzioni europee, venendo assunti come base comune di azione da parte della totalità degli Stati democratici moderni. Soltanto con l'evoluzione della forma statuale contemporanea, soprattutto nel costituzionalismo successivo alla seconda guerra mondiale, si affermano nuove tipologie di diritti fondamentali fondate sulla stretta integrazione fra la nozione di libertà e quella di eguaglianza, individuando una nuova famiglia di diritti - quelli sociali - basata sulla natura o sugli effetti giuridici di tali diritti omologa nella relativa portata a quella delle tradizionali libertà civili. In tale ottica, così, i principi cui s'ispirano le Costituzioni contemporanee - che sono anche principi di giustizia sociale - dilatano il catalogo liberale dei diritti di libertà, inserendovi una "libertà dal bisogno" ${ }^{11}$; in tal modo materializzano il diritto a esigere dallo Stato delle prestazioni atte ad assicurare alla persona e al cittadino almeno un minimo di sicurezza ${ }^{12}$ e di giustizia sociale, sì da creare quelle perequazioni materiali che sole possono rendere gli uomini "liberi ed eguali in dignità e diritti" ${ }^{13}$.

Così, le Costituzioni di cui Weimar è stata la sventurata antesignana, ricalcandone le orme, arricchiscono - superandolo - il patrimonio liberale attraverso quei diritti sociali che, impegnando lo Stato nella ricerca di nuovi equilibri economici e

\footnotetext{
11 Cfr. N. Bobbio, Sui diritti sociali, in Cinquant'anni di Repubblica italiana (a cura di G. Neppi Modona), Torino, 1997; G. Zagrebelsky, I/ diritto mite, Torino, 1992, p. 124 e nello stesso senso M. Dogliani, Interpretazioni della Costituzione, Milano, 1982, p. 316.

12 Cfr. N. Bobbio, Sui diritti sociali ... cit., p. 122.

${ }^{13}$ Art. 1 della Dichiarazione universale dei diritti dell'uomo.
} 
sociali e nel raggiungimento di sempre più ampi orizzonti di giustizia, rappresentano le radici del suo dinamismo, offrendo alla democrazia del secondo dopoguerra le premesse della sua solidità.

Proprio in questa saldatura dei diritti civili e politici con quelli sociali risiede uno degli aspetti più profondi del costituzionalismo del secondo dopo-guerra, che inaugura, con quella "moralizzazione del diritto" destinata a trovare convinta affermazione in occasione delle più tardive conquiste costituzionali della Spagna post-franchista (1978) e del Portogallo post-salazariano (1976), una nuova stagione dei diritti umani, che inizia proprio dalla loro tutela, ossia dalla collocazione degli stessi su un fondamento più saldo rispetto a quello rappresentato dalla legge dello Stato $^{14}$. Se nell'ordinamento dello Stato liberale i diritti esistono attraverso la legge, nello Stato costituzionale essi esistono attraverso la Costituzione, che della legge rappresenta qualcosa di più e di diverso: essa, infatti, è la fonte prima della produzione giuridica e il centro di riferimento di una società che riconosce nella stessa lo specchio della propria cultura e nei suoi dettati il fondamento delle proprie speranze. I principi, i valori, i diritti che essa contempla e che la società condivide rappresentano perciò un patrimonio da salvaguardare da quella mutevolezza di intenti e di interessi che di norma si riflettono nella legge. Ma ciò è possibile solo nella misura in cui questo patrimonio si pone come una "dotazione giuridica"15 dei suoi titolari, al di sopra della legge ed al riparo dalle sue contingenze. Da qui quel collocarsi delle Costituzioni del secondo dopo-guerra nella sfera più alta del diritto dove lo jus cessa di essere lex e dove i diritti cessano di essere una regola posta dal legislatore per diventare pretese soggettive assolute, che anzi precedono lo stesso Stato, limitandolo nel concreto esercizio del suo potere al loro rispetto.

Dando forma concreta all'hobessiana aspirazione di distinguere il diritto dalla legge e predilegendo l'aristotelico "governo della legge al governo degli uomini",

\footnotetext{
${ }^{14}$ Nell'ampia bibliografia cfr. almeno A. Cassese, I diritti umani, oggi, Roma-Bari, 2005; M. Patrono, I diritti dell'uomo nel Paese d'Europa. Conquiste e nuove minacce nel passaggio da un millennio all'altro, Padova, 2000; S. Panunzio (a cura di), I costituzionalisti e l'Europa. Riflessioni sui mutamenti costituzionali nel processo d'integrazione europea, Milano, 2002; G.F. Ferrari (a cura di), I diritti fondamentali dopo la Carta di Nizza. Il costituzionalismo dei diritti, Milano, 2001.

${ }^{15}$ Così G. Zagrebelsky, II diritto mite ... cit., p. 63; S. Gambino - M. Rizzo, "Le Costituzioni del '900”, in AA.VV. (a cura di L. Lopez Guerra, Estudios de Derecho Constitucional. Homenaje al profesor Dr. D. Joaquín García Morillo, Valencia, 2001.
} 
insomma, il costituzionalismo contemporaneo realizza una sostituzione della sovranità della Costituzione alla sovranità della legge, che trasforma i diritti fondamentali in diritti inviolabili. Se la Costituzione crea uno spazio dei diritti umani, la sua sovranità garantisce la certezza di questi diritti che diventano, dopo (e anche a causa di) Auschwitz, il fondamento universalistico della civile convivenza. Oltre a rappresentare le direttrici dell'agire dello Stato costituzionale e del diritto internazionale nonché il fondamento dell'organizzazione pluralistica della società, infatti, essi definiscono anche i contorni di un diritto più ampio che li assume quale ineludibile presupposto di convivenza pacifica tra gli Stati. Lo Statuto dell'O.N.U. (1945), la Dichiarazione universale dei diritti dell'uomo (1948), la Convenzione europea per la salvaguardia dei diritti dell'uomo e delle libertà fondamentali (1950) confermano e dilatano l'azione dei singoli Stati costituzionali in materia di tutela della dignità umana, contribuendo, così, a segnare i caratteri di questa nuova epoca solennemente celebrata da Bobbio come "l'età dei diritti"

Nella rinascita dei diritti umani del secondo dopoguerra, così, è possibile ritrovare le radici culturali e antropologiche di un'età che cerca di liberarsi per sempre dai fantasmi del passato gettando le ancore nei fondali del pre-positivo ed attribuendo (attraverso le Costituzioni e gli atti del diritto internazionale) validità giuridica a principi che da più di due secoli continuano ad aleggiare autonomamente nella coscienza dei popoli. Se le Costituzioni varate all'indomani dei totalitarismi rappresentano il punto d'arrivo di un'evoluzione costituzionale, esse rappresentano anche il punto di approdo di un'esperienza costituzionale matura che si accinge ad apprestare più adeguate tutele al modello di "nuovo" ordine giuridico. Collocandosi nella sfera più alta del diritto, così, le Costituzioni dell'ultimo dopoguerra diventano, secondo la kelseniana visione, "regole di procedura ma anche regole sostanziali" che riguardano "non già la formazione ma il contenuto delle leggi"17. E proprio in questo essere della Costituzione direttrice e limite degli atti legislativi prende forma quella supremazia della medesima che, conferendo immediata vincolatività ai principi e alle

16 Cfr. N. Bobbio, L'età dei diritti, Torino, 1990. Nell'ampia bibliografia sul punto cfr. anche S. Gambino, "Diritti fondamentali e costituzioni”, in Archivio di diritto costituzionale, 1997, n. 4.

${ }^{17}$ Cfr. H. Kelsen, La giustizia costituzionale, Milano, 1981. 
norme fondamentali, costituisce senza dubbio l'aspetto più innovativo ed originale del costituzionalismo contemporaneo. Oltre a segnare il distacco dalla tradizione costituzionale ottocentesca imperniata sulla legge generale e astratta quale strumento principe della garanzia dei diritti e dei rapporti giuridici, infatti, essa segna anche il distacco dal costituzionalismo razionalizzato dell'inizio del secolo scorso, il quale, pur costruendo degli argini tra Costituzione e legge, non sempre riesce ad essere una garanzia per le libertà e un presidio della democrazia. Nel principio della superiorità della Costituzione si riflette, insomma, la storica esigenza di non lasciare il sistema delle libertà e dei diritti alla mera protezione del principio di legalità e di fare della stessa uno strumento di garanzia e d'indirizzo, di protezione e di promozione. Da qui l'affermazione nelle nuove Costituzioni del secondo dopoguerra di un 'principio di costituzionalità' che, mettendo in crisi la forza assoluta della legge, la sua intangibilità quasi 'sacrale', appresta quelle nuove forme di tutela della Costituzione senza le quali il principio della sua supremazia sarebbe rimasto un'affermazione priva di contenuto. Sulla scia della Costituzione austriaca degli anni '20, le Costituzioni contemporanee, così, rimettono a un apposito organo formalmente giudiziario il compito di sindacare la legittimità costituzionale della legge sì da consentire in ogni momento l'adeguamento del sistema legislativo ai dettati della legge superiore. A differenza del controllo di costituzionalità 'diffuso' ed esclusivamente giurisdizionale della tradizione statunitense (la cosiddetta judicial rewiew, secondo cui ogni giudice è tenuto a disapplicare, nel caso concreto, la legge ritenuta in contrasto con la Costituzione), il costituzionalismo europeo dell'ultimo dopoguerra segue piuttosto la via del controllo 'accentrato' che attribuisce ad un organo ad hoc, variamente denominato nei diversi paesi, la funzione di annullare erga omnes la norma statale ritenuta illegittima ${ }^{18}$.

\footnotetext{
${ }^{18} \mathrm{Si}$ fa eccezione per la Francia in cui il controllo di costituzionalità, seguendo un criterio 'politico' (che diviene però, nel tempo, materialmente giurisdizionale, come negli altri modelli europei di giustizia costituzionale), opera in modo 'preventivo' (nella fase cioè che precede la promulgazione della legge), negli altri Paesi europei è il modello kelseniano della Costituzione di Vienna ad essere ripreso nelle sue linee fondamentali. Sul punto cfr. anche i nostri "La giustizia costituzionale in Francia. II Conseil constitutionnel da regolatore dell'attività dei pubblici poteri a garante delle libertà pubbliche", in Pol. del dir., 1988, n. 4, nonché Sistema delle fonti e controllo di costituzionalità. Il caso francese. Profili storico-dogmatici, Torino, 1988.
} 
1.2 I diritti fondamentali sociali nelle Costituzioni contemporanee.

Ciò richiamato, in via molto generale, della teoria e dell'evoluzione registrata dal costituzionalismo moderno, possiamo ora avanzare qualche considerazione sul panorama dei diritti sociali riconosciuti nelle gran parte delle Costituzioni contemporanee. All'analisi comparata e in ragione dell'esistenza o meno, al loro interno, di previsioni di riconoscimento e di protezione delle prevalenti tipologie di diritto sociale (fra gli altri: diritto al lavoro, diritto all'istruzione e alla formazione, diritto all'abitazione, diritto alla salute, diritto alla sicurezza sociale, diritto alla cultura, diritto ad un ambiente sano), tali Costituzioni evidenziano un fondo comune di riconoscimento dei diritti sociali mediante la loro positivizzazione costituzionale. Al di sopra e al di sotto di tale fondo comune possiamo individuare veri e propri modelli costituzionali di riconoscimento e di protezione di tale tipologia di diritti. Un'ulteriore differenziazione è data dalle peculiari modalità seguite nella garanzia di tali diritti: in alcuni casi essa avviene mediante la mera previsione di clausole generali di protezione dello 'Stato sociale', in altre mediante una positivizzazione dei diritti sociali fondamentali accompagnata dalla previsione di principi costituzionali fondamentali. Tranne l'ordinamento giuridico del Regno Unito (che, come è noto, non dispone di un testo costituzionale formalizzato come tale) e la Costituzione austriaca, in via generale, comunque, può dirsi che le Costituzioni, nel loro complesso, non riconoscono l'insieme dei diritti sociali (nel senso che manca un modello di Costituzione che possa cogliersi come ideal-tipico), limitandosi al loro riconoscimento costituzionale secondo standards medi, bassi ovvero elevati a seconda della diversa tradizione politico-culturale di ciascun Paese. Tale articolazione nell'intensità del loro riconoscimento costituzionale, peraltro, risponde anche a un criterio di tipo geografico, che evidenzia, al contempo, il tipo di consolidamento democratico raggiunto dal costituzionalismo del relativo Paese. Tuttavia, tali valutazioni non possono condurre a trarre la conclusione che, nelle esperienze costituzionali in cui manchi tale positivizzazione, saremmo in presenza di una mancata garanzia di tali diritti. Sotto tale profilo, ad esempio, il caso britannico risulta particolarmente illuminante, qualora si considerino le politiche accolte nel Piano Beveridge (in materia di salute e di servizi sociali) e l'influenza esercitata dallo stesso nello sviluppo dei 
diritti alla salute e all'assistenza sociale nell'ambito del Welfare State europeo postbellico. Diversamente da quanto si prevede per le libertà negative, che sono immediatamente esigibili sotto il profilo della loro giustiziabilità, dunque, per i diritti sociali (ma a ben vedere anche per i diritti politici) è indispensabile l'azione integratrice/attuativa del legislatore ordinario e, a valle, delle pubbliche amministrazioni.

Con specifico riferimento all'intensità del riconoscimento costituzionale dei diritti sociali, tre principali modelli appaiono emergere alla ricerca costituzionale. In un primo modello - diremmo di tipo liberale classico, prevalente (quanto a localizzazione geografica) nei Paesi del Nord Europa - ritroviamo le Costituzioni della Danimarca ${ }^{19}$, dell'Irlanda ${ }^{20}$, il sistema costituzionale del Regno Unito ${ }^{21}$. Ad essi occorre anche aggiungere la Scandinavia, l'Austria ${ }^{22}$ e la Germania ${ }^{23}$. Soprattutto la

\footnotetext{
${ }^{19}$ Nella Costituzione danese ritroviamo tre soli articoli (artt. 74-76) destinati al riconoscimento e alla protezione dei diritti sociali, in particolare diritto al lavoro, diritto all'istruzione e condizioni minime di esistenza. Cfr. R. Nielsen, "La protection des droits sociaux fondamentaux dans l'ordre juridique du Danemark", in J. Iliopoulos Strangas (ed.), La protection des droits sociaux fondamentaux dans les Etats membres de l'Union européenne, Bruxelles, 2000.

${ }^{20}$ La Costituzione irlandese risulta più generosa nel riconoscimento dei diritti sociali: si ricordano in tal senso gli artt. 45 (principi direttivi della politica sociale), 41.1 (famiglia), 40.3 (diritto alla vita del nascituro), 42.4 (istruzione), 40.6 diritto sindacale. Cfr. J.L. Murray - D. Rossa Phelan, "La protection des droits sociaux fondamentaux dans l'ordre juridique de l'Irlande", in J. Iliopoulos Strangas (ed.), La protection des droits sociaux fondamentaux ... cit.

${ }^{21}$ Cfr. D.A.O. Edward - W. Robinson - A. McColgan, "La protection des droits sociaux fondamentaux dans l'ordre juridique du Royaume Uni", in J. lliopoulos Strangas (ed.), La protection des droits sociaux fondamentaux ... cit.

${ }^{22}$ Risalendo a un testo costituzionale del 1867, non desta meraviglia se il diritto costituzionale austriaco non pare disciplinare la materia dei diritti sociali, a meno di non riconoscere come tali la libertà della scienza (art. 17), quella artistica (17a), la libertà di scelta della professione (art. 18). Cfr. Th. Oehlinger - M. Stelzer, "La protection des droits sociaux fondamentaux dans l'ordre juridique de l'Autriche", in J. Iliopoulos Strangas (ed.), La protection des droits sociaux ... cit.

${ }^{23}$ La LFB disciplina la materia dei diritti sociali mediante clausole generali (art. 20, I co.) di protezione dello Stato sociale volte a vincolare i pubblici poteri in ogni loro intervento: "La Repubblica Federale di Germania è uno Stato federale democratico e sociale"; inoltre nella stessa sono previsti l'art. 1 a protezione della dignità della persona umana, l'art. 6 (protezione del matrimonio e della famiglia), l'art. 9.3 (la libertà sindacale), l'art. 12 (la libertà di professione), l'art. 20a (la protezione dell'ambiente). Sul punto, fra gli altri, "La protection des droits sociaux fondamentaux dans l'ordre juridique de l'Allemagne", in J. lliopoulos Strangas (ed.), La protection des droits sociaux fondamentaux ... cit.; D. Schefold, "Lo Stato sociale e la costituzione economica", in Enciclopedia Giuridica Treccani, ad vocem); E. Eichenhofer, "Costituzione e diritto sociale", in Diritto pubblico, 1997; C. Amirante, "Diritti fondamentali e diritti sociali nella giurisprudenza costituzionale", in AA.VV., Diritti di libertà e diritti sociali tra giudice costituzionale e giudice comune, Napoli, 1999; L. Violini, "I diritti fondamentali nelle costituzioni dei Laender della Repubblica federale tedesca come fattore di costruzione delle 'tradizioni costituzionali comuni europee" (paper) e della stessa "Federalismo, regionalismo e sussidiarietà come princìpi organizzativi fondamentali del diritto costituzionale europeo", in M. Scudiero (a cura di), II
} 
Costituzione austriaca e quella britannica, tuttavia, hanno rinunciato del tutto a positivizzare i diritti sociali, ma ciò non significa, come si è già ricordato a proposito della Gran Bretagna, che tali Paesi difettino di un sistema diffuso e parimenti efficace di protezione dei diritti sociali. Al contrario, sotto il profilo in considerazione, parrebbe perfino potersi affermare un orientamento dottrinario - che non si condivide - circa la non essenzialità della previsione costituzionale ai fini della garanzia di tale famiglia di diritti (c.d. della seconda generazione). In tali ordinamenti, continua tuttora a prevalere un orientamento giurisprudenziale e dottrinario secondo cui la Costituzione non dovrebbe ritenersi direttamente applicabile nella materia dei diritti fondamentali, spettando alla sola legge di disciplinare le singole e specifiche situazioni giuridiche di protezione. Come avveniva nella prima giurisprudenza costituzionale, nel corso degli anni '60, così, i diritti sociali vengono essenzialmente colti come direttive rivolte ai pubblici poteri, sguarnite di valore cogente ${ }^{24}$, in una parola come mere 'disposizioni programmatiche'.

Quanto, poi, alla portata dei diritti sociali nell'ambito del costituzionalismo contemporaneo, più che riguardare le diverse modalità accolte negli ordinamenti costituzionali dei vari Paesi, essa riguarda le forme giuridiche della loro protezione. Come si è già detto, solo l'Italia e la Spagna, seguite dalla Francia - benché secondo formule peculiari ${ }^{25}$ di positivizzazione costituzionale - hanno registrato un'evoluzione

diritto costituzionale comune europeo. Principi e diritti fondamentali, Napoli, 2002; V. Baldini, "Autonomia costituzionale dei Laender, principio di omogeneità e prevalenza del diritto federale", in M. Scudiero (a cura di), I/ diritto costituzionale ... cit.

${ }^{24}$ Mentre alcuni ordinamenti europei disciplinano la materia mediante clausole generali (art. 20, I co., LFB) o mediante "Principi informatori della politica sociale ed economica" (Cap. II del Tit. I e Cap. III Costituzione spagnola), la Costituzione italiana tutela i diritti sociali sia mediante princìpi fondamentali sia (e soprattutto) con disposizioni costituzionali di dettaglio, anche se si ha l'impressione "che la categoria del diritto sociale sia inadeguata ad esprimere la ricchezza delle indicazioni fornite dai Titoli I e II della Costituzione" (cfr. G. Corso, "I diritti sociali nella Costituzione italiana", in Riv. trim. dir. pub., 1981, p. 757) relativamente ai rapporti etico-sociali ed ai rapporti economici (cfr., almeno, U. Allegretti, "Globalizzazione e sovranità nazionale", in Democrazia e diritto, 1998; G. Zagrebelsly, "I diritti fondamentali oggi", in Materiali per una storia della cultura giuridica, 1992, 1; L. Carlassare. "Forma di Stato e diritti fondamentali", in Quaderni costituzionali, 1995, 1).

${ }^{25}$ Cioè mediante il rinvio operato dal Preambolo della Costituzione del '58 alla Déclaration des droits de l'homme et du citoyen, confermata ed integrata dal Preambolo della Costituzione del 1946 e dai "principi fondamentali riconosciuti dalle leggi della Repubblica", ivi sanciti. Fra gli altri, sul punto, cfr. almeno D. Turpin, Droit constitutionnel, Paris, 1999; S. Gambino, "La giustizia costituzionale in Francia. II Conseil constitutionnel da regolatore dll'attività dei pubblici poteri a garante delle libertà pubbliche", in Politica del diritto, 1988, n. 4. 
del diritto positivo nonché della giurisprudenza e della dottrina nel senso del riconoscimento dei diritti sociali come diritti fondamentali, inalienabili e imprescrittibili, sia pure nel quadro di una loro affermazione graduale nonché rispettosa della discrezionalità del legislatore.

Nell'ordinamento italiano e in quello spagnolo il catalogo costituzionale dei diritti sociali risulta avere una inusuale ampiezza e sistematicità; la relativa tutela è quella propria dei diritti costituzionali e non già di quelli 'legali', benché in dottrina si sottolinei come, a ben vedere, le forme giurisdizionali della relativa tutela non sono quelle apprestate ai diritti soggettivi (con la forza propria della tutela risarcitoria e di quella inibitoria nei confronti di atti lesivi degli stessi) ma quella degli interessi legittimi, dal momento che fra il loro concreto esercizio e la previsione legale opera un facere amministrativo, che coinvolge la pubblica amministrazione con la sua supremazia speciale ${ }^{26}$. Un approccio - quest'ultimo - destinato a essere radicalmente riconsiderato alla luce dei princìpi comunitari ma soprattutto della sentenza n. 500/1999 della Corte di Cassazione $^{27}$ in tema di risarcibilità degli interessi legittimi.

Un seconda tipologia raggruppa quelle Costituzioni europee che si limitano a riconoscere ai diritti sociali una protezione secondo standards medi, né molto alti né molto bassi; fra tali Costituzioni ritroviamo quelle dell'Europa centrale e in particolare

\footnotetext{
26 Autorevoli tesi dottrinarie (A. Pace, "La garanzia dei diritti fondamentali nell'ordinamento costituzionale italiano: il ruolo del legislatore e dei giudici 'comuni'", in Scritti in onore di P. Barile. Nuove dimensioni nei diritti di libertà, Padova, 1993), sotto tale profilo, sottolineano una certa 'enfaticità' dei diritti sociali, qualora analizzati sotto l'angolo visuale della loro concreta giustiziabilità. II diritto e la giustizia amministrativa diventano, in tale contesto, lo scenario obbligato di verifica dell'effettività del diritto costituzionale e delle tutele sue proprie. Una lettura diversa attinge l'immediata esigibilità giuridica dei diritti sociali all'interpretazione del novellato art. 117 , II co., lettera $m$, Cost., secondo la quale - dal momento che i livelli essenziali delle prestazioni, ivi sanciti, impongono al legislatore statale d'individuare le risorse economiche necessarie alla relativa attuazione amministrativa - non pare potersi ulteriormente accogliere il risalente orientamento del Giudice delle leggi che parlava dei diritti sociali come di "diritti finanziariamente condizionati" (in quest'ultimo senso cfr. anche S. Gambino, "Normazione regionale e locale e tutela dei diritti fondamentali (fra riforme costituzionali, sussidiarietà e diritti fondamentali)", in A. Ruggeri - L. D'Andrea - A. Saitta - G. Sorrenti (a cura di), Tecniche di normazione e tutela giurisdizionale dei diritti fondamentali, Torino, 2007.

27 Sul punto cfr., fra gli altri, F. Siciliano - D. D'Alessandro, "L'integrazione comunitaria e la giustiziabilità delle posizioni con particolare riguardo al risarcimento dei danni da lesione di interesse legittimo", in S. Gambino (cur.), Costituzione italiana e diritto comunitario, Milano, 2002.
} 
la Costituzione belga ${ }^{28}$ e quella del Lussemburgo ${ }^{29}$, quella della Svezia ${ }^{30}$ e della Finlandia $^{31}$, quella della Francia ${ }^{32}$ e della Grecia $^{33}$. Sia pure con un'intensità differenziata fra le Costituzioni dei diversi Paesi considerati, queste ultime procedono all'integrazione dei diritti fondamentali sociali al loro interno; tuttavia, non sempre e comunque non in modo omologo alla previsione costituzionale di protezione corrisponde una protezione giudiziaria; non sempre, inoltre, viene prevista la possibilità del ricorso costituzionale.

Nell'ultimo gruppo, infine, ritroviamo le Costituzioni che si collocano al di sopra dello standard medio per quanto concerne la tipologia dei diritti sociali riconosciuti e la stessa effettività della loro protezione. Si tratta in gran parte di Costituzioni dell'Europa centro-meridionale. Fra di esse ritroviamo la Costituzione italiana ${ }^{34}$, alla quale in seguito sarà dedicato un approfondimento particolare, quella spagnola ${ }^{35} \mathrm{e}$ quella portoghese ${ }^{36}$.

Ciò brevemente richiamato quanto alle esperienze costituzionali contemporanee, possiamo concludere questo approccio generale affermando che

${ }^{28}$ Cfr. K. Lenaerts - P. Van Ypersele - J. Van Ypersele, "La protection des droits sociaux fondamentaux dans l'ordre juridique de la Belgique", in J. Iliopoulos Strangas (ed.), La protection des droits sociaux fondamentaux ... cit.

${ }_{29}$ Cfr. R. Schintgen, "La protection des droits sociaux fondamentaux dans l'ordre juridique du Luxembourg", in J. Iliopoulos Strangas (ed.), La protection des droits sociaux fondamentaux ... cit.

${ }^{30} \mathrm{Cfr}$. L. Westerhall, "La protection des droits sociaux fondamentaux dans l'ordre juridique de la Suede", in J. Iliopoulos Strangas (ed.), La protection des droits sociaux fondamentaux ... cit.

${ }^{31}$ Cfr. K. Tuori - N. Bruun, "La protection des droits sociaux fondamentaux dans l'ordre juridique de la Finlande", in J. lliopoulos Strangas (ed.), La protection des droits sociaux fondamentaux ... cit.

${ }^{32}$ Cfr. M.L. Pavia - D. Rousseau, "La protection des droits sociaux fondamentaux dans l'ordre juridique de la France", in J. lliopoulos Strangas (ed.), La protection des droits sociaux fondamentaux ... cit.

${ }^{33}$ Cfr. J. Iliopoulos-Strangas - G. Leventis, "La protection des droits sociaux fondamentaux dans l'ordre juridique de la Grèce", in J. Iliopoulos Strangas (ed.), La protection des droits sociaux fondamentaux ... cit.

${ }^{34}$ Cfr. G. De Vergottini, "La protection des droits sociaux fondamentaux dans l'ordre juridique de I'Italie", in J. Iliopoulos Strangas (ed.), La protection des droits sociaux fondamentaux ... cit.

${ }^{35}$ Cfr. M. Rodriguez-Pinero, "La protection des droits sociaux fondamentaux dans l'ordre juridique de l'Espagne", in J. lliopoulos Strangas (ed.), La protection des droits sociaux fondamentaux ... cit.: G. Ruiz-Rico Ruiz, "Fundamentos sociales y politicos en los derechos sociales de la Constitución española", in Revista de estudios politicos (Nuova Epoca), 1991, n. 71; J.J. Solozábal Echevarría, "El Estado social come Estad autonomico", in UNED, Teoria y realidad constitucional, 1999, n. 3; J.J. Solozábal Echevarría, "Algunas cuestiones basicas de la teoria de los derechos fundamentales", in Revista de estudios políticos (Nuova Epoca), 1991, n. 71; J.L. Cascajo Castro, La tutela constitucional de los derechos sociales, Madrid, 1988),

${ }^{36}$ Cfr. J.C. Vieira De Andrade, "La protection des droits sociaux fondamentaux dans l'ordre juridique de la Grèce", in J. lliopoulos Strangas (ed.), La protection des droits sociaux fondamentaux ... cit. 
nella ricerca costituzionale comparatistica è dato cogliere l'assenza di un concetto europeo condiviso in materia di qualificazione e di protezione dei diritti sociali, differenziandosene le diverse previsioni costituzionali secondo soluzioni variegate quanto alla loro qualificazione giuridica e alla stessa portata giuridica di tali diritti. La questione centrale posta da tale approccio riguarda lo statuto costituzionale, ovvero semplicemente legislativo, degli stessi. Quanto a tale ultima questione, può affermarsi che nella gran parte delle Costituzioni degli Stati europei, i diritti sociali sono catalogati nell'ambito delle stesse disposizioni costituzionali destinate a riconoscere e proteggere i diritti fondamentali classici, mentre solo in pochi casi tali diritti sono esclusi dall'elenco dei diritti fondamentali o sono rubricati in modo diverso. In questi ultimi casi, l'assimilazione dei diritti sociali a quelli fondamentali non pare implicare effetti giuridici di rilievo ${ }^{37}$.

Invero, oltre all'ordinamento costituzionale francese e alla peculiare natura del controllo preventivo della legittimità costituzionale delle leggi ivi previsto, solo l'ordinamento costituzionale italiano e quello spagnolo - in ragione della concezione normativa della Costituzione, intesa, cioè, come norma giuridica superiore (hinner law) rispetto alle leggi - appaiono contenere una disciplina costituzionale (per principi e con disposizioni di dettaglio) adeguata a farsi carico degli standard più elevati di protezione dei diritti sociali. Negli altri ordinamenti statali contemporanei, al contrario, prevale un contrasto significativo quanto alla portata dei regimi giuridici di protezione dei diritti sociali, che pare attribuire una protezione affievolita a questi ultimi rispetto alla protezione accordata alle libertà negative. D'altra parte, tale affievolimento di protezione si accompagna con la mancata previsione di controlli di costituzionalità delle leggi, come avviene appunto nei Paesi Bassi, in Danimarca, in Svezia, in Finlandia e Lussemburgo, ancorché in questi ultimi due Paesi ne venga prevista l'istituzione.

\footnotetext{
${ }^{37}$ Come osserva, sotto tale profilo, C. Grewe ("Les droits sociaux constitutionnels: propos compratifs à l'aube de la Charte des droits fondamentaux de l'Union européenne", in $R U D H, 2000$ ): en somme, l'homogeneité de ces reconnaissances n'est qu'apparente. Sous leur manteau se cache une différenciacion variable entre droits constitutionnels directement applicables et droits accordés sous réserve ou pour le principe. Cette seconde catégorie concerne la plupart de temps, mais pas systématiquement, les droits à prestations. Or c'est précisément ce type de distinction qui est plus explicitement inscrit dans d'autres constitutions".
} 
Tuttavia, se dalla definizione teorico-costituzionale dello Stato sociale e più in particolare dall'inquadramento dei diritti sociali come diritti inviolabili della persona si passa a verificare il grado di effettività degli stessi nell'ambito degli Stati che prevedono una protezione dei diritti sociali fondamentali non differenziata rispetto agli altri diritti fondamentali (di prima e di seconda generazione), non può non cogliersi lo stridente contrasto tra la loro previsione come diritti universali e assoluti e il relativo, spesso deprimente, grado di effettività. L'argomento a giustificazione di una simile situazione è dato dal fatto che i diritti sociali (istruzione, salute, previdenza, ecc.) costano e lo Stato (in Italia come altrove) conosce seri problemi di fiscalità ${ }^{38}$.

1.3 I diritti sociali nell'ordinamento costituzionale italiano (fra Costituzione, leggi e Corte costituzionale)

La questione del costo dei diritti sociali costituisce, in tale quadro, un punto di vista importante ma non risolutivo nello studio sulla struttura stessa di tali diritti. La lettura che ne dà il diritto, ma soprattutto la giurisprudenza costituzionale porta, tuttavia, ad osservare come il costo dei diritti sociali non è tale da poter incidere sulla struttura di diritti costituzionalmente garantiti. La più autorevole dottrina, peraltro, ha da tempo e ben sottolineato come il costo dei diritti costituisca un falso problema, dal momento che esso è un elemento intrinseco a tutti i diritti costituzionali, anche a quelli classici di libertà ${ }^{39}$.

II tema dei diritti sociali, soprattutto nel dibattito dottrinario italiano che precede la revisione del Tit. V Cost., si limita, così, soprattutto, alle funzioni svolte in tema di garanzia e di effettività degli stessi da parte del giudice ordinario e soprattutto da parte di quello costituzionale ${ }^{40}$. Nella nuova stagione di dibattito e di analisi

\footnotetext{
${ }^{38}$ Cfr. fra gli altri, cfr. almeno AA.VV. (a cura di A. Baldassarre - A. Cervati), Critica dello Stato sociale, Bari, 1982.

${ }^{39}$ Come bene osserva G. Lombardi, infatti, “... non sono le caratteristiche strutturali a separare i diritti di libertà dai diritti sociali ma sono le modalità di tutela a rendere diversi i meccanismi di garanzia ... entrambi sono diritti individuali (come entrambi possono essere, a seconda dei rapporti, diritti collettivi), e tanto agli uni quanto agli altri può riconoscersi una portata che non tocca solo i rapporti con l'ente pubblico ma si individua anche a livello di rapporti interprivati" (in "Diritti di libertà e diritti sociali”, in Pol. del dir., 1999, n. 1).

${ }^{40}$ Cfr. anche i nostri "Cittadinanza e diritti sociali fra neoregionalismo e integrazione comunitaria", in Quaderni costituzionali, 2003, n. 1, nonché "Federalismo e diritti (forma di Stato e diritti fondamentali)", in V. Piergigli (a cura di), Federalismo e Devolution, Milano, 2005.
} 
scientifica, l'analisi dovrà incentrarsi (come ha già iniziato a fare) sulle problematiche costituzionali poste dall'attuazione del nuovo ordinamento ('neoregionale' con tensione concretamente federalistica), con particolare riferimento ai contenuti delle novellate disposizioni di cui agli artt. 114, 116, 117 e 119 Cost. e di una loro interpretazione che assicuri il rispetto dei princìpi fondamentali della Costituzione (con particolare riferimento al principio di eguaglianza e a quello personalistasolidarista $)^{41}$.

Se ci limitiamo, a mo' di mera esemplificazione, all'analisi della protezione di un diritto sociale concreto, ad esempio quello alla salute, garantito dall'art. 32 Cost., possiamo osservare come, rispetto alla previgente disciplina legislativa in materia sanitaria, la costituzionalizzazione dei 'livelli essenziali delle prestazioni' (LEP) operata con la novellata disposizione di cui all'art. 117, II comma, lettera m, costituisca una rilevante evoluzione di fondo nell'ordinamento salutare. Per i suoi destinatari, infatti, nel nuovo quadro normativo si evidenziano nuove situazioni giuridiche protette con il rango proprio dei diritti soggettivi perfetti e non più soltanto nelle tradizionali forme di protezione accordate agli interessi legittimi. Se non leggiamo in modo errato l'evoluzione ordinamentale in materia sanitaria alla luce della novella costituzionale, in altri termini, non ci sarà più spazio per una conferma di quell'orientamento del Giudice delle leggi che assumeva il diritto alla salute come 'diritto finanziariamente condizionato', come ad esempio la Corte cost. sanciva ancora nella sent. n. 356/1992, quando affermava che "in considerazione della limitatezza delle risorse, non potrebbe consentirsi a un impiego di risorse illimitato avendo riguardo solo ai bisogni; è viceversa la spesa a dover essere commisurata alle effettive disponibilità finanziarie", ancorché tale giurisprudenza fosse stata già modificata nel fondo in una serie di importanti pronunce degli anni '90 (sentenze $\mathrm{n}$. 247/1992, n. 267/1998; n. 309/1999) e di recente nella sent. n. 509/2000, nella quale il Giudice delle leggi sottolinea che "il bilanciamento fra valori costituzionali e commisurazione degli obiettivi determinati dalle risorse esistenti non può intaccare il

${ }^{41}$ Sul punto cfr. anche il nostro S. Gambino, "Normazione regionale e locale e tutela dei diritti fondamentali (fra riforme costituzionali, sussidiarietà e diritti fondamentali)", in A. Ruggeri - L. D'Andrea - A. Saitta - G. Sorrenti (a cura di), Tecniche di normazione e tutela ... cit. 
nucleo irrinunciabile del diritto alla salute protetto costituzionalmente come valore inviolabile della dignità umana"42.

Anche a partire da queste riflessioni è da chiedersi come il 'nuovo' quadro costituzionale previsto per le Regioni e per le autonomie locali si rapporti a tali princìpi, dovendosi chiaramente assumere che l'architettura costituzionale della 'Repubblica' dopo le recenti riforme costituzionali ${ }^{43}$ risulta significativamente innovata rispetto all'ordinamento previgente, nel quale l'ambito costituzionale delle competenze legislative regionali poco (o nulla) incidevano sullo statuto della cittadinanza.

Le considerazioni fin qui svolte, ancorché essenziali nel loro svolgimento, - in tale ottica - portano a osservare che le istituzioni regionali e le autonomie locali, almeno fino alle recenti riforme costituzionali nella materia territoriale, non costituivano il terreno elettivo per un'indagine sulle tematiche relative alle modalità seguite (e da seguire) per rendere effettivi i diritti sociali, nella misura in cui alle regioni e alle minori autonomie locali non era assegnata la competenza in materia di diritti, che rimaneva attribuita alle istituzioni statali, venendo protetta dalla relativa giurisdizione. Omologo discorso dovrebbe valere per la Spagna, con riferimento alla complessa tematica delle competenze delle CCAA in materia di diritti fondamentali e della stessa riforma degli statuti delle CCAA. In tale prospettiva, la tematica dei diritti fondamentali nello Stato regionale non pare offrire un orizzonte analitico di particolare rilievo teorico se considerata dall'ottica del previgente ordinamento

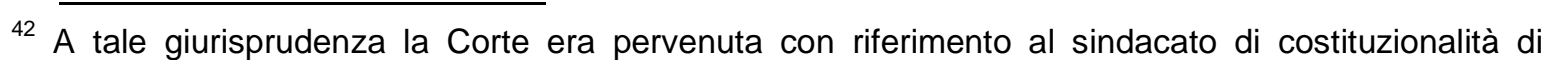
specifiche questioni poste, da ultimo, dalla disciplina accolta nel d.lgs n. 502 del 1992, ed in particolare dalla determinazione da parte di quest'ultimo dei nuovi standards prestazionali, in favore di uno di tipo 'universalistico selettivo', chiamato a conformarsi alle risorse disponibili, da una parte, e a ispirarsi ai nuovi criteri dei LEP, come imposti dalla necessità, dall'efficacia clinica e dall'appropriatezza d'uso degli interventi sanitari previsti ed erogati. Nella lettura che qui si vuole proporre, dunque, ci si chiede se la novellata disciplina costituzionale non sia da esaminare anche con riferimento alla giustiziabilità di eventuali comportamenti omissivi delle amministrazioni sanitarie in quanto "enti obbligati ad offrire i servizi nelle aree comprese nei livelli essenziali", ponendo espressamente, in tal modo, la questione dell'impatto delle organizzazioni pubbliche sulla effettività dei diritti. E, prima ancora, ci si chiede se il rispetto dei 'livelli essenziali' non debba cogliersi come un vincolo organizzativo all'interno del quale soltanto può legittimamente esercitarsi l'autonomia funzionale delle organizzazioni sanitarie.

${ }^{43}$ Fra gli altri cfr. anche S. Gambino (a cura di), II nuovo ordinamento regionale. Competenze e diritti, Milano, 2003 nonché S. Gambino (a cura di), Regionalismo, federalismo, devolution. Competenze e diritti. Confronti europei (Spagna, Germania e Regno Unito), Milano, 2003.
} 
costituzionale. Ciò anche perché il livello regionale non ha consentito di evidenziare, almeno nella prassi, il profilo attuativo delle competenze regionali capace di influenzare l'effettività dei diritti sociali, tranne che nelle tematiche relative al rapporto amministrativo - così come innervato di nuovi diritti dalla più recente legislazione di riforma amministrativa (diritto di partecipazione al procedimento amministrativo, diritto di accesso agli atti e ai documenti amministrativi, diritto alla privacy) - e alla riforma dell'ordinamento locale.

II tema dei diritti sociali, nel dibattito dottrinario, pare doversi limitare, così, alle funzioni svolte dal giudice ordinario e soprattutto da quello costituzionale in tema di garanzia e di effettività degli stessi. L'intervento del Giudice costituzionale nella materia dei diritti sociali, come è noto, è stato richiesto prevalentemente con riferimento alla violazione del principio di eguaglianza e in presenza di comportamenti omissivi da parte del legislatore ${ }^{44}$. Dopo una iniziale prudenza, l'orientamento del Giudice delle leggi si è affermato nel senso di riconoscere rango pienamente costituzionale ai diritti sociali, affermandosi, da parte dello stesso, una serie di criteri guida a cui il Giudice stesso conforma la propria dottrina ${ }^{45}$. Pur accompagnandosi con il riconoscimento della necessaria gradualità delle scelte legislative, lo sforzo della Corte costituzionale, teso a dare effettività ai diritti sociali, porta a riconoscerli come 'diritti perfetti', assicurandone una protezione immediata, pur in quelle ipotesi in cui difettasse ancora un intervento regolativo e di protezione da parte del legislatore. Per la Corte, dunque, anche i diritti sociali, e a fortiori quelli a prestazione positiva legislativamente condizionati, assurgono - al pari degli altri diritti fondamentali - al rango di "diritti inviolabili e irretrattabili della persona, in quanto espressione di valori o

\footnotetext{
${ }^{44}$ Rimane centrale sul punto il contributo di C. Mortati "Appunti per uno studio sui rimedi giurisdizionali contro comportamenti omissivi del legislatore", in Foro italiano, 1970, V.

${ }^{45}$ Essi vanno dal riconoscimento di un principio di gradualità delle riforme legislative relative ai diritti di prestazione (sentt. n. 173 del 1986 e n. 205 del 1995) a un principio di costituzionalità provvisoria di una data disciplina (sent. n. 826 del 1988), a un principio di attuazione parziale incostituzionale di un diritto sociale (sent. n. 215 del 1987), alla necessità di apprezzamento, infine, dei limiti finanziari posti dal bilancio e dalla necessaria considerazione della discrezionalità del legislatore circa la definizione del quantum delle prestazioni sociali che la Corte deve comunque valutare secondo un necessario parametro di ragionevolezza (sentt. 180 del 1982 e 455 del 1990 in tema di prestazioni sanitarie. Per una trattazione organica della materia cfr. C. Colapietro, La giurisprudenza costituzionale nella crisi dello Stato sociale, Padova, 1996.
} 
princìpi costituzionali supremi”46. In breve, nella giurisprudenza della Corte costituzionale si sottolinea come ai diritti sociali debba essere assicurata una protezione costituzionale pienamente comparabile a quella assicurata agli altri diritti fondamentali; in quanto tali, dunque, anche i diritti sociali sono irrinunciabili, inalienabili, indisponibili, intrasmissibili e inviolabili. Ciò non toglie, tuttavia, che l'immediata operatività di tali diritti, come diritti di pretesa di prestazioni pubbliche, possa e debba "essere accertata caso per caso, senza confondere ciò che è possibile in virtù della sola efficacia normativa della Costituzione con ciò che è storicamente possibile" ${ }^{\prime 4}$, a seguito di leggi o regolamenti che abbiano assicurato una data disciplina della materia.

Le conclusioni che si possono trarre da un simile ed essenziale richiamo della evoluzione giurisprudenziale della Corte costituzionale nell'assicurare effettività ai diritti sociali, tuttavia, portano a osservare come le tecniche giurisdizionali utilizzate da parte dei giudici costituzionali sono tali da rendere in qualche modo mutevole e instabile il grado di effettività assicurato a tali diritti. Le tecniche di bilanciamento fra interessi egualmente meritevoli di tutela, infatti, portano il Giudice costituzionale a operare una comparazione continua fra diversi princìpi e valori costituzionali e ciò sulla base dell'assunto secondo cui il principio della ponderazione o del bilanciamento fra beni costituzionali rappresenta il parametro in base al quale devono essere determinati i limiti e il contenuto dei diritti fondamentali e tramite il quale vengono risolti i conflitti che possono insorgere tra beni costituzionalmente contigui. Una prospettiva - quest'ultima - che (ha portato e tuttora) porta a cogliere la Corte costituzionale come vero e proprio legislatore positivo, le cui ambiguità tuttora preoccupano la più attenta dottrina in Italia, come più in generale la dottrina costituzionale europea (e non solo), quando si pone l'interrogativo sul quis custodiet custodes $^{48}$.

\footnotetext{
${ }^{46}$ È il caso, ad es., della tutela della salute, del diritto alla casa, del diritto al lavoro. Cfr. F. Modugno, I 'nuovi diritti' nella giurisprudenza costituzionale, Torino, 1995.

${ }^{47}$ Cfr. A. Pace, op. cit, p. 61 ss.

${ }^{48}$ L'analisi della giurisprudenza della Corte costituzionale conferma tale assunto (Sentt. C.C. nn. 11 del 1969; 2 del 1972; 243 del 1974; 243 del 1985; 192 del 1987; 31 del 1983; 219 del 1984; 114 del 1985; 165 del 1986; 210 e 433 del 1987; 532, 633, 1000, 1133 del 1988; 234, 447, 623, 829, 924, 1066 del 1988; 372 del 1989; 49 del 1991; 75 del 1992; 3 del 1991. In dottrina, cfr., almeno, S.
} 
La questione oggetto della nostra analisi, con specifico riferimento ai rapporti esistenti fra competenze legislative delle regioni e garanzie accordate dal principio unitario, può essere utilmente affrontata richiamando l'orientamento del Giudice delle leggi nella sent. n. 109/1993. In essa si prevede che l'esercizio del potere statale di concedere agevolazioni alle imprese a prevalente conduzione femminile trova la sua giustificazione nella "necessità di assicurare condizioni di uniformità su tutto il territorio nazionale" in ordine all'attuazione di un valore costituzionale primario, come la realizzazione dell'eguaglianza effettiva delle donne e degli uomini nel campo dell'imprenditoria. Trattandosi di misure ('azioni positive') dirette a superare condizioni di diseguaglianza fra soggetti (discriminazioni in ragione del sesso), esse "comportano l'adozione di discipline giuridiche differenziate a favore delle categorie sociali svantaggiate, anche in deroga al generale principio di parità formale di trattamento, stabilito nell'art. 3 Cost.”. Tali differenziazioni esigono - secondo le parole della Corte - che "la loro attuazione non possa subire difformità o deroghe in relazione alle diverse aree geografiche e politiche del paese". Infatti, se ne fosse messa in pericolo l'applicazione uniforme su tutto il territorio nazionale, sarebbe di tutta evidenza il rischio che le 'azioni positive' si trasformino in fattori aggiuntivi di disparità di trattamento non più giustificate dall'imperativo costituzionale di riequilibrare posizioni di svantaggio sociale legate alla condizione personale dell'essere donna. L'indirizzo giurisprudenziale appena richiamato relativamente alle c.d. 'azioni positive' in rapporto al principio di uguaglianza e di autonomia territoriale conferma una giurisprudenza costante nella quale la Corte esclude o limita le competenze regionali (sia ordinarie che speciali) ogni qualvolta queste vengano a

Bartole, "In tema di rapporti fra legislazione regionale e principio di eguaglianza", in Giurisprudenza costituzionale, 1967, p. 670; A. Cerri, L'eguaglianza nella giurisprudenza della Corte costituzionale, Milano, 1976, p. 67; F. Sorrentino, "Considerazioni su riserva di legge, principio di eguaglianza ed autonomia regionale nella giurisprudenza costituzionale", in AA.VV. (a cura di M. Occhiocupo), La Corte costituzionale fra norma giuridica e realtà sociale, Bologna, 1978; A. D'Atena, "Regioni, eguaglianza e coerenza dell'ordinamento", in Giurisprudenza costituzionale, 1978, I, p. 1255); S. Bartole, "In tema di rapporti fra legislazione regionale e principio costituzionale di eguaglianza", in Giur. cost., 1967, p. 669; L. Paladin, "Un caso estremo di applicazione del principio di eguaglianza", in Giur. cost., 1965, p. 620, A. Reposo, "Eguaglianza costituzionale e persone giuridiche", in Riv. trim. di dir. pub., 1973, p. 360. 
incidere su interessi o diritti fondamentali ${ }^{49}$. Ciò costituisce una conferma dell'interrogativo sul chi sia, nello 'Stato regionale', il garante della effettività dei diritti sociali.

Problemi costituzionali omologhi si pongono anche in un modello di Stato federale ovvero a regionalismo forte, come quello attualmente previsto dal testo di revisione del Tit. V Cost. Ancora una volta, cioè, è il Giudice delle leggi a essere chiamato a far valere, nell'eventuale conflitto delle competenze o nella protezione dei diritti di cittadinanza (ma anche dei diritti della persona), l'effettività di valori e di beni costituzionalmente protetti, limitando l'autonomia politica (dei Laender e degli Stati negli Stati federali) delle regioni (ordinarie ma anche speciali) ogniqualvolta il legislatore nazionale, nell'esercizio del suo potere e delle sue responsabilità, attui forme di tutela destinate ad assicurare l'eguaglianza e la pari dignità dei soggetti su tutto il territorio e dunque a tutelare la cittadinanza a prescindere dalle articolazioni territoriali/regionali del Paese.

\section{Diritti sociali fondamentali e integrazione europea}

L'affermazione dei diritti sociali conosce una sua problematizzazione anche con riferimento al relativo grado di riconoscimento e alle forme di tutela nell'ordinamento dell'Unione europea, ancorché tale riconoscimento rivesta tuttora le forme istituzionali della "politica sociale" (Titolo IX del nuovo TFUE), per come innovativamente ora innervate dalle previsioni che accordano alla Carta europea dei diritti la stessa forza giuridica dei trattati.

È stato ampiamente sottolineato in dottrina come i trattati di Maastricht, di Amsterdam e di Nizza costituiscano momenti particolarmente qualificanti del lungo percorso nell'evoluzione del 'diritto costituzionale comune europeo'. Con essi si determina la trasformazione ordinamentale delle originarie Comunità economiche europee in una Unione politica ispirata ai princìpi fondamentali propri dello Stato democratico e di diritto. In tale quadro, I'Unione europea s'impegna a rispettare i diritti

\footnotetext{
${ }^{49}$ Cfr. sent. C.C. n. 40 del 1993 sul rapporto fra azioni positive e principio di eguaglianza. Sul tema in generale cfr. anche G. Grottanelli de' Santi, "Perequazione, eguaglianza e principi dell'ordinamento", in Giur. cost., 1978, p. 710.
} 
fondamentali, come previsti dalla Convenzione europea per la salvaguardia dei diritti dell'uomo e delle libertà fondamentali e per come risultano dalle "tradizioni costituzionali comuni" degli Stati membri.

In assenza di previsioni in tema di diritti fondamentali nei trattati originari, come è noto, la Corte di Giustizia ha operato un riconoscimento pretorio degli stessi, attingendo al flebile materiale normativo offerto, a tal fine, da specifiche disposizioni in materia di responsabilità extra-contrattuale della Comunità (art. 288.2 TCE) ${ }^{50}$. Seguendo tale orientamento giurisprudenziale, il Giudice di Lussemburgo, come è stato ampiamente sottolineato, ha elaborato un vero e proprio catalogo dei diritti fondamentali ${ }^{51}$, anche se limitato alla categoria dei diritti civili, in cui appaiono situazioni soggettive legate prevalentemente all'ambito economico e sociale ${ }^{52}$.

\subsection{I diritti sociali e i trattati}

Occorre ora ricostruire, sia pure in modo essenziale, la lenta emersione e il processo evolutivo dei diritti sociali a livello di Unione europea, per giungere a proporsi, in seguito, lo stesso interrogativo, già posto in dottrina, circa la necessarietà di un "capitolo sociale nella futura Costituzione europea"53. II processo di integrazione europea nasce nei primi anni '50 con una finalizzazione

\footnotetext{
${ }^{50}$ A partire dai primi anni '60, con la sentenza Stauder, la Corte di Giustizia, come si vedrà meglio in seguito, riconosce, per la prima volta, che la tutela dei diritti fondamentali costituisce una parte integrante dei princìpi generali del diritto, assumendo che essa "è tenuta" a garantirne l'osservanza. Nella ricerca del parametro sul quale fondare una simile (ardita) costruzione giurisprudenziale, essa fa ricorso alle "tradizioni costituzionali comuni degli Stati membri", le quali vengono assunte come necessarie nel determinare il contenuto materiale dei diritti fondamentali, intesi come articolazione interna dei principi generali del diritto comunitario (sul punto cfr. anche S. Gambino, a cura di, Costituzione italiana e ... cit., nonché M. Scudiero (a cura di), Il diritto costituzionale comune ... cit.). Con le successive sentenze Internationale Handelsgesellschaft e Nold, la Corte comunitaria darà compiutezza alle sue tecniche argomentative finalizzate alla protezione dei diritti fondamentali comunitari.

${ }^{51}$ Sul punto, cfr. anche il nostro "Diritti fondamentali europei e trattato costituzionale", in Pol. del dir., 2005 , n. 1.

${ }^{52}$ Con la sentenza Kreil, dell'11 gennaio del 2000, tuttavia, la Corte fa un passo in avanti rispetto al rapporto fra diritto dell'Unione e ordinamenti costituzionali nazionali, sancendo che il primo rappresenta un limite all'applicazione delle norme nazionali, ancorché di natura costituzionale, quando queste violino (o comunque incidano su) i diritti fondamentali comunitari. Con tale sentenza la Corte precisa le sue competenze di controllo nell'applicazione del diritto dell'Unione, che si esplicano nell'individuazione di livelli di protezione inderogabile dei diritti fondamentali.

${ }^{53}$ Cfr. M. Ramón Alarcón Caracuel, "La necessità di un capitolo sociale nella futura Costituzione europea", in Lavoro e Diritto, 2000, n. 4.
} 
prevalentemente economica, di sostegno alla formazione e allo sviluppo di un mercato comune europeo. I costituenti europei, come è noto, non si prefiggevano un più elevato "tasso di socialità" all'interno dell'Europa, limitandosi a perseguire l'obiettivo della eliminazione di quelle "disparità di trattamento (che fossero) suscettibili di ostacolare il buon funzionamento del mercato" ${ }^{54}$. Come è stato sottolineato, le 'preoccupazioni sociali', che pure potevano già cogliersi nel Trattato di Roma, risultavano relegate sullo sfondo ${ }^{55}$; la 'frigidità sociale' non preoccupava i primi costituenti europei impegnati a disegnare l'architettura di fondo del diritto primario dell'Unione ${ }^{56} \mathrm{e}$ "la difesa della dignità del lavoratore e il miglioramento delle condizioni di vita e di lavoro erano semplici corollari" ${ }^{25}$. In tale quadro, con buona dose di ottimismo e forse anche di ingenuità, risultava forte e diffusa fra i primi costituenti europei la convinzione circa le potenzialità autopropulsive del mercato e la relativa idoneità a sostenere e diffondere diritti, ivi compresi quelli sociali ${ }^{58}$. L'idea del sostegno del mercato che porta/comporta lo sviluppo dei diritti, formulata in modo tanto netto, si presta, naturalmente, a essere colta come un evidente "errore metodologico", nel senso che l'esperienza dei diversi Paesi non pare dimostrare che il "libero gioco delle forze del mercato porti in modo naturale all'eguaglianza, bensì a una enorme disparità delle condizioni di vita e di lavoro, a seconda delle condizioni geografiche, professionali e di settore" ${ }^{59}$. Tutto al contrario, l'evoluzione dallo Stato liberal-democratico a quello sociale contemporaneo, in campo economico, pare appunto caratterizzarsi per i fallimenti del mercato e per l'esigenza di sussidiarietà dell'intervento pubblico in economia (per finalità regolative, antitrust e a sostegno della domanda aggregata). L'intento dei padri costituenti europei, probabilmente,

\footnotetext{
${ }^{54}$ Cfr. F. Carinci - A. Pizzolato, "Costituzione europea e diritti sociali fondamentali", in Lavoro e Diritto, 2000, n. 2, p. 286; A. D'Aloia, "Diritti sociali e politiche di eguaglianza nel processo costituzionale europeo", in M. Scudiero (a cura di), I/ diritto costituzionale comune europeo, Napoli, 2002, p. 852, vol. 1, t. 3.

${ }^{55}$ Cfr. M. Luciani, "Diritti sociali e integrazione europea", in Pol. del dir., 2000, n. 3, p. 367.

${ }^{56}$ Cfr. G.F. Mancini, "L'incidenza del diritto comunitario sul diritto del lavoro degli Stati membri", in $R D E, 1989$, n. 3.

${ }^{57}$ Cfr. F. Carinci - A. Pizzolato, "Costituzione europea e diritti sociali fondamentali ... cit., p. 286.

${ }^{58}$ In senso critico sul punto E. Argala Foruria, "Los derechos sociales comunitarios y su protecciòn en Europa y en Espana", in AA.VV., Derechos costitucionales y pluralidad de ordenamientos, Barcelona, 2001 , p. 700.

${ }^{59}$ Cfr. M. Ramón Alarcón Caracuel, "La necessità di un capitolo sociale ... cit., p. 608.
} 
muoveva proprio dall'idea secondo cui, ponendo le basi di una cointeressenza fra gli Stati e i popoli europei appena usciti dal conflitto mondiale, questi ultimi non si sarebbero più fatti tentare di risolvere i loro problemi ricorrendo alle armi. Sulla scorta di una simile idea di riconciliazione e sulle basi economiche che ne costituivano il supporto sarebbe stato possibile, nel futuro immediato e in quello più lontano, sviluppare la protezione degli stessi diritti e in particolare di quelli sociali, che, importando rilevanti risorse pubbliche per la loro implementazione, avrebbero imposto di ripensare a una architettura istituzionale, a competenze nonché a politiche di bilancio europee più forti (e comunque adeguate a farsi carico della garanzia di tali diritti qualora assunti effettivamente come diritti pretensivi, giustiziabili).

In ogni caso, non risulta affatto certo che l'ambito della protezione sociale (e comunque le politiche sociali) fosse completamente assente nei trattati istitutivi dell'Unione ${ }^{60}$; pertanto, non appare motivata né convincente quella tesi secondo cui risulterebbe assente ogni obiettivo sociale nella strategia istituzionale perseguita dai trattati originari. Se correttamente inquadrata nell'ambito delle politiche e non in quella dei diritti, in tale senso, possiamo osservare come nell'art. 117 dell'originario Trattato si prevedesse chiaramente come tale finalità costituisse il risultato "sia dal funzionamento del mercato comune ... sia dalle procedure previste al presente Trattato ...". Se, dunque, con tale affermazione vogliamo cogliere, nei trattati, l'esistenza di un ambito destinato a riconoscere e garantire i diritti sociali, con uno statuto giuridico pariordinato a quelli classici di libertà, dobbiamo effettivamente parlare di un forte ritardo dei primi trattati, di una loro 'frigidità' in materia, appunto. Ma se, al contrario, con tale qualificazione facciamo riferimento al quadro delle

${ }^{60}$ Come si fa bene osservare, infatti, già il Trattato del 1951, istitutivo della Comunità Economica del Carbone e dell'Acciaio (Ceca), all'art. 3, assumeva che una delle sue funzioni era di "promuovere il miglioramento delle condizioni di vita e di lavoro della manodopera". Anche nel Trattato del 1957, istitutivo dell'Euratom, si faceva riferimento all'innalzamento del livello di vita e alla tutela della salute dei lavoratori dell'industria nucleare. Tuttavia, è nel Trattato della Comunità economica europea (Roma, 1957) che ritroviamo bene illuminato il rapporto fra ambito economico e quello sociale; all'art. 2, ritroviamo disciplinati come obiettivi lo "sviluppo armonioso delle attività economiche", la "crescita continua ed equilibrata" e la "crescita rapida del livello di vita"; si aggiunga, all'art. 117 del Trattato, un chiaro richiamo all'obiettivo sociale, quando si prevede che "gli Stati membri convengono sulla necessità di promuovere il miglioramento delle condizioni di vita e di lavoro della manodopera che consenta la loro parificazione nel progresso" (cfr. M. Ramón Alarcón Caracuel, "La necessità di un capitolo sociale nella ... cit., p. 609). 
politiche pubbliche europee, non dovrebbe più parlarsi di 'frigidità sociale' dei trattati. I Padri costituenti europei avevano ben presente tutto ciò al momento della loro redazione; si può ragionevolmente assumere che, se non hanno inseguito fin da subito strategie istituzionali forti, ciò sia dipeso dalla preoccupazione, ben evidente agli stessi, che una simile strategia avrebbe potuto comportare un blocco definitivo del take off istitutivo delle istituzioni e dell'avvio delle politiche dell'Unione. La parificazione verso l'alto delle condizioni di vita e del lavoro dei lavoratori europe ${ }^{61}$,

${ }^{61}$ Secondo la ricostruzione svolta prevalentemente dai gius-lavoristi, il diritto derivato dell'Unione, analizzato con riferimento alle decadi successive ai primi trattati, consente di confermare pienamente l'affermazione appena fatta. Richiameremo, di seguito, le discipline più significative nella direzione delle tesi prima sostenute. In attuazione degli artt. 48 e 51 del Trattato di Roma, inizialmente, la priorità viene data non tanto a sostegno del lavoratore ut sic bensì ad una disciplina volta a favorire la libera circolazione dei lavoratori. Si richiamano in tel senso, in particolare, il regolamento Cee 1612/68 (del 15 ottobre 1968), la direttiva 68/360/Cee (recante la stessa data), il regolamento 3/58, antecedente del 1408/71 (sul coordinamento dei sistemi di sicurezza sociale). Segue, in una seconda fase, una disciplina che inizia a concentrarsi maggiormente sui diritti del lavoratore; in tal senso si ricordano l'adozione del Programma di azione sociale della comunità (vertice dei capi di Stato e di Governo di Parigi del 1972), accompagnata da tre direttive sull'eguaglianza di trattamento fra uomini e donne (75/1 17/Cee, 76/207/Cee e 79/7/Cee), nonché da altre direttive su specifici aspetti del rapporto di lavoro: licenziamenti collettivi $(75 / 129 / \mathrm{Cee})$, diritti dei lavoratori in caso di trasferimento dell'impresa (77/187/Cee), tutela dei lavoratori in caso di insolvenza dell'impresa (80/987/Cee). Negli anni' 80 , ha inizio un ripensamento radicale della politica sociale dell'Unione, le cui linee salienti vengono accolte nell'Atto Unico europeo (del 17 febbraio 1986), che fra i propri obiettivi enuclea appunto quello della 'integrazione economica e sociale'. Si ricordano, in tal senso l'integrazione nei trattati di un nuovo titolo (XIV), rubricato 'coesione economica e sociale' nonché l'inclusione di nuove disposizioni relative ad assicurare il miglioramento dell'ambiente di lavoro', i 'diritti e interessi dei lavoratori dipendenti', la 'salute nei luoghi di lavoro'. Gli anni '80 si concludono con l'adozione di importanti direttive sulla salute nei luoghi di lavoro (a partire dalla direttiva quadro 89/391/Cee). La quarta fase include una disciplina sistematica ed organica dei diritti dei lavoratori. Ancorché dalla incerta forza giuridica, si ricorda, in tal senso, la Carta comunitaria dei diritti sociali fondamentali dei lavoratori, firmata a Strasburgo, il 9 dicembre 1989, da undici degli allora dodici Stati membri (tutti meno il Regno Unito), il cui valore, pertanto, è prevalentemte simbolico, quello di "affermare solennemente (che) nella attuazione dell'Atto Unico deve tenersi pienamente conto della dimensione sociale e che in tale contesto è necessario garantire, ai livelli appropriati, lo sviluppo dei diritti sociali dei lavoratori della Comunità europea". Dopo il Trattato di Maastricht (che tuttavia lascia immutate le disposizioni dei trattati originari in materia di politica sociale, surrogati dal varo di un protocollo sociale, importante in quanto modifica in senso soppressivo la regola della unanimità in sede di adozione di direttive concernenti le condizioni di lavoro), sono state scarse le direttive in ambito lavoristico. Fra quelle più importanti, possiamo ricordare la direttiva 93/104/Ce del 23/11/1993 (concernente alcuni profili dell'organizzazione dell'orario di lavoro); la direttiva 94/45/Ce del 22/9/1994 (istituzione di una procedura per l'informazione e la consultazione dei lavoratori nelle imprese e nei gruppi di imprese di dimensioni comunitarie); la direttiva 96/34/Ce del 3/6/1996 (congedi parentali concluso). Da ultimo, con il Trattato di Amsterdam, del 17 giugno 1997, si procede alla modifica degli artt. 117 e 122 (rinumerati come 136 e 145), con l'incorporazione del protocollo sulla politica sociale, l'introduzione di un titolo VI bis (poi titolo VIII) sull'occupazione (nel cui primo articolo, il 109N (ora 125) si afferma che gli Stati membri si adopereranno "per sviluppare una strategia coordinata a favore dell'occupazione"), l'incorporazione, nel preambolo del Trattato della Unione europea, di un considerando nel quale le Parti firmatarie manifestano "la propria adesione ai diritti sociali fondamentali così come definiti nella Carta sociale 
così, viene assunta come la sfida basilare e originaria; tale sfida perdurrà fino alla recente riforma dei trattati, a Lisbona, per come si vedrà meglio in seguito.

D'altra parte, tali affermazioni non devono sorprendere, quando si consideri che, a metà degli anni '60, il riconoscimento dei diritti sociali risultava limitato e comunque insufficiente sia a livello internazionale sia negli Stati membri della CEE del tempo ${ }^{62}$. In questo clima, se non proprio di disinteresse, di non attenzione nei confronti dei diritti sociali, si colloca la stessa Convenzione europea per la salvaguardia dei diritti dell'uomo e delle libertà fondamentali ${ }^{63}$. Pur garantendo nel proprio catalogo numerosi diritti, essa interseca solo marginalmente quelli sociali, riproponendo, sul piano internazionale, una visione arcaica dei diritti fondamentali, quale quella del costituzionalismo delle origini che, in modo evidente, contrappone al 'nocciolo duro' dei diritti della prima generazione il corpus separato di quelli di seconda generazione, che confluiscono in un documento distinto ${ }^{64}$. Si tratta della Carta sociale europea, adottata a Torino nel 1961 e rivista, successivamente, nel 1996, a Strasburgo, al fine di rinnovare l'impegno a garantire il carattere indivisibile dei diritti dell'uomo. In entrambe le versioni della Carta risulta conservata una struttura omogenea che, a partire dalla enunciazione dei diritti, prosegue con la previsione dei vincoli giuridici gravanti sulle Parti contraenti e si conclude con la creazione di un sistema di controllo "quasi giurisdizionale", di natura eminentemente internazionalistica ${ }^{65}$. In quanto tale, quest'ultimo si limita a offrire una mera garanzia indiretta e attenuata, nella forma di monitoraggio e di verifica delle condizioni di

europea firmata a Torino il 18 ottobre 1961 e nella Carta comunitaria dei diritti sociali fondamentali dei lavoratori del 1989". Per uno sviluppo di questa evoluzione cfr. M. Ramón Alarcón Caracuel, "La necessità di un capitolo sociale nella ... cit., p. 610 ss.

${ }^{62}$ Cfr. S. Sciarra, "I diritti sociali fondamentali”, in L. Baylos Grua - E. Caruso - M. D'Antona - S. Sciarra (a cura di), Dizionario di diritto del lavoro comunitario, Bologna, 1996.

${ }^{63}$ Sul punto F. Cocozza, Diritto comune delle libertà in Europa, Torino, 1994.

${ }^{64}$ Cfr. B. Pezzini, op. cit., p. 158.

65 "La procedura di controllo prevista dalla Carta sociale, migliorata a seguito dell'entrata in vigore dei due protocolli del 1991 e del 1995, prevede la competenza di un organo di persone (il comitato degli esperti indipendenti) e un organo politico (il Comitato sociale intergovernativo). Quest'ultimo, in particolare, sulla base dei rapporti del comitato degli esperti seleziona e indica al Comitato dei Ministri del Consiglio d'Europa le situazioni nazionali che devono essere oggetto di raccomandazione individuale. Inoltre, un apposito protocollo, consente a talune organizzazioni sindacali la possibilità di presentare reclami avverso presunti inadempimenti statali derivanti dall'inosservanza delle norme della Casta sociale europea". 
adempimento degli obblighi convenuti. Tale sistema di controllo esclude il ricorso individuale, ammettendo, al più, un reclamo collettivo.

Da un punto di vista generale, la struttura che i diritti sociali assumono nella Carta sociale europea fornisce, quindi, un fondamentale argomento per superare le obiezioni che, a livello nazionale, contestano il rango costituzionale di tali diritti, degradandoli a diritti legislativi, a causa della necessità di integrarne il contenuto a un livello normativo infra-costituzionale. Se nella prima fase di integrazione europea si era tentato di risolvere il problema dell'occupazione con misure caratterizzate da logiche neoliberali, l'Atto Unico Europeo, del 1986, aveva introdotto politiche settoriali di stampo interventista senza abbandonare l'idea originaria secondo cui il mercato comune costituiva il mezzo migliore per creare piena occupazione. Con l'adozione della Carta comunitaria dei diritti sociali fondamentali dei lavoratori (il 9 dicembre 1989), si compì, apparentemente, un passo decisivo verso l'entrata formale dei diritti sociali nel quadro europeo, sia pure prevalentemente limitata all'ambito di protezione del lavoratore. Tuttavia, la portata innovativa attribuita al documento fu presto smentita dal fatto che lo stesso non si configurava né come atto giuridico obbligante dell'Unione europea né come atto internazionalmente vincolante, ovvero come fonte pattizia di diritto internazionale pubblico fra gli Stati firmatari.

Nonostante i diversi tentative, la politica sociale europea stentava comunque a decollare, tanto che durante i lavori preparatori del Trattato di Maastricht (1992) fu deciso di ampliare notevolmente la dimensione sociale della Comunità, estendendone le competenze anche a settori fino ad allora esclusi ${ }^{66}$. Tale decisione, però, che aveva registrato l'opposizione del Regno Unito, contrario a qualunque intervento in campo sociale da parte delle istituzioni europee, portò ad un vero e propro escamotage politico per superare il contrasto. II Trattato CE rimase sostanzialmente immutato negli articoli riguardanti le disposizioni sociali, ma ad esso fu aggiunto un Protocollo e un Accordo sulla politica sociale, il quale, pur non contenendo diritti sociali direttamente applicabili, sancì per la prima volta la competenza dell'Unione in

66 Cfr. E. Pagano, "I diritti fondamentali nella Comunità europea dopo Maastricht", in // diritto dell'Unione Europea, 1996, p. 169. 
materia $^{67}$, sottoscritto da 11 Stati (con l'esclusione del Regno Unito), che in pratica riscriveva gli articoli del Trattato $^{68}$. Soltanto con il Trattato di Amsterdam, del 1997, tale anomalia giuridica venne superata, dal momento che il Regno Unito accettò di aderire pienamente alle politiche sociali dell'Unione. Si è provveduto, pertanto, a trasfondere il contenuto dell'Accordo sulla politica sociale in nuovi articoli (da 136 a 145), procedendo contestualmente all'abrogazione del Protocollo n. 14 allegato al Trattato di Maastricht. Nel nuovo testo dell'art. 136 TCE si dispose: "La Comunità e gli Stati membri, tenuti presenti i diritti sociali fondamentali, quali quelli definiti nella Carta sociale europea firmata a Torino il 18 ottobre 1961 e nella Carta comunitaria dei diritti sociali fondamentali dei lavoratori del 1989, hanno come obiettivi la promozione dell'occupazione, il miglioramento delle condizioni di vita e di lavoro, che consenta la loro parificazione nel progresso, una protezione sociale adeguata, il dialogo sociale, lo sviluppo delle risorse umane atto a consentire un livello occupazionale elevato e duraturo e la lotta contro l'emarginazione". È così che i diritti sociali conquistano la qualificazione di diritti fondamentali, al pari dei diritti classici libertà; inoltre, le previsioni dei due documenti sociali, essenziali per la loro protezione a livello europeo, sembrano essere integrate nel Trattato $^{69}$. Le modifiche apportate in campo sociale dal nuovo testo adottato ad Amsterdam risultano significative, poiché sono andate oltre la sola politica sociale adottata in precedenza. Quest'ultima, infatti, si componeva, sostanzialmente, di misure volte alla tutela e alla salvaguardia delle

${ }^{67}$ Cfr. F. Carinci - A. Pizzolato, op. cit., p. 289; M. D’Antona, "Chi ha paura della sussidiarietà", in Lavoro e Diritto, 1994, p. 565.

${ }^{68}$ Secondo F. Carinci - A. Pizzolato (op. cit., p. 287), due erano le principali novità introdotte dal Protocollo: 1) estensione del raggio d'azione delle competenze sociali dell'Unione, distinguendo, a seconda del procedimento di formazione legislativa, materie sociali soggette alla regola della maggioranza qualificata (condizione di lavoro, parità uomo-donna nel mercato del lavoro, integrazione dei soggetti esclusi dal mercato del lavoro) e materie riservata alla regola dell'unanimità (sicurezza, protezione e tutela sociale dei lavoratori, tutela dei lavoratori in caso di risoluzione del rapporto di lavoro; rapppresentanza e difesa collettiva degli interessi dei lavoratori e dei datori di lavoro, promozione dell'occupazione); 2) previsione di una fonte materiale del diritto dell'Unione, la contrattazione collettiva europea, nella duplice veste degli 'accordi liberi', svincolati dal processo normativo dell'Unione e idonei a regolare anche materie escluse dalla competenza normativa sociale della Comunità, e degli 'accordi per la concertazione legislativa'. Cfr. anche F. Carinci, "Dal dialogo sociale al negoziato europeo: gli interventi degli Stati e delle Parti sociali", in AA.VV., Protocollo sociale di Maastricht: realtà e prospettive, Supplemento a XXX, n. 12,1995, p. 91.

${ }^{69}$ Dal momento che le previsioni contenute nelle Carte sociali s'impongono ai Paesi membri, tutti gli Stati ne risultano destinatari, ivi inclusi quelli che deliberatamente si erano tenuti lontani dai precedenti accordi in materia sociale. 
persone già occupate, senza prevedere alcun intervento a favore di quelle categorie escluse da ogni attività lavorativa. A tale carenza si è tentato di porre rimedio con l'introduzione, nel testo del Trattato, del Titolo VIII della Parte terza, interamente dedicato a politiche per l'occupazione ${ }^{70}$.

Non tutti i dati normativi, però, muovono verso un riconoscimento della dimensione sociale dell'integrazione europea, e in particolare non tutti confermano la nuova importanza attribuita ai diritti sociali, la cui portata giuridica, in ogni caso, risulta non comparabile in alcun modo a quella propria delle libertà negative. Al riguardo, è significativo il mantenimento, anche dopo $\mathrm{Amsterdam}^{71}$, della previsione dell'art. $\mathrm{F}$, par. 2 (ora art. 6, par. 2) che dispone: "L'Unione rispetta i diritti fondamentali quali sono garantiti dalla Convenzione europea per la salvaguardia dei diritti dell'uomo e delle libertà fondamentali, firmata a Roma il 4 novembre 1950, e quali risultano dalle tradizioni costituzionali comuni degli Stati membri, in quanto principi generali del diritto comunitario". In questo modo, alla base dell'Unione, continuano a collocarsi i soli diritti fondamentali della prima generazione, mentre i diritti sociali restano in secondo piano. Le perplessità non mancano neppure nel caso in cui si faccia riferimento alla formulazione del citato art. 136 TUE. Sebbene, al suo interno, i diritti sociali vengano riconosciuti come fondamentali, il Trattato si limita a disporre che essi debbano essere semplicemente "tenuti presenti" nel perseguimento degli obiettivi che lo stesso articolo, immediatamente dopo, provvede a fissare.

L'impressione di una notevole 'timidezza,72 del Trattato in campo sociale emerge anche dalle disposizioni successive. Infatti, l'art 137, par. 1, si limita a disporre che la Comunità "sostiene e completa" l'azione degli Stati in una serie di settori di notevole importanza sociale, come la sicurezza e la salute dei lavoratori,

\footnotetext{
${ }^{70}$ L'art. 125 del TCE recita: "Gli Stati membri e la Comunità, in base al presente titolo, si adoperano per sviluppare una strategia coordinata a favore dell'occupazione ...".

${ }^{71}$ Sul punto cfr. anche J. Baquero Cruz, "La protección de los derechos sociales en la Comunidad europea tras el Tratado de Amsterdam", in Revista de Derecho Comunitario Europeo, 1998, n. 4: G. Maestro Buelga, "Costitución económica y derechos sociales en la Unión Europea", in Revista de Derecho Comunitario Europeo, 1998, n. 4; S. Sciarra, "Verso una costituzionalizzazione dei diritti sociali fondamentali dell'Unione Europea", EUI Working Paper Law, n. 96/1.

${ }^{72}$ Sul punto M. Luciani, op. cit., p. 372.
} 
ecc. ${ }^{73}$ Si tratta di una formula generale di grande cautela, e dalle norme più puntuali che la seguono non emergono quegli elementi di immediata doverosità per gli Stati che sono invece così frequenti in materia di stabilità finanziaria e di concorrenza. L'unica eccezione, a questa concezione, è rappresentata dall'art. 141 TUE $^{74}$, relativo alle pari opportunità, direttamente applicabile e applicato dalla Corte di Giustizia.

Da tutto ciò deriva una valutazione di complessiva delusione per i progressi fatti con Amsterdam in campo sociale ${ }^{75}$. Emergeva in modo sempre più pressante, quindi, la necessità di procedere alla codificazione di un catalogo di diritti fondamentali, al fine di colmare la lacuna di una siffatta elencazione esplicita ${ }^{76}$.

\subsection{I diritti fondamentali sociali: l'approccio della dottrina}

Colti sotto il profilo più strettamente giuridico-costituzionale, come è stato già osservato $^{77}$, lo statuto europeo dei diritti sociali (la 'cittadinanza sociale' dell'Unione) e le relative garanzie rispetto agli ordinamenti costituzionali nazionali contrastano nel fondo con la loro concezione negli ordinamenti costituzionali nazionali (fra cui soprattutto - ma non solo - quello italiano, quello spagnolo e quello tedesco) ${ }^{78}$. Ciò che rileva di tali diritti nell'azione e per la realizzazione delle finalità dell'ordinamento dell'Unione è la loro finalizzazione alle esigenze proprie del mercato comune. In una simile ottica, nell'ambito più generale della 'politica sociale' dell'Unione, per come disciplinata nel nuovo Titolo IX del TFUE (già Capo I del Tit. XI del Trattato CE, art. 136-145), i diritti sociali si trasformano in meri parametri di legittimità normativa,

${ }^{73}$ Cfr. P. Magno, "Diritti sociali nell'ordinamento dell'Unione europea dopo Amsterdam", in // diritto del lavoro, 1998, parte 1, p. 123.

74 II testo recita: "Ciascuno Stato membro assicura l'applicazione del principio della parità di retribuzione tra lavoratori di sesso maschile e quelli di sesso femminile per uno stesso lavoro o per un lavoro di pari valore".

${ }^{75}$ Sul punto cfr. anche S. Gambino, “Dall'Europa dei mercati all'Europa dei diritti: alcune riflessioni su diritti fondamentali e costituzionalismo comunitario", in AA.VV., L'integrazione europea fra economia e democrazia, Cosenza, 2003.

${ }^{76}$ Sul punto cfr. U. De Siervo, "L'ambigua redazione della Carta dei diritti fondamentali nel processo di costituzionalizzazione dell'Unione Europea", in Diritto pubblico, 2001; A. Pizzorusso, "Il rapporto del comitato Simitis", in Diritto pubblico comparato ed europeo, 1999.

${ }^{77}$ Cfr. M. Luciani, "Diritti sociali e integrazione europea", in Annuario 1999. La Costituzione europea, Padova, 2000, cui adde anche Parlement européen, Droits sociaux fondamentaux en Europe, (Séries Affaires Sociales - SOCI 104 FR), 1999.

${ }^{78}$ Cfr. J. Iliopoulos Strangas (ed.), La protection des droits sociaux fondamentaux dans les Etats membres de l'Union européenne, Bruxelles, 2000. 
assumendo per questo non più una validità in sé bensì la natura di diritti complementari alle libertà economiche, riservandosene il relativo riconoscimento e la tutela all'ambito interno degli Stati membri, mentre l'intervento normativo e giurisprudenziale dell'Unione rimane esterno e subordinato alle tutele assicurate dalle legislazioni e dalle giurisdizioni degli Stati membri.

A ben considerare, sotto tale profilo, gli artt. 51, 52 e 53 della Carta dei diritti fondamentali dell'U.E. non innovano in modo significativo in questa costruzione di base $^{79}$. Nella evoluzione dell'ordinamento europeo, così, i diritti sociali, sotto il profilo strettamente giuridico-costituzionale - facendo eccezione, naturalmente, per i diritti sociali riconosciuti e protetti nella Carta europea dei diritti fondamentali - continuano ad assumere natura di diritti 'residuali', funzionalizzati agli obiettivi economici del mercato unico europeo, dovendosi giungere a una conclusione, circa la normativa europea in materia sociale, secondo cui la stessa si limita a disciplinare, in modo prevalente, disposizioni programmatiche, poco più che 'obiettivi', senza contenuti di prescrittività per le istituzioni dell'Unione a dare attuazione alle stesse se non nell'ottica della funzionalità sociale del mercato economico ${ }^{80}$.

La natura giuridica imprecisa e incerta di tali disposizioni pare, dunque, unicamente superabile con la loro positivizzazione in un 'catalogo' di diritti sociali, all'interno di una più ampia e rivisitata Carta europea dei diritti fondamentali, su cui le istituzioni europee e la dottrina vanno discutendo negli ultimi anni, pur senza

\footnotetext{
79 Nell'ampia bibliografia cfr. anche A. Ruggeri, "Carta europea dei diritti e integrazione interordinamentale, dal punto di vista della giustizia e della giurisprudenza costituzionale (notazioni introduttive)", in AA.VV. (Giornata italo-spagnola, Taormina 4 ottobre 2002), Riflessi della Carta europea dei diritti sulla giustizia e la giurisprudenza costituzionale: Italia e Spagna a confronto, Milano, 2003; nello stesso volume cfr. anche il nostro "I diritti fondamentali comunitari: fra Corte di Giustizia delle Comunità Europee, trattati e Bill of rights".

${ }^{80} \mathrm{La}$ Corte di Giustizia, da parte sua, ha fatto proprio tale indirizzo, quando, dopo un primo orientamento, nel quale assume l'esistenza di limiti ai diritti fondamentali nella sola materia dei diritti economici (Sent. 14 maggio 1974, Nold, causa 4/73, in Racc. Uff., 1974, p. 491; sent. 13 dicembre 1979, Hauer, causa 44/79, in Racc. Uff., 1979, p. 3727, su cui cfr. fra gli altri F. Mancini, "La tutela dei diritti dell'uomo: il ruolo della Corte di Giustizia delle Comunità europee", in Riv. trim. dir. proc. civ., 1989 , n. 1), ha sancito che "i diritti fondamentali riconosciuti dalla Corte non risultano ... essere prerogative assolute e devono essere considerati in relazione alla funzione da essi svolta nella società. E' pertanto possibile operare restrizioni all'esercizio di tali diritti, in particolare nell'ambito di un'organizzazione comune di mercato, purché dette restrizioni rispondano effettivamente a finalità d'interesse generale perseguite dalla Comunità e non si risolvano, considerato lo scopo perseguito, in un intervento sproporzionato e inammissibile che pregiudicherebbe la stessa sostanza di tali diritti" (Sent. 13 luglio 1989, Wachauf, causa 5/88, in Racc. Uff., 1989, p. 2609 ss.).
} 
pervenire ancora a una intesa (considerate, in particolare, le resistenze in tal senso recentemente reiterate a Lisbona - della Gran Bretagna e della Polonia) ${ }^{81}$. Evidentemente, l'adeguatezza di una simile Carta dei diritti sociali è funzione delle scelte politiche e costituzionali sul futuro (qualora auspicato) dello 'Stato sociale' in Europa. In definitiva, dunque, il futuro dei diritti sociali nel processo di costruzione europea non pare doversi ulteriormente affidare alla sola giurisprudenza pretoria della Corte di Giustizia, alla discutibilità delle sue tecniche argomentative e ai relativi, sempre possibili, conflitti con le giurisdizioni costituzionali nazionali, dovendosi necessariamente prevedere una loro positivizzazione normativa capace di farsi carico, in modo più convinto (certo e garantito), delle più avanzate 'tradizioni costituzionali comuni' in tale materia ${ }^{82}$. Solo a partire da una disciplina europea capace di conformarsi alle più avanzate 'tradizioni' costituzionali in materia di diritti e di giustizia sociale, potranno ritenersi risolte le problematiche poste dall'esercizio dello stesso diritto alla tutela giudiziaria effettiva in materia (principio - quest'ultimo affermato come fondamentale dalla Corte di Giustizia) sia con riferimento ai diritti c.d. negativi, sia e soprattutto ai 'diritti prestazionali' ${ }^{83}$.

\section{I diritti sociali nei nuovi trattati}

Sia pure con una gradualità che è chiamata a farsi carico delle differenziate modalità di tutela dei diritti nelle Costituzioni nazionali, a livello europeo è dato ormai registrare (tale affermazione avrà piena effettualità solo a seguito della entrata in

\footnotetext{
${ }^{81}$ Nell'ampia bibliografia relativa alla Carta di Nizza, cfr. almeno, AA.VV., Riscrivere i diritti in Europa, Bologna, 2001; F. Petrangeli, Una Carta per l'Europa. Diritti fondamentali e mercato nel processo d'integrazione, Roma, 2001; A. Apostoli, La Carta dei diritti dell'Unione Europea, Brescia, 2000; A. Baldassarre, "La Carta europea dei diritti", in Osservatorio costituzionale Luiss; E. Denninger, "I diritti fondamentali nel quadro dell'Unione Europea", in Osservatorio costituzionale Luiss; U. De Siervo, "I diritti fondamentali europei ed i diritti costituzionali italiani (a proposito della Carta dei diritti fondamentali", in Diritto pubblico comparato ed europeo, 2001, n. 1 (cui adde, nella stessa Rivista il Forum, con interventi di V. Atripaldi, G.G. Floridia, A. Giovannelli, M. Luciani, S. Mangiameli, E. Pagano, A. Ruggeri, R. Toniatti); il num. spec. di Diritto pubblico, 2001, n. 3.

${ }^{82}$ Cfr. M. Cartabia, Princìpi inviolabili e integrazione europea, Milano, 1995 e (a cura della stessa Autrice), I diritti in azione. Universalità e pluralismo dei diritti fondamentali nelle Corti europee, Bologna, 2007.

${ }^{83}$ Sul punto cfr. anche i nostri "Il diritto a un giudice autonomo e indipendente. Ri-forma di stato e sistema di giustizia nell'ottica interna, comparata e comunitaria", in Democrazia e diritto, 2005, n. 3, nonché "Modelli europei di ordinamento giudiziario e tradizioni costituzionali in materia giudiziaria comuni agli stati membri dell'U.E.", in http://www.federalismi.it, 2005, n. 3.
} 
vigore dei nuovi trattati riformati a Lisbona, il 12 dicembre 2007) una positivizzazione dei diritti fondamentali classici, mentre si registrano tuttora ritardi nel pieno riconoscimento dei cataloghi dei diritti politici ${ }^{84}$ e sociali previsti nelle Costituzioni europee $^{85}$, la cui "minorità comunitaria", rispetto ai modelli costituzionali nazionali (soprattutto italiano, spagnolo e tedesco, ma non solo, come si è visto nella parte introduttiva dello studio), risulta confermata dalla disciplina dell'art. 136 TFUE $^{86}$. Secondo tale disposizione, infatti, 'I'Unione e gli Stati membri, tenuti presenti i diritti sociali fondamentali, quali quelli definiti nella Carta sociale europea firmata a Torino il 18 ottobre 1961 e nella Carta comunitaria dei diritti sociali fondamentali dei lavoratori del 1989, hanno come obiettivo la promozione della occupazione, il miglioramento delle condizioni di vita e di lavoro, che consenta la loro parificazione nel progresso, una protezione sociale adeguata, il dialogo sociale, lo sviluppo delle risorse umane atto a consentire un livello occupazionale elevato e duraturo e la lotta contro la emarginazione". Nella realizzazione di tale complesso obiettivo, inoltre, al II par., si prevede che sia l'Unione che gli Stati membri attuino misure compatibili con la diversità delle prassi nazionali e idonee a farsi carico della "necessità di mantenere la competitività dell'economia dell'Unione". In tale ottica, fra le altre innovazioni dei trattati, ricordiamo l'integrazione, immediatamente dopo l'art. 136, di una nuova disposizione (art. 136 bis) volta ad assicurare, al contempo, il riconoscimento al suo livello delle prassi di sussidiarietà, con l'attivo coinvolgimento delle parti sociali nel perseguimento del dialogo fra le parti e dello sviluppo del dialogo sociale. In tal senso, infatti, si prevede che "I'Unione riconosce e promuove il ruolo delle parti

\footnotetext{
${ }^{84}$ Cfr. F. Ferrara, "I diritti politici nell'ordinamento europeo ... cit.; E. Grosso, "La limitata garanzia dei diritti di partecipazione politica nella Carta dei diritti fondamentali ... cit.

${ }^{85}$ Cfr. J. Iliopoulos Strangas (ed.), La protection des droits sociaux fondamentaux ... cit.; J.F. Flauss (dir.), Droits sociaux et droit européen. Bilan et perspectives de la protection normative, Bruxelles, 2002; AA.VV. (Actes Conférecnce organiseée par le Secrétariat de la Charte sociale européenne, Sofia, Bulgarie, $5 / 7$ juillet 2000), La protection des droits sociaux fondamentaux en Europe par la Charte sociale européenne, Strasbourg, 2001; B. Veneziani, "Nel nome di Erasmo di Rotterdam. La faticosa marcia dei diritti sociali fondamentrali nel'ordinamento comunitario", in Riv. giur. lav. e previd. sociale, 2000, I. J. Baquero Cruz, "La protección de los derechos sociales en la Comunidad europea tras el Tratado de Amsterdam", in Revista de derecho comunitario europeo, 1998, 4.

${ }^{86}$ Cfr. M. Luciani, "Diritti sociali e integrazione europea", in Politica del diritto, 2000; S. Giubboni, "I diritti sociali fondamentali nell'ordinamento comunitario", in II diritto dell'UE, 2003, nn. 2/3; G. Bronzini, " II modello sociale europeo", in AA.VV. (a cura di E. Paciotti), La Costituzione europea ... cit.; U. Allegretti, "I diritti sociali", in Osservatorio costituzionale LUISS (21 maggio 2004).
} 
sociali al suo livello, tenendo conto della diversità dei sistemi nazionali. Essa facilita il dialogo fra tali parti, nel rispetto della loro autonomia. II vertice sociale trilaterale per la crescita e l'occupazione contribuisce al dialogo sociale", riaffermandosi, in tal modo, gli orientamenti già accolti, nel fondo, all'interno del Trattato di Amsterdam, nel senso della "apertura alle fonti ed al negoziato fra soggetti collettivi organizzati, pur nella perdurante abstention dell'Unione rispetto alle regole e ai principi associativi di questi ... : un atteggiamento che lascia alla Corte di giustizia giudicare sulla razionalità dei criteri selettivi adottati dagli organi di Bruxelles nella scelta degli interlocutori di parte sindacale e sulla loro adeguata rappresentativitàn" ${ }^{n 7}$. La realizzazione di tali finalità comportano un maggior protagonismo della Commissione (art. 140 TFUE) nel senso dell'incoraggiamento alla cooperazione fra gli Stati membri e della facilitazione del coordinamento della loro azione in tutti i settori della politica sociale contemplati nella medesima disposizione. A tal fine, le innovazioni introdotte dai nuovi trattati si estendono alla previsione di forme fin qui non previste, in base alle quali la Commissione, che opera a stretto contatto con gli Stati membri mediante studi e consultazioni, e comunque tenendo pienamente informato il Parlamento europeo, possa operare "in particolare mediante iniziative finalizzate alla definizione di orientamenti e di indicatori, all'organizzazione di scambi di migliori pratiche e alla preparazione di elementi necessari per il controllo e la valutazione periodici" (art. 140 TFUE, par. 2).

Le altre innovazioni introdotte dai nuovi trattati nella materia di cui ci stiamo occupando - comunque né numerose né tali da far mutare segno all'orientamento di perplessità espresso in questa riflessione - si collocano in parti diverse del nuovo articolato dei trattati, imponendosene per questo una lettura/interpretazione di tipo unitario. Una prima disposizione innovativa è data dall'art. $2 \mathrm{C}$ del nuovo TFUE, che ascrive alla competenza concorrente dell'Unione, fra le altre, quella della "politica sociale, per quanto riguarda gli aspetti definiti nel presente trattato", che, come abbiamo appena osservato, non appaiono di grande rilievo. Unitamente a tale ambito materiale, ma senza conoscere le limitazioni proprie della materia concorrente, è

${ }^{87}$ Così G. Bronzini, "Il modello sociale europeo .... cit., par. 3. 
tuttavia da ricordare la previsione, essa stessa del tutto nuova, posta dall'art. 2E TFUE che, fra gli ambiti materiali riguardati dall'azione dell'Unione volta a "sostenere, coordinare e completare l'azione degli Stati membri", include la "tutela e miglioramento della salute umana", la "cultura", l'“istruzione, formazione professionale" che - unitamente alle previsioni di cui all'art. 35 e all'art. 14 della Carta europea dei diritti fondamentali - costituiscono appunto una transizione molto significativa di taluni ambiti materiali dello Stato sociale europeo contemporaneo dalla sfera delle politiche a quella dei diritti.

È stato già ben sottolineato, inoltre, come fra le importanti novità registrate nella recente riforma dei trattati debba richiamarsi lo sviluppo, accanto alle forme della sussidiarietà verticale - che coinvolgono appunto l'Unione, gli Stati membri e le regioni - di quelle riferibili alla sussidiarietà orizzontale che, nel quadro di un rafforzato 'pluralismo ordinamentale', riportano e sviluppano, a livello di Unione, "le fonti della contrattazione collettiva legata al cosiddetto 'dialogo sociale europeo' e, su un piano più generale, anche le dinamiche di confronto e mutual learning tra i principali attori europei (compresa la società civile, dai sindacati alle ONG) incentrate sulle ibride procedure dell'open method of coordination (OMC)"88.

Un rafforzato quadro di disposizioni comuni nella materia relativa ai valori dell'Unione arricchisce quanto già previsto in materia dal Preambolo della Carta, implicando la loro violazione l'attivazione delle procedure previste al successivo art. 7. In tal senso, nel nuovo TUE, viene previsto l'art. 1 bis, secondo il quale "I'Unione si fonda sui valori del rispetto della dignità umana, della libertà, della democrazia, dell'uguaglianza, dello Stato di diritto e del rispetto dei diritti umani, compresi i diritti delle persone appartenenti a minoranze. Questi valori sono comuni agli Stati membri in una società caratterizzata dal pluralismo, dalla non discriminazione, dalla tolleranza, dalla giustizia, dalla solidarietà e dalla parità tra donne e uomini”. Rispetto a quanto previsto nell'art. I-3 (Obiettivi dell'Unione) nel Trattato costituzionale, nell'art. 2 del nuovo TUE trova ora collocazione una delle disposizioni probabilmente più significative nella direzione della spiegazione dei rapporti esistenti fra gli obiettivi

${ }^{88}$ Cfr. G. Bronzini, "Il modello sociale europeo ... cit., par. 1; B. Caruso, "Sistemi contrattuali e regolazione legislativa in Europa", in Diritto del lavoro e delle relazioni industriali, 2006, n. 4. 
del mercato interno e le innovate ragioni della sua necessaria socialità. Se è indubbiamente rilevante, e non solo dal punto di vista simbolico, la scomparsa della previsione accolta in precedenza nel Trattato costituzionale (art. I-3, par. 2, TC) nella quale veniva sancito che "la concorrenza è libera e non è falsata", dal punto di vista strettamente giuridico risulta indubbio che la nuova formulazione dell'art. 2 del TUE, in unum con i principi della Carta ormai incorporati nei trattati (sia pure con le formule peculiari dell'assegnazione a quel documento politico della stessa forza giuridica dei trattati), potrà orientare l'indirizzo giurisprudenziale della Corte di Giustizia "verso un riequilibrio nella gerarchia tra principi di diversa natura, che ora conta anche sul più solido e chiaro sostegno della Carta di Nizza che proclama al suo Preambolo solennemente l'indivisibilità tra i diritti che elenca e protegge" ${ }^{\prime 89}$. Nei nuovi artt. 2 e 3 del TUE, infatti, accanto alla previsione secondo cui "I'Unione instaura un mercato interno", si prevede che la stessa si adopera "per lo sviluppo sostenibile dell'Europa, basato ... su un'economia sociale di mercato fortemente competitiva, che mira alla piena occupazione e al progresso sociale ... Essa combatte l'esclusione sociale e le discriminazioni e promuove la giustizia e la protezione sociale, la parità tra donne e uomini, la solidarietà fra generazioni e la tutela dei diritti del minore. Essa promuove la coesione economica, sociale e territoriale, e la solidarietà tra gli Stati membri". Nelle disposizioni di applicazione generale del TFUE, infine, si prevedono norme volte ad assicurare la coerenza fra le varie politiche e azioni dell'Unione nel quadro della conformazione ai valori e nel perseguimento degli obiettivi positivizzati nei nuovi trattati. In tale ambito, in particolare, all'art. 5 bis del TFUE, si prevede che "I'Unione tiene conto delle esigenze connesse con la promozione di un elevato livello di occupazione, la garanzia di una adeguata protezione sociale, la lotta contro l'esclusione sociale e un elevato livello di istruzione, formazione e tutela della salute umana". Non siamo molto distanti, come si può osservare, dalle tenui forme di protezione dei diritti sociali accolte nell'art. 136 del TUE e ora del TFUE, quando si prevede che l'Unione "tiene presente i diritti sociali fondamentali"; anche nella disposizione da ultimo richiamata (art. 5bis del TFUE), infatti, si prevede che l'Unione

${ }^{89}$ Cfr. G. Bronzini, "Il modello sociale europeo ... cit., par. 2. 
"tiene conto delle esigenze connesse ..."; in altri termini, il quadro era e resta ancorato ad una evoluzione ordinamentale dell'Unione molto lenta sulla strada di politiche di sviluppo e di coesione compatibili con i diritti ${ }^{90}$. Lungo questo sviluppo sarà probabilmente la Corte di Giustizia ad imprimere nuove spinte evolutive nella direzione di una più piena effettività dei diritti fondamantali comunitari; tuttavia, quando e ove ciò dovesse realizzarsi, le condizioni sarebbero ormai mature per l'avvio di più compiuti processi di costituzionalizzazione dell'Unione.

La giurisprudenza della C.G.U.E., d'altra parte, aveva già da tempo offerto chiari riscontri di tale bilanciamento fra esigenze economiche e diritti sociali, oltre che nella giurisprudenza in materia di divieto di discriminazione (parità uomo-donna), nella soluzione di conflitti relativi alla protezione del lavoratore (previdenza sociale pubblica, ferie retribuite, contrattazione collettiva) ${ }^{91}$. Diversamente dai diritti di prima

90 Come è stato bene sottolineato, "Si tratta di disposizioni che vogliono chiaramente imprimere un'intima coerenza alle azioni degli organi sovranazionali in modo da coniugare - per dirla con Jurgen Habermas - le ragioni dell'integrazione sistemica con quelle dell'integrazione sociale impedendo che le misure di natura economica o di rafforzamento della competitività della «zona Europa» prevalgano su quegli obiettivi di coesione e solidarietà che l'Unione ha da tempo accolto nei suoi Statuti primari. Come si accennerà, questa esigenza di conciliazione cui accenna l'art. 5bis è oggi fatta valere in moltissimi atti comunitari con la catchword della flexicurity. Rimane incerto il «valore» della clausola; se cioè sia meramente di natura «politica", fornendo elementi di orientamento interpretativo per la Corte di giustizia o indirizzando gli organi dell'Ue a motivare i loro provvedimenti anche dal punto di vista dell'«impatto sociale», o invece se sia ipotizzabile la sua giustiziabilità. Le espressioni usate sembrano voler trascendere la mera natura politica della «clausola»: non solo questa è, unitamente alla norma gemella antidiscriminatoria, inserita in un titolo II denominato "disposizioni di applicazione generale» (come nel TC), ma l'art. 2F TFUE irrobustisce gli impegni presi proclamando che «'Unione assicura la coerenza fra le varie politiche e azioni, tenendo conto dell'insieme dei suoi obiettivi e conformandosi al principio di attribuzione delle competenze»; l'inciso sulle competenze fa pensare che i redattori del Trattato si siano preoccupati dell'incidenza della clausola sociale, circoscrivendone l'ambito di operatività, ma al tempo stesso dandone per scontata una natura autenticamente vincolante. L'art. $2 \mathrm{~F}$, inoltre, facendo rinvio agli obiettivi nel loro insieme dell'Unione ha una primaria finalità di giuntura e saldatura tra i due trattati che assegna alle clausole previste nel Titolo II un ruolo privilegiato di "cartine di tornasole" di un equilibrato funzionamento del sistema europeo" (cfr. G. Bronzini, "Il modello sociale europeo ... cit., par. 2).

${ }_{91}$ Fra le altre, C-67/96 del 21.9.1999 Albany International BV; C-173/99 del 26.6. 2001, The Queen v Secretary of State for Trade and Industry. Sul tema cfr. anche "J. Iliopoulos-Strangas, "La Chrate des droits fondamentaux de l'Union européenne face à la protection constitutionnelle des droits sociaux", in J.-F. Flauss (dir.), Droits sociaux et droit européen ... cit. Sul punto, oltre al già citato U. Allegretti per il quale appare del tutto 'misterioso' e paradossale come il 'modello sociale europeo' dei primi trattati comunitari risulti pienamente eccentrico rispetto alla affermazione nel corso di quegli anni del modello di 'Stato sociale' - cfr. anche G. Bronzini, "Il 'modello sociale europeo'”, in E. Paciotti (a cura di), La Costituzione europea ... cit. e dello stesso A, "Il modello sociale europeo", in F. Bassanini - G. Tiberi (a cura di), Le nuove istituzioni europee. Commentario al nuovo Trattato europeo, Bologna, 2008; M. Barbera, Dopo Amsterdam: i nuovi confini del diritto sociale comunitario, Brescia, 2000; S. Giubboni, Diritti sociali e mercato. La dimensione sociale dell'integrazione comunitaria, Bologna, 2003, 
generazione, tuttavia, come viene lucidamente sottolineato ${ }^{92}$, la protezione dei diritti sociali è solo "indiretta e puramente eventuale, in quanto i vincoli riconosciuti non sono connessi direttamente alla difesa di taluni diritti sociali ma sono giudicati rilevanti nella sola misura in cui essi siano riconducibili ad interessi pubblici collegati all'attuazione di determinate politiche della Comunità (come quella agricola nel caso Hauer). Non solo, ma, come rilevato dalla dottrina gius-lavoristica, anche alcuni dei diritti sociali riconosciuti sono sottoposti ad una "infiltrazione", da parte del diritto della concorrenza e del mercato, che ne altera significativamente la consistenza ${ }^{93}$. Ciò ha prodotto il risultato di una predilezione da parte della Corte di Giustizia per la libertà di concorrenza nei confronti di un diritto sociale quale ad esempio la salute".

II quadro normativo comunitario in materia di diritti sociali solleva molteplici perplessità, sia per quanto riguarda la disciplina positiva di tali peculiari situazioni giuridiche dalla natura pretensiva, sia l'estensione agli stessi della medesima natura di diritti inviolabili e pertanto di principi supremi costitutivi dell'ordinamento democratico, sia, ed infine, per quanto riguarda l'effettiva loro 'giustiziabilità'. Ma prima ancora, tale quadro solleva la centrale questione della natura e dei corrispondenti contenuti normativi dei princìpi fondamentali cui lo stesso s'ispira. All'interno di tale quadro, si pone l'interrogativo sull'esistenza di un raccordo fra principio di eguaglianza formale e principio di eguaglianza sostanziale, come avviene all'interno delle tradizioni costituzionali comuni più avanzate degli Stati membri dell'U.E. ${ }^{94}$

per il quale, tuttavia, lo sviluppo settoriale delle politiche europee, soprattutto di quella gricola, potrebbero essere colte come un "vero e proprio sistema settoriale di welfere state"; dello stesso A. cfr. anche "Libertà di mercato e cittadinananza sociale europea", in Atti Convegno Fondazione Lelio e Lisli Basso, Le prospettive del welfare in Europa, Roma, 2007; R. Greco, "Il modello sociale della Carta di Nizza" (paper).

${ }_{92}$ Cfr. U. Allegretti, "I diritti sociali", in Osservatorio costituzionale LUISS (21 maggio 2004).

${ }^{93}$ Cfr. la giurisprudenza Dassonville - C-8/74 dell'11.7.1974 - e soprattutto Cassis de Dijon - C120/78 del 20.2.1979 -, solo in seguito attenuata in Keck e Mithouard - C-267 e 268/91 del 24.11.1993. In tal senso, in dottrina, cfr. soprattutto S. Giubboni, Diritti sociali e ... cit.

${ }^{94}$ In questo senso cfr. anche G. Azzariti, "Uguaglianza e solidarietà nella Carta dei diritti di Nizza", in M. Siclari, Contributi allo studio della Carta dei diritti fondamentali dell'Unione europea, Torino, 2003, per il quale le disposizioni della Carta in tema di eguaglianza sostanziale (artt. 20, 21 e 23 sembrano limitare tale principio al solo ambito "dei rapporti tra i sessi ed esclisivamente nella forma specifica dell'azione positiva" (p. 71). 
Si pone, parimenti, il quesito se i diritti sociali comunitari, (soprattutto) per come riconosciuti nella Carta dei diritti e delle libertà fondamentali, si limitino a far proprio e a dare attuazione al principio di eguaglianza, inteso nel senso originario di divieto di discriminazione fra i soggetti o se, piuttosto, non accolgano anche quello di eguaglianza sostanziale posto a base del costituzionalismo europeo del secondo dopo-guerra, coinvolgendo in tal senso la questione della copertura della spesa e pertanto dell'esistenza in capo alla U.E. di una competenza in materia che non risulti lesiva della competenza costituzionale di ogni singolo Stato membro ${ }^{95}$.

Diversamente da quanto viene sancito nelle originarie Carte costituzionali (liberal-democratiche) e in quelle che hanno vita nel costituzionalismo successivo al secondo conflitto mondiale (Carte social-democratiche), come si è osservato in precedenza, nelle finalità originarie dei trattati, non rientrava né l'enunciazione di un principio generale di eguaglianza né la previsione di un generale principio di divieto di discriminazione, tranne quello relativo alla nazionalità, sia pure in quest'ultimo caso come clausola non espressa. È il Giudice di Lussemburgo - come si ricorderà a identificarlo come species del più ampio genus dei princìpi generali del diritto dell'Unione, attingendo allo stesso patrimonio delle tradizioni costituzionali comuni agli Stati membri, cui lo stesso ha fatto ricorso per la tutela dei diritti fondamentali dell'Unione ${ }^{96}$.

Tuttavia, se di indubbio rilievo appare la ricerca volta a evidenziare l'apporto del patrimonio costituzionale europeo alla formazione di tali principi e con essi alla stessa fondazione del 'blocco di comunitarietà' approntato dalla C.G.U.E., meno approfondito (e perciò di maggiore interesse scientifico) risulta il contributo che tale

\footnotetext{
${ }^{95}$ Nell'ampia bibliografia sul punto, cfr., di recente, almeno, O. Pollicino, "Di cosa parliamo quando parliamo di uguaglianza? Un tentativo di problematizzazione del dibattito interno alla luce dell'esperienza sopranazionale", in http://www.forumcostituzionale.it (25.7.2005), cui adde anche V. Onida, "L'eguaglianza ed il principio di non discriminazione", in http://www.luiss.it (n. 10/2003); A. Saccomanno, "Eguaglianza sostanziale e diritti sociali nel rapporto fra ordinamento interno e ordinamento comunitario", in S. Gambino (a cura), Costituzione italiana e diritto comunitario, 2002 ; C. Di Turi, "La protezione dei diritti sociali fondamentali a livello internazionale ed europeo", in S. Gambino, Costituzione italiana ... cit.

${ }^{96}$ Cfr. Corte di Giust., sent. Sermide SPA c. Cassa Conguaglio e altri, C-106/83, in Racc., I-1984; sent. Racke, 13-11-1984 C-283/83, in Racc., I-3791; sent. 17-5-1997. EARL, C-15/95, in Racc. I1961. Nello stesso senso, le Conclusioni dell'Avvocato generale Van Gerven del 15-9-1993 nella causa Koinopaxia Enoseon e altri v. Minister van LandBouw, C-146/91, in Racc. I-4199.
} 
giurisprudenza potrà apportare alla giurisprudenza costituzionale nazionale, ancora per molti profili ferma ad un'attenzione limitata ai soli profili del divieto di discriminazione di cui all'art. 3, I co., Cost., come, ad esempio, è dato osservare nella giurisprudenza costituzionale in materia di divieto di discriminazione nell'accesso alle cariche elettive ${ }^{97}$.

La ricostruzione dei nuovi percorsi della giurisprudenza della Corte di Giustizia $^{98}$ successiva al trattato di Amsterdam, in tal senso ${ }^{99}$, evidenzia un orientamento sostanzialistico del principio di eguaglianza ${ }^{100}$, nel quale il Giudice di Lussemburgo tende a superare l'originaria visione formalistica e individualistica del principio medesimo, per orientarsi, in modo graduale, verso l'affermazione, nell'ambito europeo, della dimensione del 'diritto diseguale', capace di farsi carico (soprattutto in materia di discriminazione in base al sesso) della nozione di discriminazione indiretta ${ }^{101}$, ispirandosi, in tale percorso, alla stessa giurisprudenza della Corte suprema nord-americana in materia di equal protection clause e di disparate impact ${ }^{102}$. Da tale approccio, ne segue che "l'ordinamento comunitario, partendo da una situazione di partenza che relegava le c.d. azioni positive a mera

${ }^{97}$ Cfr. S. Gambino, "Verso la democrazia paritaria ... cavalcando le lumache: parità, pari opportunità e accesso alle cariche elettive", in Astrid Rassegna, 2005, Vol. 1, n. 4; L. Carlassare, "La rappresentanza femminile, principi formali ed effettività", in F. Bimbi - A. del Re (a cura di), Genere e democrazia, La cittadinanza delle donne a 50 anni dal voto, Torino, 1997; L. Carlassarre, Parere sulla legittimità costituzionale della previsione di una quota del 50\% riservata alle candidature femminili (paper); U. De Siervo, "La mano pesante della Corte sulle quote nelle liste elettorali", in Giur. Cost., 1995; V. Ballestrero, "Azioni positive e quote nel giudizio di due autorevoli Corti", in S. Scarponi (a cura di), Le pari opportunità nella rappresentanza politica e nell'accesso al lavoro, Trento, 1997; G. Cinanni, "Le leggi elettorali ed azioni positive in favore delle donne", in Giur. Cost., 1995. Sul principio di eguaglianza sostanziale e la relativa giurisprudenza costituzionale, cfr. nell'ampia bibliografia, almeno, sent. n. 109 del 1993, in Giur. Cost., 1993, p. 873 ss., con note di A. Anzon, "L'additiva 'di principio' nei giudizi in via principale' e di M. Ainis, "L'eccezione e la sua regola"; C. Colapietro, La giurisprudenza costituzionale nella crisi dello Stato sociale, Padova, 1996; A. Baldassarre, "Diritti sociali", in Enc. giur., XI, Roma, 1989; M. Luciani, "Sui diritti sociali", in Dem. e dir., 1994, 4 e 1995, 1; A. Anzon, "L'altra 'faccia' del diritto alla salute", in Giur. cost., 1979; L. Chieffi (a cura di), I diritti sociali tra regionalismo e prospettive federali, Padova, 1999.

${ }^{98}$ Cfr. O. Pollicino, "Di cosa parliamo ... cit., p. 4, p. 8 ss.

${ }^{99}$ Sent. 17 ottobre 1995, causa C-450/93, Kalanke, Racc.I-3051.

100 Sent. 11 novembre 1997, causa C-409/95, Marschall, Racc. I-6363.

101 Sent. 7 dicembre 2000, causa C-79/99, Schnorbus Racc. I-10997.

102 Cfr. G.F. Ferrari, Localismo ed Eguaglianza nel sistema americano dei servizi sociali, Padova, 1984; A. Cerri, "I modi argomentativi del giudizio di ragionevolezza, Cenni di diritto comparato", in AA.VV, II principio di ragionevolezza nella giurisprudenza costituzionale. Riferimenti comparatistici, Milano, 1994. Sulle recenti tendenze della Corte suprema americana nell'applicazione della Equal Protection Clause v. G.F. Ferrari, La Corte suprema degli Stati Uniti nei terms 1997/1998 e 1998/1999, in Giur. Cost., 1999, 2259 ss. 
eccezione del principio di equal treatment, ha in corso un processo evolutivo orientato, attraverso l'incessante operazione di approfondimento da parte della Corte di giustizia del divieto di discriminazione sulla base del sesso ed il parallelo percorso del legislatore comunitario nello stesso senso, verso una prospettiva, assiologicamente caratterizzata, in cui il trattamento preferenziale, lungi dall'essere considerato una violazione momentanea e difficilmente ammissibile del principio di uguaglianza possa essere riqualificato come proiezione in concreto dello stesso, valorizzando quindi il nucleo duro dello strumento in questione, ossia la sua naturale vocazione, ove animato dall'intento di rimuovere le situazioni di disuguaglianza di fatto esistenti, a farsi portatore del valore dell'uguaglianza effettiva"103. Un'evoluzione - quest'ultima - che, al momento, non pare trovare una 'parallela' attenzione da parte del Giudice italiano delle leggi "in tema di trattamento preferenziale", pur disponendo - quest'ultimo - di un patrimonio costituzionale ben più ricco rispetto a quello dell'Unione.

La stessa nozione di 'dignità umana', da parametro prevalentemente eticofilosofico nelle Carte internazionali, si offre ora nel diritto derivato dell'Unione come importante se non risolutivo parametro, idoneo ad ampliare il margine di interpretazione nei giudizi in tema di discriminazione ${ }^{104}$. Le previsioni dell'art. 3.2 della Direttiva 2000/43, per come interpretate dalla dottrina appena richiamata, infatti, consentono di affermare come siamo ormai in presenza di una piena emancipazione "del giudizio di discriminazione dalla componente comparativa relazionale ... La vittima di una molestia è, infatti, secondo il legislatore comunitario, discriminato per il solo fatto (non è poco) di aver subito un pregiudizio alla sua dignità a prescindere dall'accertamento che altri abbiano potuto o meno subire la stessa lesione ... È proprio il riferimento alla dignità dell'uomo, meta-principio che non accetta comparazioni e tanto meno uguagliamenti al ribasso essendo un valore assoluto per

\footnotetext{
${ }^{103}$ Cfr. O. Pollicino, "Di cosa parliamo ... cit., p. 8.

${ }^{104}$ Cfr. D. Schefold, "La diginità umana", in http://www.luiss.it; V. Feldman, "Human Dignity as legal value", in Public law, 1999; A. Ruggeri - A. Spadaro, "Dignità dell'uomo e giurisprudenza costituzionale (prime notazioni)", in V. Angiolini (a cura di), Libertà e giurisprudenza costituzionale, Torino, 1992; Ruggeri A., "Sovranità dello Stato e sovranità sopranazionale, attraverso i diritti umani, e prospettive di un diritto europeo 'intercostituzionale', in Diritto pubblico comparato ed europeo, II/2001.
} 
natura, che libera il giudizio antidiscriminatorio dalla trappola relativistica in cui, per natura, tende a impantanarsi” ${ }^{105}$.

Tali preoccupazioni, invero, appaiono condivise dalla stessa dottrina che ha partecipato ai lavori della Convenzione incaricata di redigere il progetto della Carta fondamentale dei diritti, benché da parte della stessa si faccia osservare che la ratio che ha guidato i lavori della Convenzione non potesse che ispirarsi ad un necessario 'compromesso costituzionale" ${ }^{, 106}$. Tuttavia, non può non osservarsi come, in tale ottica, le previsioni dell'art. 20 della Carta dei diritti (uguaglianza davanti alla legge), se paragonate con la ricchezza normativa del I e del II comma dell'art. 3 della Costituzione italiana, appaiano operare un arretramento significativo del dibattito e delle tutele assicurate dal costituzionalismo moderno e contemporaneo ${ }^{107}$.

Di tal ché, le problematiche dell'armonizzazione fra ordinamenti (Costituzioni nazionali e Unione europea) sono, ancora una volta, rinviate ad un futuro indefinito, prevedendosi da parte della Carta dei diritti, all'art. 53, una (evidentemente) necessaria clausola di salvaguardia dei diritti per come sono costituzionalmente e internazionalmente protetti.

Pertanto, come è stato bene sottolineato, la disciplina dei diritti sociali a livello di Unione, se non contrasta, di certo non corrisponde, nel fondo, alla sua concezione negli ordinamenti costituzionali nazionali a base sociale (fra cui soprattutto I'Italia, la Spagna e la Germania), nei quali "i diritti sociali sono immaginati come una condizione a priori dell'azione dei pubblici poteri e gli interessi sociali ad essi connessi come semplici reflexinteresse" ${ }^{108}$. Ciò che rileva di tali diritti nell'azione e

\footnotetext{
${ }_{105}$ Cfr. O. Pollicino, "Di cosa parliamo ... cit., p. 5.

106 Cfr. S. Rodotà, "La Carta come atto politico e documento giuridico", in AA.VV., Riscrivere $i$ diritti...cit:; F. Petrangeli, Una Carta per l'Europa. Diritti fondamentali e mercato nel processo d'integrazione, Roma, 2001; E. Paciotti (a cura di), La Costituzione europea ... cit.

${ }_{107}$ Sul punto cfr. anche G. Azzariti, "Uguaglianza e solidarietà nella Carta dei diritti di Nizza", in M. Siclari (a cura di), Contributi allo studio della Carta dei diritti fondamentali dell'Unione europea, Torino, 2003; G. Azzariti, "La Carta dei diritti fondamentali dell'U.E. nel 'processo costituente europeo'", in Rassegna di diritto pubblico comunitario, 2002, 1.

${ }_{108}$ Cfr. Luciani M., "Diritti sociali e ... cit. Nello stesso senso cfr. anche G. Azzariti, "Uguaglianza e solidarietà nella Carta ... cit., secondo il quale non risulta dubbio che il "diritto sociale si configura come obiettivo delle politiche dell'Unione. Un obiettivo peraltro indicato con una certa indeterminatezza di contenuto", come deve dirsi, ad. es. per la protezione della salute (art. 35), per la tutela dell'ambiente (art. 37) e per la protezione dei consumatori (art. 38). Per un inquadramento dei "diritti propriamente sociali" e di quelli che, al contrario, costituiscono nuovi diritti con riflessi
} 
per la realizzazione delle finalità dell'ordinamento europeo è, dunque, la loro strumentalità (si direbbe, perfino, la loro 'funzionalizzazione') alle esigenze dello sviluppo economico e alle esigenze di competitività proprie del mercato comune europeo.

Nell'ambito più generale della politica sociale dell'Unione, disciplinata nel Titolo IX del nuovo TFUE (art. 136-145), e nella reiterata sottolineatura che il loro riconoscimento costituzionale non modifica l'assetto delle competenze dell'Unione, così, i diritti sociali, come si è già osservato in precedenza, si trasformano in meri parametri di legittimità normativa di quest'ultima, assumendo per questo non più una validità in sé, bensì la natura di 'diritti complementari' alle libertà economiche, riservandosene il relativo riconoscimento e la tutela al solo ambito interno degli Stati membri.

Nella costruzione dell'ordinamento dell'Unione, pertanto, i diritti sociali conservano, nel fondo, la natura di diritti 'residuali' e 'strumentali' agli obiettivi economici del mercato unico europeo ${ }^{109}$, natura - quest'ultima - che, a giudizio di parte della dottrina, sarebbe stata messa in questione qualora avesse concluso positivamente il suo lungo iter (contrastato da Parlamenti nazionali e soprattutto da forze e movimenti sociali e culturali) la Proposta di direttiva del Parlamento europeo e del Consiglio relativa ai servizi nel mercato interno ${ }^{110}$, finalizzata, nella intenzione del proponente e della Commissione, a “... stabilire un quadro giuridico che elimini gli ostacoli alla libertà di stabilimento dei prestatori di servizi ed alla libera circolazione dei servizi tra Stati membri e che garantisca a prestatori e destinatari dei servizi la certezza giuridica necessaria all'effettivo esercizio di queste due libertà fondamentali del trattato"111.

nell'ambito sociale cfr. J.L. Gil y Gil, "Los derechos sociale en la Carta de los Derechos fundamentales de la Union Europea", in Cuadernos Electronicos de Filosofia del Derecho, 2002, n. 5.

${ }_{109}$ Cfr. nello stesso senso, anche, G. Maestro Buelga, "Los derechos sociales en la Union Europea: una perspectiva constitucional", in Revista vasca de administración pública, 1996, n. 46, p. 119 ss.

${ }_{110}$ II testo della Direttiva Bolkestein (IP/04/37) è in http://www.europa.eu.int/comm/internal_market/fr/services/services/index.htm.

${ }_{111}$ Qualora adottata nella formulazione originaria, tale Direttiva avrebbe prodotto inevitabili impatti negativi (soprattutto) sui servizi sanitari, sociali, di istruzione, in un'ottica di 'Stato minimo' che sarebbe risultato in conflitto in modo inevitabile con la filosofia istituzionale che regge la stessa, pur timida, ripresa di attenzione da parte delle Istituzioni comunitarie al 'modello dello Stato sociale'. La 
La normativa dell'Unione in materia sociale, in tal senso, si limiterebbe tuttora a disciplinare mere disposizioni programmatiche, prevedendo poco più che semplici 'obiettivi', sia pure rafforzati nel loro contenuto materiale rispetto alle precedenti formulazioni dei trattati. In altri termini, mancherebbero veri e propri contenuti prescrittivi per le istituzioni europee meramente attuativi delle stesse se non nell'ottica della più volte richiamata 'funzionalità sociale' del mercato comune, nel senso della già sottolineata idoneità ad assicurare la "competitività della economia della Comunità".

La C.G.U.E., come si è ricordato, ha fatto proprio tale indirizzo, quando, dopo un primo orientamento nel quale assume l'esistenza di limiti ai diritti fondamentali nella sola materia dei diritti economici ${ }^{112}$, ha sancito che "i diritti fondamentali riconosciuti dalla Corte non risultano ... essere prerogative assolute e devono essere considerati in relazione alla funzione da essi svolta nella società ${ }^{113}$. È pertanto possibile operare restrizioni all'esercizio dei riferiti diritti, in particolare nell'ambito di un'organizzazione comune di mercato, purché dette restrizioni rispondano effettivamente a finalità d'interesse generale perseguite dalla Comunità e non si risolvano, considerato lo scopo perseguito, in un intervento sproporzionato e inammissibile che pregiudicherebbe la stessa sostanza di tali diritti" ${ }^{114}$.

La natura giuridica imprecisa e incerta di tali disposizioni, dunque, pare unicamente superabile con la loro (innovata) positivizzazione in un più compiuto

previsione, poi, del "principio del Paese di origine" (art. 16), alle cui sole leggi in materia di impresa sarebbe stato assoggettato il fornitore di servizi (e non più dunque a quelle del Paese dove avrebbe effettivamente fornito il servizio), avrebbe introdotto - soprattutto nell'ottica dell'Europa allargata ora a 27 Paesi - pericolosi e difficilmente risolvibili contrasti e dumping sociali, con il conseguente abbandono delle politiche di armonizzazione della legislazione da parte dei Paesi membri.

112 Sent. 14 maggio 1974, Nold, causa 4/73, in Racc. Uff., 1974, p. 491; sent. 13 dicembre 1979, Hauer, causa 44/79, in Racc. Uff., 1979, p. 3727, su cui cfr. fra gli altri F. Mancini, "La tutela dei diritti dell'uomo: il ruolo della Corte di Giustizia delle Comunità europee", in Riv. trim. dir. proc. civ., 1989, n. 1.

${ }_{113}^{113}$ Corsivi nostri.

114 Wachauf, sent. 13 luglio 1989, causa 5/88, in Racc. Uff. 1988, p. 2609, nella quale, da parte della CGCE, si riconosce che "i diritti fondamentali costituiscono parte integrante dei princìpi generali del diritto di cui la Corte garantisce l'osservanza. In tale compito essa è tenuta ad uniformarsi alle tradizioni costituzionali comuni agli Stati membri, di guisa che non possono essere ammessi nella Comunità provvedimenti incompatibili con i diritti fondamentali riconosciuti dalle costituzioni di detti stati". Sul punto cfr. anche, fra gli altri, U. De Siervo, "L'ambigua redazione della Carta dei diritti fondamentali nel processo di costituzionalizzazione dell'Unione Europea", in Diritto pubblico, 2001. 
'catalogo' di diritti sociali, all'interno di una rivisitata Carta dei diritti, su cui le istituzioni europee e la dottrina vanno discutendo negli ultimi anni (conoscendo, tuttavia, forti resistenze di alcuni Paesi membri, fra cui soprattutto la Gran Bretagna e Polonia). Un catalogo la cui formulazione, tuttavia, risulta inevitabilmente destinata a essere rinviata nel tempo, dopo i negativi pronunciamenti referendari dei francesi e degli olandesi e dopo l'opting out riconosciuto ai britannici e ai polacchi. Evidentemente, l'adeguatezza di una simile Carta dei diritti sociali è funzione delle scelte politiche e costituzionali sul futuro dello Stato sociale in Europa; ciò soprattutto se si considerano le esigenze integratrici alla base del recente allargamento del parterre europeo a nuovi Stati membri ${ }^{115}$.

In definitiva, se nell'immediato futuro appare più che ragionevole ipotizzare uno sviluppo ulteriore dei diritti sociali a livello giurisprudenziale, il futuro dei diritti sociali nel processo di costruzione europea non dovrebbe essere ulteriormente affidato alla sola giurisprudenza pretoria della Corte di Lussemburgo e ai relativi, sempre possibili, conflitti con le giurisdizioni costituzionali nazionali, dovendosi prevedere una loro positivizzazione normativa capace di farsi carico - in modo più convinto (certo e garantito) rispetto al regime giuridico vigente e a quello de jure condendo - delle più avanzate 'tradizioni costituzionali comuni' in materia ${ }^{116}$. Tuttavia, ciò non toglie che la recente riforma dei trattati, come diremo meglio in seguito, consentirà un nuovo protagonismo della Corte di Giustizia, la quale disporrà ormai del parametro della Carta dei diritti per arricchire la sua giurisprudenza in materia di diritti fondamentali e fra essi degli stessi diritti fondamentali sociali ${ }^{117}$.

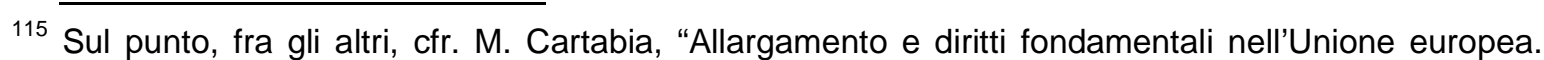
Dimensione politica e dimensione individuale", in S. Guerrieri - A. Manzella - F. Sdogati, Dall'Europa a Quindici alla Grande Europa. La sfida istituzionale, Bologna, 2001; J.D. Giuliani, L'élargissement de l'Europe, Paris, 2004.

${ }^{116}$ Come è stato ben osservato, infatti, (A. Baldassarre, "La Carta europea dei diritti ... cit., p. 3) "è difficile cogliere una tradizione comune ed il significato più probabile da ricondurre ad essa ... non è quello che fa riferimento alla formazione di un patrimonio comune europeo su questi diritti ma al patrimonio dei diritti dello Stato che meglio si adatta alla soluzione del caso all'esame della Corte". Nello stesso anche F. Sorrentino, "La Costituzione italiana di fronte al processo di integrazione europa", in Politica del diritto, 1993, p. 11 e A. Cannizzaro, "Princìpi fondamentali della Costituzione e Unione Europea", in Riv. it. dir. pub. com., 1994, p. 1176.

${ }_{117}$ Come già sottolineato nel nostro "La protección de los derechos fundamentales: el parámetro de los principios y de los derechos fundamentales en la jurisprudencia constitucional, comunitaria y del tribunal europeo de los derechos del hombre", in Revista de derecho const. europeo, 2007, n. 8.
} 
Tuttavia, solo a partire da una disciplina dell'Unione capace di conformarsi al più avanzato 'patrimonio costituzionale europeo' in materia di diritti e di effettività della tutela giurisdizionale, potranno ritenersi risolte le problematiche poste dall'esercizio dello stesso diritto alla tutela giudiziaria effettiva in tale ambito (principio, peraltro, affermato come fondamentale dalla C.G.U.E.) sia con riferimento ai diritti c.d. negativi, sia e soprattutto ai diritti a prestazioni da parte dei pubblici poteri europei ${ }^{118}$.

A partire da tale disciplina positiva, potrà conoscersi una limitazione della giurisprudenza della Corte di Giustizia, nel senso che la stessa si vedrebbe legittimata nella sua interpretazione, fin qui orientata alla realizzazione delle finalità del mercato unico in ossequio ai valori di base accolti nei trattati originari, ad aprirsi ad una lettura delle disposizioni dei trattati capace di assicurare la garanzia dei diritti per sé considerati.

Per come è stato bene osservato, una soluzione interlocutoria capace, se non certo di superare i presenti limiti redazionali e assiologici dei trattati, almeno di proporsi come valido criterio interpretativo da parte del Giudice di Lussemburgo, viene individuata nella previsione, de jure condendo, tra le competenze dell'U.E., della "fissazione dei livelli essenziali dei diritti sociali, in maniera analoga a quanto avviene in Italia da parte della legislazione statale nei confronti di quelle regionali, affinché l'organizzazione federale non comporti fughe antisociali e rotture dell'unità economico-sociale del Paese. II problema in chiave europea si presenta in maniera analoga; quindi, si può forse tentare di trasferire tali formule a livello comunitario, naturalmente con qualche diversa valenza e sfumatura, in modo da non causare l'assorbimento, da parte della Comunità, di tutti i grandi servizi nazionali ma indicare solamente obiettivi comuni (quantificati, ove possibile), pur nel mantenimento della statualità dei singoli servizi. L'effetto di una disposizione di tal genere potrebbe

\footnotetext{
${ }^{118}$ Cfr. J. Lozano Miralles, "Lo Stato di diritto come Stato garantista: il valore della giustizia (art. 1.1 $\mathrm{CE}$ ) e il principio-diritto alla tutela giudiziaria effettiva (art. $24 \mathrm{CE}$ )", in M. Scudiero (a cura di), I/ diritto costituzionale comune europeo. Principi e diritti fondamentali, Napoli, 2003, t. I., nonché S. Gambino G. Moschella, "L'ordinamento giudiziario fra diritto comparato, diritto comunitario e CEDU", in Pol. del dir., 2005, n. 4: S. Gambino, "Modelli europei di ordinamento giudiziario e tradizioni costituzionali in materia giudiziaria comuni agli Stati membri dell'Unione europea", in http://www.federalismi.it (n. 3/2005).
} 
essere duplice: da un lato questi livelli essenziali sarebbero incorporati alle politiche monetarie e finanziarie dell'Europa, così che tutte le istituzioni europee, Banca Centrale inclusa, ne debbano tenere conto, mentre dall'altro restituirebbero agli Stati la possibilità e il dovere di realizzare quei livelli”"19.

Tuttavia, tale orientamento che, nel fondo fa proprie le conclusioni cui era pervenuto il Rapporto del Comitato Simitis, nel suo farsi promotore di un forte invito alla Convenzione ${ }^{120}$ incaricata di redigere la Carta a operare "una ricomposizione dei valori fondamentali del modello sociale europeo nel nome della unità e delle complementarietà dei diritti di prima, seconda e terza generazione” ${ }^{\text {"121 }}$, non intende affatto sottovalutare il significato delle scelte operate dalla Carta in materia di diritti sociali, significativamente disciplinati, in parte, al titolo III (Uguaglianza) per quanto concerne i diritti sociali incondizionati (divieto di discriminazione), e in parte al titolo IV (Solidarietà) per quanto concerne sia i diritti sociali c.d. incondizionati che quelli c.d. condizionati. Una parte di tali disposizioni riguarda il diritto del lavoro (ma non il diritto al lavoro), concretizzandosi in previsioni volte a garantire il diritto dei lavoratori all'informazione e alla consultazione nell'ambito dell'impresa, il diritto alla negoziazione e alle azioni collettive, il diritto di accesso ai servizi di collocamento, la tutela in caso di licenziamento ingiustificato, le condizioni di lavoro giuste ed eque, il divieto di lavoro minorili e la protezione dei giovani sul lavoro. Altre disposizioni riguardano, sia pure con diversa modalità di protezione, la vita familiare e professionale, la sicurezza e l'assistenza sociale, la protezione della salute, l'accesso ai servizi di interesse economico generale, la tutela dell'ambiente e la protezione dei consumatori. Con tali disposizioni di protezione, come è stato bene osservato, si determina il "transito simbolico dall'integrazione attraverso il mercato a quella attraverso i diritti” ${ }^{122}$.

\footnotetext{
${ }_{119}$ Cfr. U. Allegretti, "I diritti sociali", in http://www.luiss.it (21 maggio 2004), p. 7.

120 Su cui, fra gli altri, cfr. anche V. Atripaldi, "Verso un Trattato che stabilisce una Costituzione per l'Europa", in V. Atripaldi - R. Miccù, L'omogeneità costituzionale nell'Unione europea, Padova, 2003; nonché M. Atripaldi, "II 'metodo' della Convenzione e i 'valori' della Carta dei diritti: una cronaca dei lavori preparatori', in V. Atripaldi - R. Miccù, L'omogeneità costituzionale ... cit.

${ }^{121}$ Cfr. S. Giubboni, "I diritti sociali ... cit.

${ }^{122}$ Cfr. S. Giubboni, "I diritti sociali ... cit.; AA.VV. (A. Manzella - P. Melograni - E. Paciotti - S. Rodotà), Riscrivere i diritti in Europa, Bologna, 2001; L. Azzena, L'integrazione attraverso i diritti. Dal
} 
Quanto al catalogo della Carta dei diritti fondamentali dell'Unione europea ${ }^{123}$, più in particolare, il primo diritto sociale che si incontra nel campo delle libertà è il diritto all'istruzione (art. 24) che, per quanto genericamente formulato, non può prescindere da un contenuto di tipo sociale ${ }^{124}$ come reso evidente dal secondo comma, che dispone la gratuità dell'istruzione obbligatoria ${ }^{125}$. Gli altri diritti sociali si incontrano sotto il titolo 'uguaglianza'. II quadro normativo è sufficientemente articolato: principio generale (art. 20), divieto di qualsiasi forma di discriminazione (art. 21), salvaguardia delle differenze culturali, religiose e linguistiche (art. 22), parità di trattamento tra uomini e donne, in tutti i settori, e legittimazione delle misure indirizzate a favore del sesso sotto-rappresentato (art. 23, c. 2). Si configurano in questo stesso Capo altri interventi di promozione dell'uguaglianza sostanziale a favore di soggetti deboli, quali i bambini, gli anziani e i disabili. Nel Capo della 'solidarietà' si ritrovano: l'accesso al collocamento gratuito, la protezione del lavoro giovanile, la protezione economica e sociale della famiglia. Più limitata è l'assunzione dei diritti di sicurezza sociale (previdenziale); sono declinati gli eventi della maternità, malattia, infortunio sul lavoro, dipendenza o vecchiaia, nonché perdita dell'occupazione (art. 34, c. 1), al fine di "riconoscere e rispettare il diritto di accesso" con una formula che si allontana dal problema di conformare tali prestazioni, limitandosi a prendere in esame il problema di garantire un accesso indiscriminato alle prestazioni esistenti. Si tratta di un diritto sociale condizionato, nel senso che le modalità di esercizio sono riservate alla disciplina del diritto dell'Unione, alle legislazioni e alle prassi nazionali ${ }^{126}$. Non si può negare, pertanto, che la Carta introduca elementi di novità che impediscono di considerarla come 'doppione' della CEDU; tale elemento innovatore si coglie, come già detto, dalla struttura stessa del

cittadino italiano ai mercati comunitari, Torino, 1988; S. Gambino, "Le sfide dell'Unione Europea: l'integrazione attraverso i diritti', in D. Infante (a cura di), Crescita e prospettive dell'Unione europea allargata, Bologna, 2006.

${ }_{123}$ Cfr. M. Ramón Alarcón Caracuel, "La necessità di un capitolo sociale ... cit., p. 607 ss.

${ }^{124}$ Cfr. M.V. Ballestrero, "Brevi osservazioni su Costituzione europea e diritto del lavoro italiano", in Lavoro e diritto; S. Giubboni, "Il primo dei diritti sociali. Riflessioni su diritto al lavoro fra Costituzione italiana e ordinamento europeo", IWP (Università di Catania), 2006, n. 46.

${ }^{125}$ Cfr. R. Del Punta, "I diritti sociali come diritti fondamentali: riflessioni sulla Carta di Nizza", relazione al convegno su: "Principi, diritti e regole nella Carta Europea" (Firenze 26-27 aprile 2001), pp. 339-343; G. Bronzini, "I diritti sociali nella Costituzione europea", in Politiche e diritti, 2001.

${ }^{126}$ Cfr. B. Pezzini, op. cit., p. 187. 
documento che non separa i diritti delle diverse generazioni, ma mescola nei Capi, di cui si compone, i 'vecchi' diritti (libertà negativa) accanto a quelli 'nuovi' ed ai 'nuovissimi' (ad es. il diritto alla vita, il diritto alla salvaguardia del proprio patrimonio genetico rispetto alla clonazione riproduttiva) ${ }^{127}$.

In tale nuovo ambito normativo, i diritti sociali, sia pure con modalità e contenuti assolutamente non comparabili alle più avanzate discipline costituzionali europee, risultano disciplinati in modo non differenziato rispetto agli altri diritti fondamentali e alle libertà economiche dell'Unione, condividendone ormai la natura di diritto fondamentale dell'Unione e concorrendo a ripensare funditus il concetto di cittadinanza europea "a partire dalla sua capacità di effettiva inclusione sociale"128. Rimane confermato, in ogni caso, che tale ricostruzione rischia di restare astratta in assenza di una compiuta vigenza dei nuovi trattati, pur non negandosi il valore di moral suasion che simili disposizioni della Carta avrebbero comunque per il Giudice e le istituzioni dell'Unione nel loro complesso.

\section{Dalla 'costituzione giurisprudenziale' alla Carta dei diritti fondamentali dell'Unione europea}

\subsection{Verso uno statuto europeo dei diritti.}

Alla lacuna in tema di diritti fondamentali riscontrabile nei trattati, come è ben noto, in un primo tempo, ha cercato di far fronte la Corte di Giustizia. L'evoluzione di tale giurisprudenza in tema di diritti fondamentali - benché nota - appare utile da richiamare, unitamente ai contenuti più significativi che la connotano, per argomentare in materia di forme del riconoscimento di tali diritti e di effettività delle relative tutele. Tale ricostruzione sarà qui operata per richiami essenziali, rinviandone l'approfondimento alle trattazioni specifiche ${ }^{129}$. Dopo una prima fase di sostanziale

\footnotetext{
${ }^{127}$ Cfr. C. Salazar, "Diritti sociali nella Carta dei diritti fondamentali dell'Unione europea: un 'viaggio al termine della notte'?", in G.F. Ferrari (a cura di), I diritti fondamentali dopo la Carta di Nizza. II costituzionalismo dei diritti, Milano, 2001, p. 245.

${ }_{128}$ Cfr. S. Giubboni, "I diritti sociali ... cit.

${ }^{129}$ Nell'ampia bibliografia sul punto, oltre a M. Cartabia, Principi inviolabili e integrazione europea, Milano, 1995, cfr. anche, almeno, G. Tesauro, "Il ruolo della Corte di Giustizia nell'elaborazione dei princìpi generali dell'ordinamento europeo e dei diritti fondamentali", in AA.VV. (A.I.C.), La
} 
indifferenza al tema, è solo negli anni '60 - con le sentenze Stauder ${ }^{130}$ e, soprattutto, a mente dei considerata della sentenza Internationale Handelsgesellschaft ${ }^{131}$ - che la Corte di Giustizia riconosce che la "tutela dei diritti fondamentali costituisce parte integrante dei princìpi giuridici generali di cui la Corte di Giustizia garantisce l'osservanza" e che "la salvaguardia di questi diritti, pur essendo informata alle tradizioni costituzionali comuni agli Stati membri, deve essere garantita entro l'ambito della struttura e delle finalità della comunità". Nella sentenza Internationale Handelsgesellschaft, la Corte di Giustizia ricorre, quindi, alla centrale (ancorché incerta) nozione di "tradizioni costituzionali comuni agli Stati membri" per determinare il contenuto materiale dei princìpi generali del diritto comunitario, riconoscendo, per la prima volta, che di questi fa parte integrante la tutela dei diritti fondamentali. Con la successiva sentenza Nold $^{132}$, il medesimo organo di giustizia completerà il ricorso alle tradizioni costituzionali comuni incorporando gli strumenti internazionali di protezione dei diritti dell'uomo e delle libertà fondamentali (cui gli Stati membri hanno cooperato o aderito).

A seguito di questa, per molti versi essenziale (e poco motivata), giurisprudenza della Corte di Giustizia, si riconosce come pienamente conseguita l'incorporazione dei diritti fondamentali nell'ordinamento dell'Unione, almeno nel senso che tale giurisprudenza possa essere estesa, oltre che alle istituzioni e agli atti di tale ordinamento sovra-nazionale ${ }^{133}$, alla stessa normativa degli Stati membri attuativa del diritto dell'Unione. Un assunto, questo, dal quale rimarrebbe preclusa la

Costituzione europea, Padova, 2000; G. Recchia, "Corte di Giustizia delle Comunità europee e tutela dei diritti fondamentali nella giurisprudenza costituzionale italiana e tedesca. Verso un 'catalogo' europeo dei diritti fondamentali?", in AA.VV., La Corte costituzionale tra diritto interno e diritto comunitario, Milano, 1991; G. Gaja, "Aspetti problematici della tutela dei diritti fondamentali nell'ordinamento comunitario", in Rivista di diritto internazionale, 1988; E. Pagano, "I diritti fondamentali nella Comunità europea dopo Maastricht", in Il diritto dell'Unione Europea, 1996, n. 1; M. Scudiero, "Comunità europea e diritti fondamentali: un rapporto ancora da definire", in Rivista di diritto europeo, 1996; S. Gambino, "II diritto costituzionale europeo: principi strutturali e diritti fondamentali", in S. Gambino (a cura di), Costituzione italiana e diritto comunitario ... cit.

${ }_{130}$ Cfr. Sent. Stauder del 12 novembre 1969, causa 29/69, in Racc. Uff. 1969, p. 420.

131 Cfr. sent. Internationale Handelsgesellschaft del 17 dicembre 1970, causa 11/70, in Racc. Uff. 1979, p. 1125; sent. Hauer, causa 44/1979, in Racc. Uff. 1979, p. 3727.

${ }_{132}$ Causa 4/73, 14 maggio 1974.

${ }^{133}$ Come si sancisce nella sentenza Wachauf (causa 5/88, 13 luglio 1989). 
sola normativa nazionale priva di ogni legame con quest'ultimo ordinamento ${ }^{134}$, con la logica conseguenza che, in tal modo, i diritti fondamentali, di cui la Corte di Giustizia assicura la tutela, sono "sì libertà fondamentali ma ... in quanto strumentali agli obiettivi economici dei trattati, cioè come garanzie proprie del sistema comunitario"135.

È stato già da più parti sottolineato, in dottrina, come il metodo seguito dalla Corte di Giustizia nella sua individuazione pretoria dei diritti fondamentali dell'Unione sollevi qualche perplessità. In assenza di stringenti previsioni dei trattati, quanto al loro ruolo di garanti del "rispetto del diritto nell'interpretazione e nell'applicazione del ... Trattato" (art. 220 e 230 TCE), infatti, il Giudice di Lussemburgo ha operato un'interpretazione estensiva delle disposizioni contenute negli stessi in tema di responsabilità extra-contrattuali, utilizzando, come è stato sottolineato, "il riferimento ai princìpi generali anche nelle materie per le quali esso non è previsto, quanto meno esplicitamente, nei trattati istitutivi quale modo per elaborare regole concrete muovendo dalla considerazione degli ordinamenti degli stati membri”'136. È seguendo questa linea giurisprudenziale, tuttavia, che la Corte di Giustizia ha elaborato, nel trentennio successivo ai primi anni sessanta, un vero e proprio catalogo di diritti fondamentali, benché limitato nella sua estensione alla sola categoria dei diritti civili, e nel quale appaiono situazioni giuridiche soggettive relative alla stessa effettività della tutela giudiziaria, principalmente riferite alla materia economica e sociale.

In assenza di una compiuta costituzionalizzazione dei diritti fondamentali dell'Unione (che avverrà solo in presenza di procedure costituenti espresse ${ }^{137}$ ),

\footnotetext{
${ }_{134}$ Come viene sancito nella sentenza Kremzow (causa C-299/95, 29 maggio 1997).

${ }^{135}$ Causa C-299/95, 29 maggio 1997.

${ }^{136}$ Così G. Gaja, "Princìi del diritto ... cit., p. 543.

137 Sulla questione cfr. anche i nostri "La (recente) evoluzione dell'ordinamento comunitario come processo materialiter costituente: un'analisi alla luce delle categorie classiche del diritto pubblico europeo e della esperienza concreta", in La cittadinanza europea, 2006, n. 1; "La (reciente) evolución del ordenamiento comunitario como proceso materialiter constituyente: un análisis tras las categorías clásicas del derecho público europeo y de la experiencia concreta", in AA.VV., Reforma de la Constitución y control de constitucionalidad, Bogotà, 2006; "Integrazione comunitaria e legittimazione costituzionale", in Scritti in memoria di G. Floridia (in corso di stampa); "Diritti fondamentali, costituzioni nazionali e trattati comunitari", in S. Gambino (a cura di), Trattato che adotta una Costituzione per l'Europa, costituzioni nazionali, diritti fondamentali, Milano, 2006.
} 
tuttavia, la disciplina di tali diritti ${ }^{138}$ ha già costituito un'importante apertura al tema del bilanciamento fra valori economicistici e valori sociali dell'originario ordinamento comunitario. Questi ultimi, così, registrano una novità particolarmente significativa, almeno sotto il profilo simbolico e sotto quello della visibilità, presentandosi come contenuto fondamentale del 'patrimonio costituzionale comune' europeo ${ }^{139}$. La stessa dottrina, che è stata impegnata validamente nel sostenere le ragioni della necessarietà della 'Carta dei diritti', non ha omesso di ricordare come lo stesso art. 136 TCE - ove si prevede che la Comunità e gli Stati membri s'impegnano a 'tenere presenti' i diritti sociali nel perseguimento degli obiettivi di politica sociale definiti nella medesima disposizione - esclude "tassativamente dalle competenze comunitarie le materie delle retribuzioni, del diritto di associazione, del diritto di sciopero, ecc." ${ }^{\text {140. }}$.

\footnotetext{
${ }_{138}$ Sulla rilevanza delle positivizzazone dei diritti, cioè sulla "scrittura" degli stessi, cfr. C. Pinelli, "La Carta dei diritti, la cittadinanza, la vita democratica dell'Unione", in F. Bassanini e G. Tiberi, La Costituzione europea. Un primo commento, Bologna, 2004; dello stesso autore, II momento della scrittura, Bologna, 2002. Sulle "domande inappagate sulla Costituzione europea e il tempo lungo del dibattito sulle tradizioni comuni", dell'Autore appena citato cfr. anche "Il dibattito sulla Costituzione europea e le virtù trasformative delle tradizioni costituzionali comuni", Relazione al Seminario A.I.C. (Fiesole, 14/5/2004), ora anche in www.associazionedeicostituzionalisti.it; cui, oltre all'ormai classico A. Pizzorusso (Il patrimonio costituzionale europeo, Bologna, 2002), adde, almeno P. Ridola, "I diritti di cittadinanza, il pluralismo ed il 'tempo' dell'ordine costituzionale europeo. Le 'tradizioni costituzionali comuni' e l'identità culturale europea in una prospettiva storica" (paper), nonché L. Lacchè, "Europa una et diversa. A proposito di jus commune europaeum e tradizioni costituzionali comuni", in Teoria del diritto e dello Stato, 2003, p. 40 ss. Per una lucida analisi sul futuro dei diritti fondamentali nella prospettiva della globalizzazione, di recente, cfr. anche G. Azzariti, "Il futuro dei diritti fondamentali nell'era della globalizzazione", in Pol. del dir., 2003, 3, secondo il quale le peculiari tecniche di positivizzazione dei diritti accolte nel TC, non sempre omologhe per tutti i diritti positivizzati, portano ad affermare che "pur se inserita nei trattati ... la copertura 'costituzionale' e le garanzie effettivamente e direttamente fornite dalla Carta dei diritti fondamentali - almeno con riferimento a molti dei classici diritti sociali - non appare soddisfacente, non si mostra neppure in grado di assicurare il livello di protezione attualmente esistente nel diritto dell'Unione, non può infine nemmeno aspirare a proporsi come vincolo nei confronti di eventuali violazioni o modifiche peggiorative della tutela dei diritti operate nelle legislazioni e prassi degli Stati membri" (p. 339).

139 Cfr. A. Pizzorusso, II patrimonio costituzionale europeo, Bologna, 2002; M. Patrono, I diritti dell'uomo nel Paese d'Europa. Conquiste e nuove minacce nel passaggio da un millennio all'altro, Padova, 2000.

${ }^{140}$ Cfr. A. Manzella., "Agnizione e innovazione: nascita di una Costituzione", in AA.VV. (a cura di E. Paciotti), La Costituzione europea. Luci e ombre, Roma, 2003; S. Rodotà, "La Carta come atto politico e documento giuridico", in AA.VV. (A. Manzella - P. Melograni - E. Paciotti - S. Rodotà), Riscrivere i diritti in Europa, Bologna, 2001; R. Bifulco - M. Cartabia - A. Celotto, Commento alla Carta dei diritti fondamentali dell'UE, Bologna, 2001.
} 
Il tema della collocazione della Carta nell'ambito della gerarchia delle fonti del diritto dell'Unione ha costituito un problema da approfondire ${ }^{141}$ nell'ultimo decennio di dibattito dottrinario. Benché la volontà della Commissione, del Parlamento Europeo e di alcuni Stati (tra cui l'Italia) fosse quella di un inserimento della Carta nel corpus dei trattati, e malgrado che l'organo costituito per la sua redazione avesse lavorato sul presupposto della sua efficacia vincolante, il Consiglio europeo, a Nizza, si era limitato a 'proclamare' solennemente la Carta dei diritti fondamentali, senza assumerne l'integrazione nei trattati. II Consiglio di Colonia (3/4 giugno 1999), nelle sue conclusioni, aveva precisato, in proposito, che, solo dopo la proclamazione comune della 'Carta' ad opera del Parlamento europeo, del Consiglio e della Commissione, si sarebbe potuto "esaminare se, ed eventualmente in quale modo, la 'Carta' ... potesse ... essere integrata nei trattati'.

Pur non avendo natura giuridica ed efficacia vincolante fino alla ratifica dei nuovi trattati, dunque, bisogna chiedersi quale ruolo sia stato riservato alla 'Carta' nella prassi applicativa ${ }^{142}$. Se, infatti, in quest'ultima, e soprattutto nella giurisprudenza della Corte di Lussemburgo, potessero individuarsi concrete modalità applicative, la Carta - a mo' di Bill of rights sia pure in senso sostanziale del costituzionalismo europeo - avrebbe già rappresentato un passo significativo verso una futura Costituzione dell'Unione, rendendo più chiara l'esigenza di ripensare se non a forme di statualità compiute, almeno a un nuovo e peculiare costituzionalismo inclusivo della relativa legittimazione costituzionale ${ }^{143}$. In diversa ipotesi, il rischio sarebbe stato quello che la Carta restasse una dichiarazione d'intenti o di diritti non

\footnotetext{
141 Fra gli altri, P. Caretti, "I riflessi del nuovo sistema delle fonti comunitarie sul diritto interno" (paper) e M. Cartabia, "I diritti fondamentali e la cittadinanza dell'Unione", in F. Bassanini e G. Tiberi, La Costituzione europea. Un primo commento, Bologna, 2004; M. Siclari, Contributi allo studio della Carta dei diritti fondamentali dell'Unione europea, Torino, 2003.

${ }_{142}$ Cfr. A. Celotto e G. Pistorio, "L'efficacia giuridica della Carta dei diritti fondamentali dell'Unione europea (rassegna giurisprudenziale 2001-2204)", in Giur. it.; M. Cartabia e A. Celotto, "La giustizia costituzionale in Italia dopo la Carta di Nizza", in Giur. cost., 2002; B. Randazzo, "Giudici comuni e corti europee dei diritti", in Riv. it. dir. pub. com., 2002; C. Di Turi, "La prassi giudiziaria relativa all'applicazione della Carta di Nizza", in Dir. Un. eur., 2002; M. Cartabia - A. Ninatti, "L'efficacia giuridica della Carta dei diritti: un problema del futuro o una realtà del presente?", in Quad. cost., 2001.

${ }_{143}$ Cfr. L.S. Rossi, "Constitutionnalisation' de l'Unione européenne et des droits fondamentaux", in R.T.D.E., 2002, 1, p. 27, nonché Carta dei diritti fondamentali e Costituzione dell'Unione europea, Milano, 2002
} 
cogenti, di cui è ricca la storia delle organizzazioni internazionali, che spiega in modo semplificato diritti, del resto già riconosciuti in tutti gli Stati dell'Unione europea ${ }^{144}$.

Tuttavia, è da rilevare che la Carta, quale 'ricognizione' di un comune patrimonio costituzionale europeo, ha già iniziato a costituire un importante punto di riferimento, soprattutto in sede giurisdizionale, ancorché ciò non possa affermarsi compiutamente per la giurisprudenza della Corte di Giustizia delle Comunità europee. Già, nelle sue conclusioni nella causa BECTU vs. Secretary of State for Trade and Industry ${ }^{145}$, l'Avvocato Generale della Corte di Giustizia Antonio Tizzano, fondandosi sull'art. 31.2 della Carta, ad esempio, dava piena conferma della natura di diritto sociale con riferimento al diritto alle ferie annuali retribuite ${ }^{146}$. In precedenza, uno specifico riferimento alla Carta dei diritti era stato fatto dal Tribunal Constitucional spagnolo ${ }^{147}$. La Corte costituzionale italiana, nell'iter argomentativo di

${ }^{144}$ Cfr. A. Pace (in "A che serve la Carta dei diritti fondamentali dell'Unione Europea? Appunti preliminari”, in Giur. cost., 2001, p. 194) evidenzia come già in passato importanti dichiarazioni politiche, ancorché esplicitamente prive di efficacia giuridica (es. la Dichiarazione Universale dei diritti dell'uomo del 1948), hanno costituito un "riferimento 'retorico' di grande importanza". Inoltre, l'Autore sottolinea come sia ben difficile "che un documento solennemente proclamato e che sia stato predisposto ricorrendo alla tecnica giuridica ... non assuma di fatto rilevanza giuridica (nonostante che nelle intenzioni dei suoi autori, tale documento dovesse rivestire solo un'importanza politica), costituendo quanto meno un immediato ausilio interpretativo per 'rafforzare' conclusioni raggiungibili comunque su altre basi". L'Autore, infine, non esclude che in futuro possano esserci applicazioni maggiormente rilevanti della Carta "man mano che ci si distacchi dal contesto storico-politico nell'ambito del quale quel documento è stato proclamato". Nella stessa direzione cfr. anche G.G. Floridia, "'Nell'intenzion dell'artista, e agli occhi degli abitanti' (osservazioni sulla 'Dichiarazione dei diritti' di Nizza)", in Dir. pub. comp. ed europeo, 2001, n. 1, p. 163 ss.

${ }^{145}$ Causa C-173/99.

${ }^{146}$ In tal senso, egli affermava "... ancor più significativo, peraltro, mi pare il fatto che detto diritto trovi oggi una solenne conferma nella Carta dei diritti fondamentali dell'Unione europea ... Certo, al pari di alcuni degli atti precedentemente citati, anche la Carta dei diritti fondamentali dell'U.E. non si è vista riconoscere autentica portata normativa, è rimasta cioè priva, dal punto di vista formale, di autonomo valore vincolante. Tuttavia, anche a non voler entrare qui nell'ampio dibattito già in corso circa gli effetti che, in altre forme e per altre vie, la 'Carta' potrebbe comunque produrre, resta il fatto che essa racchiude enunciazioni che appaiono in gran parte come ricognitive di diritti già altrove sanciti ... Credo quindi (che) in un giudizio che verte sulla natura e sulla portata di un diritto fondamentale non si possano ignorare le pertinenti enunciazioni della Carta, né soprattutto se ne possa ignorare l'evidente vocazione a fungere, quando le sue disposizioni lo consentono, da sostanziale parametro di riferimento per tutti gli attori - Stati membri, istituzioni, persone fisiche e giuridiche - della scena comunitaria. In questo senso, quindi, ritengo che la 'Carta' ci fornisca la più qualificata e definitiva conferma della natura di diritto fondamentale che riveste il diritto a ferie annuali retribuite".

${ }_{147}$ STC 292/2000, del 30 novembre 2000. In data addirittura antecedente alla proclamazione della 'Carta' stessa, aveva affermato testualmente, al punto 8 della motivazione: "Por último, otro tanto ocurre en el ámbito comunitario, con la Directiva 95/46, sobre protección de las personas fisicas en lo que respecta al tratamiento de datos personales y la libre circulación de estos datos, asi como con la 
una sua recente sentenza ${ }^{148}$ in tema di libertà di domicilio, ha fatto ricorso alla Carta con un ragionamento ad adiuvandum.

Sebbene tale orientamento non sia ancora seguito dalla Corte di Giustizia, che in merito si attiene ad un prudente self-restraint ${ }^{149}$, esso offre il vantaggio di consentire una individuazione chiara e definitiva dei diritti fondamentali, assicurandone l'indivisibilità (fra diritti civili, economici e sociali) e l'inscindibilità rispetto ai valori e alla pregressa esperienza europea, in maniera tale da permettere di stabilizzare il processo, a volte tumultuoso, che ha permesso al Giudice di Lussemburgo di travalicare i limiti dei trattati e, quindi, di spingersi oltre, attraverso un procedimento d'interpretazione indubbiamente evolutivo, di tipo 'progressivo'.

È pur vero però che, in astratto, una fissazione rigida dei diritti fondamentali potrebbe rischiare di comportare una riduzione di tutela, in quanto limitata a quanto espressamente stabilito nella Carta ${ }^{150}$. Altra dottrina ha osservato che la Carta si riduce a una elencazione di diritti, senza nessuna previsione di doveri o quantomeno di limiti all'esercizio degli stessi (ad es., nel caso del diritto di proprietà e di iniziativa economica, non è stato previsto il limite della 'funzione sociale', necessario a legittimare gli interventi legislativi di conformazione dei diritti medesimi a finalità sociali). A fronte di tale orientamento, tuttavia, non manca chi si richiami in modo autorevole alle origini per così dire giusnaturalistiche dei diritti nell'ambito del costituzionalismo europeo, così come in quello nord-americano. In tale contesto, i diritti costituiscono un acquis consolidato "che limita e relativizza qualsiasi sovranità

Carta de derechos fundamentales de la Unión Europea del presente ano, cuyo art. 8 reconoce este derecho, precisa su contenido y establece la necesidad de una autoridad que vele por su respet".

${ }^{148}$ sottolineando che "l'ipotizzata restrizione della tipologia delle interferenze della pubblica autorità nella libertà domiciliare non troverebbe riscontro né nella Convenzione per la salvaguardia dei diritti dell'uomo e delle libertà fondamentali (art. 8), né del Patto internazionale sui diritti civili e politici (art. 17), né, infine, nella Carta dei diritti fondamentali dell'Unione europea, proclamata a Nizza nel dicembre 2000 (artt. 7 e 52), qui richiamata - ancorché priva di efficacia giuridica - per il suo carattere espressivo di princìpi comuni agli ordinamenti europei" (punto 2.1 del considerato in diritto). In precedenza, un 'richiamo' alla Carta dei diritti era stato fatto, in una sua ordinanza, dalla Corte di appello di Roma, che, in un suo considerando, si richiamava alla Carta dei diritti, rispetto alla quale si sosteneva che, "anche se non ancora inserita nei trattati, è ormai considerata pienamente operante come punto di riferimento essenziale non solo per l'attività delle istituzioni comunitarie, ma anche per l'attività interpretativa dei giudici europei" (Corte cost., sent. n. 135/2002).

149 Superato, tuttavia, dal Tribunale di primo grado, almeno in due pronunce: causa T-54/99 del 30 gennaio 2002 e causa T-177-01 del 3 maggio 2002.

${ }^{150}$ Cfr. Pizzorusso A., "La codificazione internazionale dei diritti fondamentali e la loro influenza sugli ordinamenti nazionali" (paper). 
... essi sono per così dire l'antisovrano"151, ed ecco perché "scrivere una carta europea dei diritti significa (e ha significato) non tanto redigere un testo su cui dovesse esprimersi una volontà legislativa, ma trovare e raccogliere, nel secolare 'deposito' della tradizione costituzionale - fatta di carte, di testi, ma anche e soprattutto di giurisprudenza, sia essa dei giudici nazionali o comunitari o della Corte di Strasburgo - ciò che vi è di essenziale e di comune: un'opera, appunto, prevalentemente ricognitiva" ${ }^{\prime 152}$.

Le disposizioni della Carta, nella previsione accolta a Nizza, hanno un ambito di applicazione limitato agli atti delle istituzioni e degli organi dell'Unione e agli atti degli Stati membri che danno attuazione al diritto dell'Unione, così come previsto espressamente all'art. 51, par. 1, della stessa Carta, mentre il par. 2 della medesima disposizione afferma che la Carta non introduce nuove competenze per la Comunità e per l'Unione, né apporta modifiche ai compiti e alle competenze definiti dai trattati. Fino alle recenti riforme dei trattati adottate a Lisbona, così, si assume che la Carta non richiede modifiche delle Costituzioni degli Stati membri, né (naturalmente) si sostituisce a esse, limitandosi a proporre una sistemazione (per fini di visibilità) che offre uno spazio comune di diritti, un denominatore comune fra tradizioni giuridiche e sensibilità diverse, diventando, in tal modo, premessa di una (quasi ma non certo) compiuta 'cittadinanza europea'153.

In ogni caso, la Carta ha già conosciuto una sua valenza, a testimoniare quel sentimento comune europeo che è costituito di diritti e di importanti conquiste civili e a manifestare quello che è il carattere profondo di una Europa non solo economica ma sempre più aperta alla ricerca di tradizioni costituzionali comuni che possano

\footnotetext{
${ }^{151}$ Cfr. V. Onida, "Il difficile compito della Convenzione sull'avvenire dell'Europa", in Forum di Quad. cost., 2004.

${ }_{152}$ Ult. op. cit.

${ }^{153}$ Cfr. M. Cartabia, "I diritti fondamentali e la cittadinanza dell'Unione", in F. Bassanini - G. Tiberi, La Costituzione europea ... cit.; S. Gambino, "Cittadinanza e diritti sociali fra neoregionalismo e integrazione comunitaria", in Quaderni costituzionali, 2003, n. 1; S. Gambino, "Il diritto costituzionale europeo: principi strutturali e diritti fondamentali", in S. Gambino (a cura di), Costituzione italiana e diritto comunitario, Milano, 2002; S. Gambino, "Los derechos fundamentales comunitarios: entre Tribunal de Justicia de la Comindad Europea, tratados y Bill of rights", in Revista Vasca de Administración pública, 2003, Vol. 65 (II); C. Amirante, "Cittadinanza (teoria generale)", in Enciclopedia Giuridica (Aggiorn. XII), 2004; V. Lippolis, "La cittadinanza europea", in Quaderni costituzionali, 1993, n. 1, p. 136.
} 
costituire l'ethos condiviso dei diversi popoli europei riunificati giuridicamente attraverso le istituzioni dell'Unione europea.

La soluzione al problema della natura giuridica della Carta (e, di conseguenza, il problema della sua collocazione nell'ambito della gerarchia delle fonti), a seguito del perfezionamento della procedura di ratifica dei trattati, trova ora una sua definizione nel già richiamato assunto di cui all'art. 6 del nuovo TUE, nel quale si riconosce alla Carta non certo lo status proprio dei trattati, ma neppure quello di Costituzione vera e propria (cui con enfasi eccessiva rinviava la più recente bozza del trattato costituzionale non ratificata), quanto piuttosto una forza giuridica omologa a quella dei trattati.

Quanto all'ambito materiale delle protezioni accolte nella Carta, era stato osservato (e oggi viene ribadito, si direbbe, in modo ossessivo) che alcune disposizioni della stessa sembrerebbero disciplinare materie di più ampio respiro rispetto al nucleo delimitato delle competenze dell'Unione. Era stata, a tal fine, predisposta una 'clausola orizzontale', secondo la quale la Carta non ha la finalità di modificare le competenze dell'Unione, in quanto una siffatta innovazione avrebbe potuto essere introdotta solo attraverso l'attivazione dell'apposito iter procedimentale di revisione dei trattati. In conclusione, appare certo come lo sforzo di positivizzare le 'tradizioni costituzionali comuni' dei Paesi membri dell'Unione europea in materia di diritti fondamentali, in corso ormai da almeno un decennio, consegni alla Carta europea dei diritti fondamentali un evidente ruolo di 'ponte' fra passato e futuro dell'Europa. Non appare dubbio, così, che l'Europa si lascia alle spalle un complesso ordinamento giuridico pensato soprattutto per le merci e i capitali, e si profila all'orizzonte (più o meno vicino, più o meno chiaro) un'Europa dei cittadini e dei diritti. Un'Europa che potrà attrarre (e mobilitare) le sensibilità e le culture dei popoli europei, molto più di quanto non ha potuto e saputo fare l'Europa dei mercati (e dei mercanti).

In tale nuovo scenario, importanti scelte di fondo riguardano il contenuto, l'estensione e le garanzie giurisdizionali dei singoli diritti, intesi non come mere 
questioni tecnico-redazionali, ma nel loro significato assiologico-oggettivo ${ }^{154}$. Esse hanno un primario carattere politico, proponendosi, perfino, secondo autorevoli ma non convincenti approcci dottrinari, come momento fondativo di un ordinamento democratico-costituzionale (quasi) pienamente compiuto e, pertanto, autoreferenziale. Secondo parte della dottrina ${ }^{155}$, infatti - le cui argomentazioni, tuttavia, in assenza di un compiuto procedimento costituente (che segua l'impervia via delle assemblee costituenti ovvero quella, più domestica, del referendum confermativo o meglio ancora della recezione del trattato con legge costituzionale), non riteniamo di poter condividere (salvo a considerarle come espressione di un mero 'fatto' costituzionale 0 , meglio ancora, come espressione di un costituzionalismo consuetudinario, ormai pienamente riconosciuto dagli stessi Stati membri dell'Unione europea) -, la Carta dei diritti fondamentali, in tal senso, potrebbe trasformare la stessa fonte di legittimazione dell'ordinamento europeo, che passerebbe in tal modo dalla volontà degli Stati membri a quella dell'Unione.

Pur dovendo prendere atto della evidenza costituita dall'effettività osservabile, oltre che nel processo ${ }^{156}$, nella (pienamente conseguita e riconosciuta) normatività costituzionale europea, a noi pare doversi sottolineare, in senso diverso, che l'incorporazione formale della Carta dei diritti all'interno dei trattati deve affrontarsi con riferimento alle problematiche costituzionali poste dalla legittimazione costituzionale del (nuovo) ordinamento costituzionale dell'Unione, come appunto tale

\footnotetext{
154 Cfr. A. Ruggeri, "Quale Costituzione per l'Europa”, Relazione al Convegno (Messina, 19 dicembre 2003) su "Una Costituzione per l'Europa: quali prospettive?" (paper), nonché "Carta europea dei diritti e integrazione interordinamentale: il punto di vista della giustizia e della giurisprudenza costituzionale", in AA.VV., Riflessi della Carta europea dei diritti sulla giustizia e la giurisprudenza costituzionale: Italia e Spagna a confronto, Milano, 2003. Nel Volume appena citato cfr., inoltre, almeno, i contributi di R. Romboli, "Carta europea dei diritti e garanzie giurisdizionali (notazioni introduttive)" (p. 107 ss.), nonché A. Spadaro, "Verso la Costituzione europea: il problema delle garanzie giurisdizionali dei diritti" (p. 115 ss.)

${ }^{155}$ Così A. Baldassarre, "La Carta europea dei diritti", resoconto (a cura di F. Politi e G. Scaccia) dell'incontro tenuto presso la L.U.I.S.S. il 28 maggio 1999 nell'ambito del Seminario su "I mutamenti costituzionali in Italia nel quadro dell'integrazione europea", in www. luiss.it/semecost/europa/carta/index.html.

156 Cfr. A. Spadaro, "Dalla Costituzione come 'atto' (puntuale nel tempo) alla Costituzione come 'processo' (storico). Ovvero della continua evoluzione del parametro costituzionale attraverso i giudizi di costituzionalità", in Quad. cost., 1998, p. 343 ss.; dello stesso autore "Il caso esemplare della Costituzione europea come 'insieme di atti' (puntuali nel tempo) e 'insieme di processi' (storici): dalle C.E.E. alla C.E., all'U.E.", in L. Leuzzi - C. Mirabelli (a cura di), Verso una Costituzione europea, Roma, 2003, p. 721 ss.
} 
diritto si presenterà al Giudice di Lussemburgo ma anche a quelli ordinari e costituzionali dei singoli Paesi dell'Unione europea. Analogo percorso argomentativo, peraltro, può seguirsi, in via generale, anche per le transizioni costituzionali o per l'instaurazione di nuovi ordinamenti costituzionali ${ }^{157}$, ancorché tale orientamento sia contrastato da chi osserva come non sia affatto scontato ai fini della legittimazione dei nuovi ordinamenti costituzionali - sia per le transizioni europee del secondo dopoguerra sia per quelle della transizione post-comunista degli anni Novanta - il ricorso ad assemblee costituenti, e dovendosi, per questo, sottolineare come "negli Stati membri dell'Unione, il potere costituente si è estrinsecato in una pluralità di forme, il cui tendenziale quid comune è costituito dalla deliberazione dell'atto da parte di un'assemblea parlamentare, non importa se appositamente costituita, e dalla successiva approvazione con referendum popolare"158.

4.2 Valore giuridico della Carta dei diritti fondamentali dell'U.E.

Una volta respinta una 'scrittura' che faccia propria la simbologia e il linguaggio costituzionale tradizionali (da più parti colti come una minaccia insostenibile alle identità costituzionali nazionali e alle relative sovranità), l'impasse segnato dal processo d'integrazione europeo a seguito dei negativi pronunciamenti referendari della Francia e dell'Olanda sul 'Trattato che istituisce una Costituzione per l'Europa' ha riproposto ai governi e agli Stati dell'U.E. l'interrogativo su come riprendere la strada dell'integrazione. In tal senso, si ripropone la domanda già da tempo sollevata nella dottrina costituzionale circa la possibilità tecnica di procedere nel processo d'integrazione europea anche senza appoggiarsi su un trattato che ambiva a definirsi Costituzione, ancorché senza poterlo essere in senso formale, in assenza di idonee procedure di legittimazione democratica ${ }^{159}$. Le scelte

\footnotetext{
${ }^{157}$ Cfr. S. Gambino, Costituzionalismo europeo e transizioni democratiche, Milano, 2003.

158 Cfr. C. Pinelli, "Ratifica e referendum: verso la conclusione del processo costituente europeo?" (paper), p. 2.

159 Sulla questione cfr. anche il nostro "Integrazione comunitaria e legittimazione costituzionale", in Scritti in memoria di G. Floridia (in corso di stampa), nonché "Le sfide dell'Unione Europea: l'integrazione attraverso i diritti", in D. Infante (a cura di), Crescita e prospettive dell'Unione Europea allargata, Bologna, 2006.
} 
recentemente accolte nella modifica dei trattati ${ }^{160}$, come abbiamo già ricordato, offrono una nuova soluzione, che, senza incorporare formalmente la Carta dei diritti all'interno dei trattati, si limita ad assegnarle la stessa vis giuridica di questi ultimi. Una soluzione che appare pienamente idonea a farsi carico delle esigenze di protezione giurisdizionale dei diritti fondamentali dell'Unione, offrendo al Giudice di Lussemburgo un parametro ben più saldo rispetto a quelli di cui disponeva fin qui, e che lo hanno portato alla vera e propria formulazione di una 'Costituzione giurisdizionale' dei diritti fondamentali europei. Un parametro che consentirà, al contempo, lo sviluppo di un più appropriato sistema di protezione multilevel dei diritti, nell'ottica suggerita dalla stessa migliore dottrina europea ${ }^{161}$, la quale non potrà che portare le istituzioni rappresentative europee, in un futuro più o meno prossimo, a rivedere la Carta dei diritti per arricchirla con cataloghi di diritti maggiormente aderenti alle più avanzate tradizioni costituzionali europee (soprattutto in materia di diritti sociali e di diritti politici), volti a conseguire una evoluzione graduale verso un costituzionalismo europeo compiuto ${ }^{162}$. Anche se ciò dovrà/dovesse essere portato a buon fine solo dalle generazioni europee che verranno!

Ciò richiamato in via generale circa l'incerta forza giuridica - fino alla ratifica definitiva dei trattati - della Carta, fondata sulla sua solenne proclamazione quale

\footnotetext{
${ }_{160}$ Al momento della redazione di questo scritto, la citazione del Trattato, più correttamente, dovrebbe essere quella, formale, di "Progetto di Trattato che modifica il Trattato sull'Unione Europea e il Trattato che istituisce la Comunità europea" (ovvero, in senso atecnico, Trattato di Lisbona), in quanto la relativa ratifica da parte dei 27 Stati membri dell'U.E. è annunciata per il 13 dicembre 2007 (mentre la sua entrata in vigore è fissata al $1^{\circ}$ gennaio 2009, qualora non insorgano ritardi nel processo di ratifica). cfr. J. Ziller, II nuovo Trattato europeo, Bologna, 2007.

${ }^{161}$ Sul concetto, si veda: I. Pernice, "Multilevel Constitutionalism and the Treaty of Amsterdam: European Constitution - Making Revisited?", in Common Market Law Review, 1999, 36, p. 703 ss; I. Pernice, "L'Unione Costituzionale europea (Der Europäische Verfassungsverbund) nella prospettiva della Conferenza Intergovernativa del 2000" e M. Morlok, "Il diritto costituzionale nel sistema europeo a più livelli", in S. Panunzio (a cura di), I costituzionalisti e l'Europa. Riflessioni sui mutamenti costituzionali nel processo d'integrazione europea, Milano, 2002, pp. 335 ss. e pp. 507 ss; I. Pernice F. Mayer, "La Costituzione integrata dell'Europa", in G. Zagrebelsky, Diritto e Costituzione nell'Unione europea, Roma-Bari, 2003, p. 43 ss.; F. Sorrentino, "La tutela multilivello dei diritti", in Riv. It. Dir. Pub. Com., 2005; P. Bilancia - E. De Marco, La tutela multilivello dei diritti. Punti di crisi, problemi aperti, momenti di stabilizzazione, Milano, 2004; G. Morbidelli, "La tutela giurisdizionale dei diritti nell'ordinamento europeo", in AA.VV. (Atti del Convegno annuale A.I.C., 1999), Annuario 1999. La Costituzione europea, Padova, 2000.

162 Cfr. anche il nostro, "Multilevel Constitutionalism e diritti fondamentali", in G. D'Ignazio (a cura di), Multilevel constitutionalism tra integrazione europea e riforme degli ordinamenti decentrati: 'nuove' frontiere per 'nuovi' diritti, Milano, 2008.
} 
documento politico ricognitivo dei diritti corrispondenti alle tradizioni costituzionali comuni agli Stati membri dell'U.E. e circa gli indubbi progressi segnati, sotto tale profilo, dai nuovi trattati, occorre ora interrogarsi più specificamente sulla natura, la tipologia e sulla stessa esigibilità giuridica dei diritti sociali accolti nella Carta. Lo abbiamo fatto in precedenza con ottica comparativa, individuando nell'esperienza costituzionale italiana (positivizzazione costituzionale e relative forme di tutela giurisdizionale) un modello di riferimento al fine di cogliere le problematiche giuridiche poste dall'incerta formulazione delle tutele accordate a tale tipologia di diritti a livello di U.E.

Pur dovendosi sottolineare le significative discontinuità rispetto alle previsioni anteriori in materia di riconoscimento e di protezione dei diritti fondamentali europei, per molto tempo non è sembrato potersi affermare che le soluzioni accolte nella Carta dei diritti fondamentali dell'Unione europea (adottata il 7-9 dicembre 2000 ed ora nuovamente proclamata dal Consiglio, dalla Commissione e dal Parlamento europeo $^{163}$ ) potessero ritenersi adeguate a farsi carico dell'esigenza del definitivo superamento a livello di Unione delle asimmetrie nella disciplina dei diritti fondamentali rispetto alle maggioritarie esperienze costituzionali europee. Ciò soprattutto se si considera il regime giuridico previsto per i diritti politici e sociali europei, per come definiti - questi ultimi - sia nella Carta di Nizza che nella Convenzione di Roma e nelle Carte sociali (sottoscritte dalla gran parte degli Stati membri dell'Unione europea, ma dalla incerta forza giuridica, con riferimento a queste ultime $\left.{ }^{164}\right)$.

Invero, il pronunciamento referendario della Francia e dell'Olanda, prima, la mancata ratifica del 'Trattato che istituisce una Costituzione per l'Europa', in seguito, e da ultimo gli sforzi negoziali che hanno portato alla sottoscrizione dei nuovi trattati (Lisbona, 13 dicembre 2007) fanno ritenere che le soluzioni accolte nell'art. 6 del nuovo TUE - secondo cui “'’Unione riconosce i diritti, le libertà e i principi sanciti nella Carta dei diritti fondamentali del 7 dicembre $2000, \ldots$ che ha lo stesso valore

${ }_{163}$ Cfr. E. Paciotti, "La seconda 'proclamazione' della Carta dei diritti e il trattato di riforma" e L.S. Rossi, "I diritti fondamentali nel Trattato di Lisbona", ambedue in europeanrights.eu (2008).

${ }_{164}$ Cfr. J.-F. Flauss, "Les interactions entre les instruments européens relatifs à la protection des droits sociaux", in J.-F. Flauss (dir.), Droits sociaux et droit européen ... cit. 
giuridico dei trattati" - costituiscano, sotto il profilo giuridico e della protezione giurisdizionale dei diritti dell'Unione, una situazione diversa rispetto al più visibile processo d'incorporazione della Carta all'interno dei trattati, previsto dal più recente Trattato costituzionale (non ratificato) e in ogni caso con una effettività non dissimile della relativa protezione giurisdizionale assicurata. Nella stessa disposizione sancita al I comma, di seguito, si ribadisce che, in ogni caso, "le disposizioni della Carta non estendono in alcun modo le competenze dell'Unione definite nei trattati". In tal senso, invero, appare ispirata a una definizione come minimo incerta quella previsione sancita all'art. 1 del protocollo n. 7, relativo all'applicazione della Carta dei diritti fondamentali alla Polonia e al Regno Unito. Se, infatti, ne può risultare chiara (nel senso di giuridicamente comprensibile) la ratio posta alla base (della pretesa e della positivizzazione politico-diplomatica) dell'opting out dei due richiamati Paesi, pare altrettanto indubbia la forza novatrice da assegnare alla disposizione (art. 6), nel senso del riconoscimento alla Carta della medesima forza giuridica dei trattati. Pur assumendo come di dubbia effettività quelle disposizioni che, in modo più che discutibile, si propongono di conformare/orientare l'interpretazione della Carta da parte dei giudici di Lussemburgo - "i diritti, le libertà e i principi della Carta sono interpretati in conformità alle disposizioni generali del titolo VII della Carta ... e tenendo in debito conto le spiegazioni cui si fa riferimento nella Carta, che indicano le fonti di tali disposizioni” (art. 6.1., terza frase normativa, del TUE) -, nonostante la "decostituzionalizzazione" della Carta operata nei nuovi trattati ${ }^{165}$ - pare di poter affermare che, più che nelle Costituzioni e nelle prassi nazionali ovvero nell'ambito di applicazione della CEDU, la principale acquisizione della novellata disciplina dei trattati deve individuarsi nella sua applicazione alle stesse istituzioni dell'Unione. Se non può dubitarsi che le tradizioni costituzionali comuni agli Stati membri, soprattutto agli Stati dell'U.E. provenienti dalla vecchia conformazione dell'Europa - sia pure in modo differenziato da Paese a Paese - costituiscano un'esperienza di costituzionalismo avanzato, si tratta, allora, come è stato bene sottolineato, della

165 'La Carta ha poi, nonostante la sua 'decostituzionalizzazione' un potente valore simbolico: una Carta dei diritti rappresenta al contempo un nucleo di identità comune e un idea di Costituzione. La Carta diventa infine anche il parametro su cui dovranno misurarsi le nuove adesioni” (così L.S. Rossi, "I diritti fondamentali nel Trattato di Lisbona", in europeanrights.eu, 2008). 
previsione che disciplina un evidente "habeas corpus contro l'Unione ... Le istituzioni europee sono chiaramente vincolate al rispetto della Carta e si potrà chiedere l'annullamento di un atto dell'U.E. che sia con essa incompatibile ... allo stato attuale le Costituzioni nazionali e la CEDU difficilmente raggiungono il campo di applicazione del diritto comunitario"166.

Si può legittimamente discettare circa la natura di Bill of rights per l'Unione Europea di una simile scelta operata dai (nuovi) trattati, ma, se si fa eccezione per le limitazioni imposte dai protocolli aggiuntivi per il Regno Unito e per la Polonia (peraltro di difficile comprensibilità giuridica ... ma anche politica, qualora lette nella stessa ottica delle 'clausole orizzontali' sancite nel capo VII della Carta), non si può che prendere atto della considerazione secondo cui, in tal modo, si pone fine a una situazione d'incertezza circa la natura e l'efficacia giuridica da riconoscere alla Carta dei diritti fondamentali dell'U.E., che si era protratta per un tempo indubbiamente eccessivo. Un tempo - quest'ultimo - come si ricorderà e come abbiamo altrove sottolineato - che, anche in ragione di ciò, aveva legittimato quelle innovative letture giurisprudenziali che, pur a fronte della natura di documento politico della Carta, l'accoglievano come parametro nella tutela dei diritti fondamentali, ancorché in unum con altri parametri di protezione ${ }^{167}$.

Dopo la stagione di dibattito intenso nel quale la Carta dei diritti veniva individuata come il Bill of Rights del costituzionalismo europeo, che avrebbe trasformato, con la sola sua previsione, la carente legittimazione democratica e costituzionale dell'U.E., deve ora dirsi che la nuova redazione dei trattati non sembra più ispirarsi a tali pretese fondative del costituzionalismo politico, e neppure può forse ritenersi che ne sia stata prevista una forza giuridica pariordinata a quella dei trattati allo scopo di colmare un vuoto di tutela dei diritti fondamentali da parte delle

\footnotetext{
166 Ult. op. cit., p. 1.

167 Cfr. S. Gambino, "La protezione dei diritti fondamentali: il parametro dei princìpi e dei diritti fondamentali nella giurisprudenza costituzionale, comunitaria e della Corte europea dei diritti dell'uomo", Relazione alle "V Jornadas sobre la Constitucion europea", organizzate dalla Facultad de derecho della Universidad de Granada e dall'Institut Andaluz de Administración Pública (28-29 de marzo de 2007), ora in Revista de derecho const. europeo (2007, n. 8) con il titolo: "La protección de los derechos fundamentales: el parámetro de los principios y de los derechos fundamentales en la jurisprudencia constitucional, comunitaria y del tribunal europeo de los derechos del hombre".
} 
istituzioni dell'Unione, per come era stato affermato da una parte della dottrina e della giurisprudenza costituzionale europea.

Lo spazio giuridico della Carta, così, rimane individuato in quella protezione multilevel che viene individuata come più appropriata per le esigenze di garanzia dello Stato contemporaneo ${ }^{168}$ e che viene solennemente affermata nel suo Preambolo: "La presente Carta riafferma, nel rispetto delle competenze e dei compiti dell'Unione e del principio di sussidarietà, i diritti derivanti in particolare dalle tradizioni costituzionali e dagli obblighi internazionali comuni agli Stati membri, dal trattato sull'UE e dai trattati comunitari, dalla Convenzione europea di salvaguardia dei diritti dell'Uomo e delle libertà fondamentali, dalle carte sociali adottate dall'Unione e dal Consiglio d'Europa, nonché i diritti riconosciuti dalla giurisprudenza della Corte di giustizia delle Comunità europee e da quella della Corte europea dei diritti dell'Uomo".

\subsection{L'adesione alla CEDU da parte dell'Unione europea}

Con una formulazione identica a quella prevista nell'art. I-9 del (non ratificato) Trattato costituzionale, nell'art. 6.2 del nuovo TUE si stabilisce che "L'Unione aderisce alla Convenzione europea di salvaguardia dei diritti dell'uomo e delle libertà fondamentali. Tale adesione non modifica le competenze dell'Unione definite nei trattati". La sussunzione della medesima disciplina, già prevista nel precedente (progetto di) trattato, consente di richiamarsi ad un'analisi già svolta, nel fondo, in occasione dei lavori della Convenzione e della bozza del Trattato costituzionale (Gruppo di lavoro II costituito all'interno della Convenzione di Laeken).

Rispetto ai quesiti posti dal Mandato del 'Gruppo Carta'169, si trattava di approfondire le "conseguenze di un'eventuale adesione della Comunità/Unione alla CEDU", dovendosi chiarire, in particolare, "in quale misura l'adesione (potesse) conciliarsi con il principio dell'“autonomia del diritto comunitario"; in tale quadro, ci si chiedeva se tale adesione non rischiasse di modificare il riparto delle competenze fra l'Unione e gli Stati membri e se, per tale ragione, non dovessero prevedersi

\footnotetext{
${ }^{168}$ Cfr. anche il nostro, "Multilevel constitutionalism e diritti fondamentali ... cit.

${ }^{169}$ CONV 72/02.
} 
meccanismi diversi da quelli dell'adesione alla CEDU. Le conclusioni generali e le relative raccomandazioni del Gruppo, accolte nella Relazione finale, e almeno in parte nel testo del Trattato costituzionale, si orientavano nel senso favorevole all'introduzione di una disposizione autorizzante I'Unione ad aderire alla CEDU. Le argomentazioni invocate alla base di tale orientamento risultavano essere le seguenti: a) unitamente alla incorporazione della Carta nei trattati, l'adesione avrebbe costituito "un segnale politico importante della coerenza fra l'Unione e la 'grande Europa', rispecchiato nel Consiglio d'Europa e nel relativo sistema paneuropeo dei diritti umani"; b) l'adesione alla CEDU avrebbe assicurato ai cittadini, rispetto all'azione dell'Unione, il medesimo livello di protezione di cui già beneficiano negli Stati membri; c) l'adesione - infine - (avrebbe costituito) "lo strumento ideale per assicurare uno sviluppo armonioso della giurisprudenza delle due Corti europee competenti in materia di diritti umani”.

Secondo quanto previsto nella Relazione finale, inoltre, l'incorporazione della Carta nei trattati e l'adesione dell'Unione alla CEDU non dovevano considerarsi come misure alternative bensì complementari, nell'ottica della garanzia del pieno rispetto dei diritti fondamentali da parte dell'Unione; tali misure avrebbero condotto a una situazione comparabile a quella in cui versa ogni Stato membro che preveda nel suo ordinamento costituzionale la protezione dei diritti fondamentali ma, al contempo, si sottopone al controllo supplementare esterno dei diritti umani previsto dal sistema giurisdizionale di Strasburgo. In tale quadro, la relazione fra la Corte di giustizia e la Corte europea dei diritti dell'uomo non può essere descritta in termini gerarchici; quest'ultima, infatti, può solo sancire le violazioni della CEDU, ma non ha il potere d'intervenire sulla validità della interpretazione delle norme delle parti contraenti.

Già nella situazione antecedente la riforma dei trattati, dunque, è dato un controllo della Corte di Strasburgo, diretto o indiretto ed esercitato con un evidente sel-restraint, sugli atti dell'Unione; tuttavia, le istituzioni dell'Unione non hanno la possibilità di difendersi adeguatamente dinnanzi alla Corte di Strasburgo, il che si ripercuote sugli Stati membri, responsabili, in alcuni casi, di atti od omissioni rispetto ai quali hanno poca o nessuna influenza. Tale situazione, dunque, potrebbe trovare parziale soluzione in seguito all'adesione alla CEDU da parte dell'Unione europea. 
Per quanto riguarda, infine, l'influenza dell'adesione sulla posizione che gli Stati membri hanno rispetto alla Convenzione stessa, si faceva rilevare come le suddette posizioni sarebbero rimaste intatte. Tali azioni, infatti, ineriscono alla sfera del diritto interno e l'adesione non produrrebbe effetti giuridici se non quando venga in rilievo il diritto dell'Unione europea. In realtà, rispetto ad alcuni interrogativi cruciali relativi alle conseguenze dell'adesione stessa, è stato correttamente obiettato che se anche "la Corte di Strasburgo non interpreta il diritto nazionale (e in futuro non interpreterà il diritto dell'Unione), lo tiene presente nella sua decisione; se anche non giudica la validità di tale diritto, quando è necessario si esprime più o meno indirettamente sulla sua compatibilità alla Convenzione. Quale altra conclusione può e deve trarsi dalla sentenza della Corte europea dei diritti dell'uomo nel caso Matthews del 18 febbraio 1999?"170.

Sulla base di tali valutazioni, la Convenzione incaricata di predisporre il testo del trattato proponeva una formulazione dell'art. 7, par. 2, secondo la quale "L'Unione persegue l'adesione alla Convenzione europea di salvaguardia dei diritti dell'uomo e delle libertà fondamentali. Tale adesione non modifica le competenze dell'Unione definite nella Costituzione". Se l'uso del verbo "perseguire" sembrava riflettere il generale compromesso raggiunto dai membri del Gruppo di lavoro II - Carta, l'estrema sinteticità di tale formulazione non consente di chiarire alcune condizioni pure ritenute imprescindibili per gli stessi 'convenzionali'.

Quanto, infine, alla dibattuta questione se l'introduzione della Carta dei diritti fondamentali e l'adesione alla CEDU annulli gli altri riferimenti ai medesimi diritti richiamati all'art. 6 TUE, o se le stesse, al contrario, comportino una 'cristallizzazione' della giurisprudenza in materia di diritti fondamentali soprattutto rispetto a quella elaborata dalla Corte di giustizia, nei nuovi trattati si prevede (come già avveniva nell'ambito della Convenzione e nel Trattato costituzionale) una clausola che fa riferimento ai princìi generali dell'Unione europea, ispirati ai trattati internazionali sui

\footnotetext{
${ }^{170}$ Cfr. A.S. Arnaiz, "I diritti fondamentali nel Trattato per l'istituzione di una Costituzione per l'Europa (un bilancio della Convenzione)", in S. Gambino (a cura di), La protezione dei diritti fondamentali, Milano, 2004, p. 265; S. Gambino, "Diritti fondamentali, costituzioni nazionali e trattati comunitari", in S. Gambino (a cura di), Trattato che adotta una Costituzione per l'Europa, costituzioni nazionali, diritti fondamentali, Milano, 2006.
} 
diritti fondamentali e alle tradizioni costituzionali comuni dei Paesi membri. L'art. 6.3 del nuovo TUE, in tal senso, statuisce che "I diritti fondamentali, garantiti dalla Convenzione europea di salvaguardia dei diritti dell'uomo e delle libertà fondamentali e risultanti dalle tradizioni costituzionali comuni agli Stati membri, fanno parte del diritto dell'Unione in quanto princìpi generali di diritto comunitario".

Rispetto a tale quadro normativo innovato, occorre chiedersi, pertanto, quali siano gli strumenti affinché la Corte di Giustizia (ma anche il Tribunale di primo grado) possa assolvere ai delicati compiti che la sua trasformazione in Tribunale costituzionale dell'Unione - da taluno prospettata - richiederebbe. Sulla questione posta dalle 'vie di ricorso' riconosciute ai singoli, in particolare alla luce del diritto fondamentale europeo a una tutela giudiziaria effettiva, esiste in dottrina un intenso dibattito, che ha toccato sia l'ipotesi della previsione di una procedura speciale dinanzi alla Corte di Giustizia ai fini della tutela dei diritti fondamentali, sia la questione della necessità di una riformulazione delle condizioni alle quali una persona fisica o giuridica possa adire giurisdizionalmente la Corte (art. 230, IV co., TCE), sempre ai fini di una efficace tutela dei diritti fondamentali ${ }^{171}$.

\footnotetext{
${ }^{171}$ Sulla 'fluidità' e 'ambiguità' in tema di tutela effettiva dei diritti fondamentali cfr. anche I.J. Patrone, "La protezione giurisdizionale dei diritti nei lavori della Convenzione", in http://www.magistraturademocratica.it/md.php/8/277. Sui rischi di una positivizzazione dei diritti a livello di U.E. senza la previsione di un contestuale, coerente ed organico sistema di giurisdizione cfr. anche G. Zagrebelsky, "Corti europee e corti nazionali" (Seminario organizzato dalla LUISS, il 12 gennaio 2001, nel resoconto redatto da R. Calvano e M. Corrado), secondo il quale una simile situazione finirebbe per operare una duplice delegittimazione, sia dell'Unione che dei sistemi politici nazionali. L'autore sottolinea, tuttavia, come l'orientamento giurisprudenziale del Giudice delle leggi in materia di 'controlimiti' (sent. 170 del 1984 e successive) verrebbe inevitabilmente travolto a seguito dell'incorporazione della Carta dei diritti nel TC, in quanto tale ultima ipotesi produrrebbe "il risultato di tagliare fuori la Corte costituzionale da tutte le controversie sui diritti fondamentali". In un simile scenario, che è appunto quello attuale, la stessa giurisprudenza costituzionale che, pur esprimendo forte sensibilità verso la CEDU, ne ha comunque riconosciuto mera natura legislativa, salvo far presente l'evoluzione giurisprudenziale registrata sul punto nelle sentenze n. 348 e 349 del 2007 che rappresentano i nuovi ed inevitabili corollari interpretativi ed applicativi del novellato art. $117, \mathrm{I}$ co. Cost., ora non potrebbe che dover prendere atto che "per quanto riguarda la CGCE e la Corte di Strasburgo si tratta di vere Corti costituzionali, quanto meno dal punto di vista del diritto che usano e che fanno valere. È facilmente comprensibile come una concorrenza di giurisprudenze sfasate produrrebbe la delegittimazione della nostra Corte nazionale. C'è una logica in queste vicende per cui la legittimità superiore, che coinvolge più soggetti statali, prevale sulla legittimità del singolo, a meno di una rivolta generalizzata, che però è inimmaginabile". Quanto infine alle possibili 'interferenze' fra le giurisprudenze delle Corti di Lussemburgo e di Strasburgo (come il Caso Matthews vs Regno Unito evidenzia), non può trascurarsi come una evoluzione significativa in materia sia già presente. La Corte di Strasburgo già esercita le sue competenze sul diritto derivato dell'Unione per come attuato negli ordinamenti nazionali e per come interpretato dai giudici nazionali e dell'Unione (sent. Cantoni vs
} 
Se la formulazione dell'art. 6.3 (come in precedenza l'art. I-9 del Trattato costituzionale) richiederebbe indubbiamente una migliore definizione del sistema giudiziario europeo, al fine di chiarire i ruoli delle rispettive Corti nell'ambito della tutela dei diritti fondamentali, e in particolare i limiti all'attività interpretativa delle stesse, la necessità di riformare alcuni aspetti dello stesso sistema giurisdizionale deriva soprattutto dal 'perseguimento' dell'adesione alla CEDU, per come statuito nella richiamata disposizione, e dall'assegnazione della forza giuridica dei trattati alla stessa Carta. Tali riforme si rivelano indispensabili se si considerano le statuizioni dell'art. 47 della Carta, nonché degli artt. 6.1 e 13 della CEDU. Come si può osservare, l'art. 47 pone una ulteriore condizione rispetto all'art. 13 della CEDU, e cioè che la garanzia del diritto a un rimedio effettivo debba essere giudiziaria; diversamente, la tutela del diritto non corrisponderebbe al diritto sancito nell'art. 47 della 'Carta'172.

Anche con riferimento alle previsioni dei commi 2 e 3 dell'art. 6 del nuovo trattato, in conclusione, può dirsi che con tale previsione si conferma quanto già previsto nel trattato costituzionale non ratificato. II quadro normativo che si presenta all'interprete, pertanto, prevede due distinti e concorrenti disposizioni. Con la prima (art. 6.2 TUE) I'Unione aderisce alla CEDU, senza con ciò implicare modifiche nell'assetto delle competenze dell'Unione. Con la seconda disposizione (art. 6.3.) si stabilisce che "i diritti fondamentali, garantiti dalla CEDU e risultanti dalle tradizioni

Francia, del 1996). Se a tale tendenza si aggiunge il dato processuale, ne consegue in modo assolutamente inevitabile che l'adesione dell'U.E. alla CEDU porrebbe (almeno in via astratta) la Corte di Strasburgo "in una posizione superiore rispetto a quella di Lussemburgo, se non altro perché la prima può essere investita dalla decisione solo una volta esaurite le vie di ricorso interne, compreso il rinvio pregiudiziale al giudice dell'Unione, come prescrive l'art. 35 CEDU" (in tal senso I.J. Patrone, "La protezione giurisdizionale dei diritti ... cit.). Sul punto, in generale, cfr. anche A. Ruggeri, "Carta europea dei diritti e integrazione interordinamentale: il punto di vista della giustizia e della giurisprudenza costituzionale ... cit, nonché G. De Muro, "I rapporti fra CGCE e Corte europea dei diritti dell'uomo", in AA.VV. (a cura di P. Falzea, A. Spadaro, L. Ventura), La Corte costituzionale e le Corti ... cit.

${ }^{172}$ Cfr. anche P. Biavati, "L'art. 47 della Carta dei diriti e il processo comunitario", in AA.VV. (a cura di M. Taruffo e V. Varano), Diritti fondamentali e giustizia civile in Europa, Torino, 2002; L.P. Comoglio, "L'effettività della tutela giurisdizionale nella Carta dei diritti fondamentali dell'UE", in AA.VV. (a cura di M. Taruffo - V. Varano), Diritti fondamentali e giustizia civile in Europa, Torino, 2002; F. Carpi, "Prime considerazioni sulle garanzie processuali dell'U.E.", in AA.VV. (a cura di M. Taruffo - V. Varano), Diritti fondamentali e giustizia civile in Europa, Torino, 2002; N. Trocker, "Il diritto ad una tutela giurisdizionale effettiva nell'opera creatrice della CGCE”, in AA.VV. (a cura di M. Taruffo e V. Varano), Diritti fondamentali e giustizia civile in Europa, Torino, 2002. 
costituzionali comuni agli Stati membri, fanno parte del diritto dell'Unione in quanto principi generali". Inoltre, nel rispetto di quanto previsto dall'art. 6.1 (terza frase normativa), diritti, libertà e principi accolti nella Carta dei diritti fondamentali sono interpretati in conformità alle disposizioni generali del capo VII della Carta. Tanto considerato, quando ci si interroghi sul contenuto novativo dell'adesione della Unione alla CEDU, non può non sottolinearsi che esso appare come minimo sfuggente e ambiguo, in accordo con la migliore dottrina intervenuta sul punto ${ }^{173}$.

A ben cogliere, infatti, nell'art. 52.3 della Carta dei diritti, con riferimento all'eventuale disciplina di diritti nelle due Carte di tipo corrispondente, si contiene una mera disciplina di rinvio alla CEDU, con ciò stabilendosi una clausola interpretativa secondo la quale fra le garanzie assicurate dalla Carta e quelle assicurate dalla CEDU, in ipotesi di coincidenza di oggetti, vede prevalere la disciplina di quest'ultima.

Tanto sottolineato circa la primazia della CEDU rispetto alla Carta in ipotesi di diritti corrispondenti, l'ultima frase normativa dell'art. 52.3 della Carta prevede che in ogni caso nulla osta a che il diritto dell'Unione possa "concedere una protezione più estesa". Con il ché - come bene sottolinea Rescigno - "la Carta di nuovo confessa di voler essere una legge superiore a tutte le altre, perché è essa Carta che prevede, legittima la possibilità di nuove disposizioni future dell'Unione, purché più favorevoli, e dice appunto che, se più favorevoli, prevalgono anche su quelle della CEDU"174.

L'ambiguità esistente nei rapporti fra Carta e CEDU, consistente nella sola parziale sovrapponibilità dei relativi regimi giuridici ${ }^{175}$, si riflette nella dibattuta e non risolta questione dei rapporti e delle pretese primazie della Corte di Giustizia o al contrario della Corte europea dei diritti dell'uomo ${ }^{176}$. Decisa l'adesione alla CEDU da

\footnotetext{
${ }^{173}$ Così G.U. Rescigno, "La Carta dei diritti come documento", in M. Siclari (a cura di), Contributi allo studio della Carta dei diritti fondamentali dell'Unione europea, Torino, 2003.

${ }_{174}$ Ult. Op. cit., p. 10. In tal modo "nella prima frase del paragrafo 3 la Carta in fondo dice di se stessa di essere inutile sul piano normativo per la parte già disciplinata dalla CEDU, giacché in tal caso si applica un altro documento; nella seconda frase invece, esattamente al contrario, si pone come fonte suprema, che distribuisce e disciplina il potere normativo su un determinato oggetto (in questo caso, i diritti fondamentali)" (pp-10-11).

175 V. Zagrebelsky, "La prevista adesione dell'Unione Europea alla CEDU", in http://www.europeanrights.eu.

${ }^{176}$ Sul punto cfr. G. Tiberi, "La questione dell'adesione della Comunità alla CEDU al vaglio della Corte di Giustizia", in Riv. it. dir. pub. com., 1997; A. Tamietti, "La nuova Carta dei diritti fondamentali
} 
parte dell'Unione - come è stato bene sottolineato - così, "la discussione si apre ora attorno alle modalità di essa, affinché la particolare natura dell'Unione sia presa nel debito conto senza che il sistema di tutela uniforme dei diritti dell'uomo in Europa ne risulti snaturato"177.

\section{Diritti fondamentali e spazio europeo di libertà, sicurezza e giustizia} (nuove positivizzazioni e incerte protezioni giurisdizionali)

Se il riconoscimento alla Carta dei diritti fondamentali di una forza giuridica pariordinata a quella dei trattati, e se dunque la 'scrittura' di questi ultimi in un ampio (benché ancora incompleto) catalogo che - unitamente alla previsione di alcuni nuovi diritti civili (soprattutto nel campo del bio-diritto) - riepiloga, positivizza e rende visibile la giurisprudenza del Giudice di Lussemburgo ${ }^{178}$ e di quello di Strasburgo non consente ancora di poter essere assunto quale espressione di una piena costituzionalizzazione dell'ordinamento dell'Unione, indubbiamente esso incide in

dell'Unione europea: quali rapporti con la CEDU?", in I diritti dell'uomo. Cronache e battaglie, 2000, nn. 1-2; T. Groppi, "Art. 52", in R. Bifulco - M. Cartabia - A. Celotto, L'Europa dei diritti. Commento alla Carta dei diritti fondamentali dell'Unione Europea, Bologna, 2001; G. Demuro, "I rapporti fra Corte di giustizia delle Comunità europee e Corte europea dei diritti dell'uomo", in www.associazionedeicostituzionalisti.it.

${ }_{177}$ V. Zagrebelsky, "La prevista adesione dell'Unione Europea alla CEDU", in http://www.europeanrights.eu, p. 10.

${ }_{178}$ Cfr. Sent. Stauder del 12 novembre 1969, causa 29/69, in Racc. Uff. 1969, p. 420; sent. Internationale Handelsgesellschaft del 17 dicembre 1970, causa 11/70, in Racc. Uff. 1979, p. 1125; sent. Hauer, causa 44/1979, in Racc. Uff. 1979, p. 3727. In dottrina cfr., fra gli altri, E. Pagano, "I diritti fondamentali nella Comunità europea dopo Maastricht", in Il diritto dell'Unione Europea, 1996, n. 1, p. 164 ss.; G. Tesauro, "Il ruolo della Corte di Giustizia ... cit., p. 305 ss.; A. Adinolfi, "I princìpi generali nella giurisprudenza comunitaria e la loro influenza sugli ordinamenti degli Stati membri", in Rivista italiana di diritto pubblico comunitario, 1994, p. 525 ss.; G. Gaja, "Princìpi del diritto (dir. intern.), in Enc. dir, p. 542; A. Adinolfi, "I princìpi generali ... cit., p. 561 ss.; P. Pescatore, "Le recours, dans la jurisprudence de la Cour de justice des Communautés européennes, à des normes déduites de la comparaison de droits des Etats membres", in Revue internationale de droit comparé, 1980, p. 337 ss.; V. Capelli, "I princìpi generali come fonte di diritto", in Diritto comunitario e degli scambi internazionali, 1986, p. 541; G. Gaja, "Aspetti problematici della tutela dei diritti fondamentali nell'ordinamento comunitario", in Riv. dir. inter., 1988, p. 574; P. Mengozzi, "La tutela dei diritti dell'uomo e il rapporto di coordinamento-integrazione funzionale fra ordinamento comunitario e ordinamenti degli Stati membri nei recenti sviluppi della giurisprudenza italiana e tedesca", in Diritto comunitario e degli scambi internazionali, 1987; M. Cartabia, Principi inviolabili ... cit., passim; F. Mancini, "La tutela dei diritti dell'uomo: il ruolo della Corte di Giustizia delle Comunità Europee", in Riv. trim. dir. proc. civ., 1989, n. 1; A. Rizzo, "L'Unione Europea e la Carta dei diritti fondamentali. Un rapporto ancora da definire", in La Comunità internazionale, 2001, n. 1, p. 112; F. Cocozza, Diritto comune delle libertà in Europa, Torino, 1994, p. 132; G. Maestro Buelga, "Los derechos sociales en la Union Europea: una perspectiva constitucional ... cit., p. 119 ss. 
modo rilevante nel 'processo di costituzionalizzazione' dello stesso, costituendone momento, se non certo definitivo, particolarmente rilevante ${ }^{179}$.

Con la positivizzazione europea dei diritti fondamentali può affermarsi, infatti, che alla previgente funzione di mero limite all'adozione di atti comunitari in eventuale loro violazione se ne accompagna, ora, una di tipo positivo, quella di costituire uno spazio comune di libertà, sicurezza e giustizia, capace di guidare, ma anche di limitare, lo stesso esercizio da parte delle istituzioni europee delle competenze loro riconosciute ${ }^{180}$. Così, se le stesse hanno svolto fin qui una funzione per così dire strumentale, in ragione delle esigenze connesse ai progressi della costruzione del mercato comune europeo, le nuove forme del loro riconoscimento e della protezione giuridica ne disvela una nuova vocazione capace di assicurare maggiore linfa e smalto a concetti ugualmente centrali nel processo di costruzione europea, come la cittadinanza dell'Unione o il significato della reciproca fiducia tra gli Stati in uno spazio comune di libertà, di sicurezza e di giustizia.

I diritti fondamentali, pertanto, non costituiscono più un mero limite imposto all'azione delle istituzioni europee o degli Stati membri nel campo di applicazione del diritto dell'Unione. Al previgente obbligo (di non violare i diritti fondamentali) imposto alle istituzioni e agli organi dell'Unione come anche agli Stati membri in sede di attuazione del diritto dell'Unione, ne segue ora anche uno di tipo promozionale, quello secondo cui "i suddetti soggetti rispettano i diritti, osservano i principi e ne promuovono l'applicazione secondo le rispettive competenze" (art. 51.1 Carta).

Come è stato già sottolineato, nella dinamica evolutiva che ha preceduto l'attuale fase di positivizzazione sono bene evidenziabili tre stadi/dinamiche, due dei quali sono stati maggiormente approfonditi dalla dottrina. II primo è costituito dalla giurisprudenza creatrice dei diritti da parte del Giudice di Lussemburgo fondata sulla Ioro individuazione, come un contenuto necessario, all'interno dei principi generali

\footnotetext{
179 Cfr. M. Cartabia, "I diritti fondamentali ... cit., p. 57; G. Zagrebelsky, "Corti europee e corti nazionali" (Seminario organizzato dalla LUISS, il 12 gennio 2001, nel resoconto redatto da R. Calvano e M. Corrado).

180 Cfr. O. De Schutter, "Les droits fondamentaux dans le projet ... cit., p. 81 ss.
} 
del diritto ${ }^{181}$. Tale dinamica si ricollega alla volontà della Corte di giustizia di rispondere alla stessa minaccia che incombeva sull'affermazione del primato del diritto dell'Unione sull'insieme del diritto nazionale degli Stati membri, soprattutto rispetto a quegli ordinamenti nazionali le cui Costituzioni si pongono come 'controlimiti' all'azione delle istituzioni dell'Unione nella materia dei principi e dei diritti fondamantali. Una seconda dinamica, a partire dal Trattato di Maastricht, si è sviluppata con la creazione della nozione di cittadinanza dell'Unione europea. Tale nozione non si sostituisce a quella nazionale, ma viene ad aggiungere, a beneficio dei cittadini degli Stati membri, un certo numero di diritti, creando al contempo un sentimento di appartenenza comune. In tale ambito, i cittadini dell'Unione si vedono riconosciuti il diritto di circolare e soggiornare liberamente sul territorio degli Stati membri e quello di votare ed essere eletti alle elezioni municipali degli Stati membri in cui ogni cittadino risiede, il diritto di beneficiare della protezione diplomatica o consolare da parte delle autorità di qualsiasi Stato europeo.

Una terza dinamica appare maggiormente rilevante ai fini della stessa comprensione della innovativa giurisprudenza pretoria in tema di diritti fondamentali. In essa si evidenzia come i diritti fondamentali siano colti come strumento costitutivo di uno spazio comune, relativamente omogeneo, fra gli Stati membri dell'Unione. Si tratta di una dinamica indubbiamente complessa, coincidente con il fine ultimo dell'Unione, che è quello di creare le condizioni per una libera circolazione dei fattori produttivi tra gli Stati membri, accompagnato dall'eliminazione delle principali fonti di distorsione della concorrenza. Tale spazio, a partire dal Trattato di Amsterdam fino a quello riformato a Lisbona, si è arricchito con l'obiettivo di conseguire uno spazio di libertà, di sicurezza e di giustizia, "senza frontiere interne, in cui sia assicurata la libera circolazione delle persone insieme a misure appropriate per quanto concerne i controlli alle frontiere esterne, l'asilo, l'immigrazione, la prevenzione della criminalità e la lotta contro quest'ultima" (art. 3.2 TUE). Con tale affermazione si vuole sottolineare come alcune libertà fondamentali fossero state accolte fin dall'origine della costruzione europea (Trattato di Roma, 1957). Fra queste ultime, accanto alle

181 Fra gli altri cfr. anche S. Gambino, "Il diritto costituzionale europeo: princìpi strutturali e diritti fondamentali" in S. Gambino (a cura di), Costituzione italiana e diritto comunitario ... cit. 
libertà economiche, figurano, come si è già visto, libertà classiche come il diritto dei lavoratori a ricercare un impiego in altro Stato membro (facendosi divieto pertanto delle discriminazioni fondate, oltre che sul genere, sulla nazionalità), la libera prestazione dei servizi, la libertà di concorrenza, e il divieto di abuso di una posizione predominante. Tali libertà rappresentano lo strumento di realizzazione del mercato comune, costituendo componente essenziale dell'armamentario giuridico del mercato stesso.

I diritti fondamentali sono stati progressivamente riconosciuti, pertanto, come dei complementi indispensabili dello spazio unico europeo, benché ancora non omogeneo e comunque idoneo a divenirlo sulla base della sua piena operatività. Le differenze fra gli Stati membri nel campo della tutela di questa categoria di diritti non potevano che richiamare in causa l'idea di uno spazio unico, creando pertanto delle interdipendenze tra Stati, tali che le realizzazioni di ciascuno Stato in tale ambito producano necessariamente delle conseguenze in tutti gli altri, in ciò concependosi come vere e proprie limitazioni delle autonomie/sovranità di questi ultimi. L'obiettivo di specifiche direttive adottate in tale ambito è appunto quello di evitare un dumping sociale che può verificarsi a causa delle legislazioni degli Stati che non riconoscono delle garanzie minime ai lavoratori, dal punto di vista delle remunerazioni, delle ore di lavoro, della durata del congedo pagato, ecc. Esse pertanto consentono anche di favorire il rispetto di taluni diritti sociali fondamentali dei lavoratori, rinviando per le relative misure attuative alla disciplina nazionale ${ }^{182}$.

La creazione di tale spazio di libertà, sicurezza e giustizia fra gli Stati membri, e la stessa idea di una rete fiduciaria che si crea fra gli stessi trovano poi un ulteriore fondamento nell'adesione di tali Stati alla CEDU e alle altre Carte internazionali di protezione dei lavoratori (e non solo), con l'assoggettamento da parte di questi ultimi a taluni standards minimi. La disciplina europea in materia di diritto di asilo e di immigrazione costituiscono una buona esemplificazione di tale affermazione. In assenza di una competenza esclusiva, l'iniziativa europea in materia deve conformarsi al rispetto del principio di sussidiarietà, giustificandosi i propri interventi

\footnotetext{
182 Nell'ampia bibliografia, sul punto, cfr. anche C. Di Turi, Globalizzazione dell'economia e diritti umani fondamentali in materia di lavoro: il ruolo dell'OIL e dell'OMC, Milano, 2007.
} 
sulla considerazione che una mancata armonizzazione fra gli Stati membri in tali materie può produrre distorsioni, "di tal ché le scelte di ogni Stato producono necessariamente ripercussioni nei confronti di tutti gli altri Stati che condividono il medesimo spazio"183. In conclusione, si deve sottolineare come nella ratio sottostante alla creazione di uno spazio comune per il mercato europeo, alla base dei primi trattati europei, non possa non rilevarsi un apporto almeno comparabile a favore dei diritti fondamentali. Un loro riconoscimento e garanzia nei soli livelli nazionali avrebbe, infatti, comportato dei riflessi negativi, dei veri e propri impedimenti, nella creazione di uno spazio europeo più ampio. Ne segue, così, per richiamare la tesi conclusiva di questo orientamento dottrinario, che sia pure in ambiti limitati (protezione dei dati personali, protezione dei diritti dei lavoratori), 'l'armonizzazione di tali diritti sul piano dell'Unione europea si giustifica ... sulla base della necessità di superare quell'ostacolo che l'attuazione decentrata dei diritti fondamentali può costituire per l'emersione di uno spazio davvero unico" ${ }^{\text {"184 }}$.

Un profilo di pari rilevanza rispetto a quello ora in considerazione è posto dalla clausola (di cui all'art. 51.2 della Carta, ora anche art. 6.1 TUE) secondo cui "le disposizioni della Carta non estendono in alcun modo le competenze dell'Unione definite nei trattati"; una clausola - quest'ultima - da interpretare anche alla luce dell'art. 5 del TUE. Già altri hanno autorevolmente osservato, sotto tale profilo, come le richiamate disposizioni della Carta, in presenza dell'ampia flessibilità accolta nelle stesse, si prestino in modo pressoché inevitabile a influenzare la natura e i compiti dell'Unione ${ }^{185}$. L'ambito di tali competenze concorrenti, infatti, è piuttosto ampio. Le competenze condivise tra gli Stati membri e l'Unione attengono principalmente al mercato interno, allo spazio di libertà, sicurezza e giustizia, alla politica sociale per gli aspetti definiti dai nuovi trattati. L'Unione dispone di una serie di possibilità al fine di realizzare i valori inscritti nella Carta; il riconoscimento alla stessa della forza giuridica dei trattati ne incoraggerà l'utilizzo.

\footnotetext{
183 Ult. op. cit., p. 91; COM (2001) 287, 18 luglio 2001.

184 Ult. op. cit., p. 92.

${ }^{185}$ Cfr. G. De Burca, "Fundamental rights and Citisenship", in B. De Witte (éd), Ten Reflections on the Constitutional Treaty for Europe, Fiesole, 2003, p. 11.
} 
Nonostante l'innovato quadro normativo (in part. art. 3.3 TUE) impegni le istituzioni europee ad attivarsi nella lotta contro le discriminazioni e le esclusioni sociali, a promuovere la giustizia e la protezione sociale, la parità tra donne e uomini, la solidarietà tra generazioni e la tutela dei diritti del minore, a promuovere la coesione economica, sociale e territoriale e la solidarietà fra gli Stati membri, rimane che l'orizzonte normativo accolto nei nuovi trattati non colloca l'attuazione della Carta dei diritti fra gli obiettivi dell'Unione. Cosicché la conclusione che può trarsi rimane ancora quella accolta in un noto Rapporto (Duff) al Parlamento europeo, secondo cui "la Carta non attribuisce competenze all'Unione; al contrario, essa ha come effetto di limitare l'esercizio del potere delle istituzioni europee in ragione dell'obbligo loro fatto di rispettarla", ancorché nello stesso Rapporto si aggiunga che "nel quadro delle proprie competenze, le istituzioni hanno parimenti il dovere di promuovere il rispetto delle sue disposizioni”"186. D'altra parte, ciò è quanto risulta dalla previsione di cui all'art. 51 della Carta.

Possiamo, ora, trarre qualche orientamento conclusivo di ordine generale, anche richiamando la più autorevole dottrina che si è fin qui espressa in materia. La questione centrale da dipanare - già posta con riferimento all'art. 52 della Carta rimane quella del rapporto esistente fra la tutela europea dei diritti fondamentali, le altre disposizioni europee e le 'tradizioni costituzionali comuni' agli Stati membri, nonché quella, strettamente connessa, se sia stato previsto un controllo di costituzionalità sugli atti normativi ordinari. La risposta che se ne dà è nel senso assertivo; e da ciò se ne trae la conclusione da parte di qualche studioso che tale controllo costituisce sintomo ed evidenziamento di un processo di costituzionalizzazione europeo che sarebbe ormai compiuto. Come è stato autorevolmente osservato, infatti, “... questo mi sembra il momento essenziale in cui nasce una vera Costituzione: finché non c'è nessun giudice che può utilizzare la Costituzione per contestare la legalità di un altro atto, anche legislativo, il documento

186 Rapport sur l'impact de la Charte des droits fondamentaux de l'Unione européenne et son statut futur (§ M del considerato in diritto) (2002/2139/INI; Doc. final A5-0332/2002, 8 ottobre 2002). 
rimane una mera enunciazione politica; si trasforma in un documento giuridico quando questo controllo è possibile"187.

Pertanto, quanto ai relativi profili della tutela giurisdizionale, che si dia una competenza (di giurisdizione costituzionale europea) in capo alla Corte di Giustizia pare problema non più revocabile in dubbio. Che tale competenza confonda in una sola giurisdizione competenze di merito (a risolvere la causa) e competenze di legittimità (degli atti comunitari ai trattati) è parimenti indubitabile. Ciò che costituisce, al momento, un problema aperto (e che potrà accompagnarsi con eventuali pronunce divergenti fra le diverse giudisdizioni in sede di applicazione del diritto dell'Unione) - più che l'incerta individuazione del contenuto dei singoli diritti (che pure è problema aperto) - è quello, risalente e ancora senza soluzione, del "rapporto fra le diverse enunciazioni degli stessi diritti e fra le diverse giurisdizioni sui diritti”, e in particolare del rapporto fra giudice comunitario, Corti costituzionali nazionali e Corte europea dei diritti dell'uomo ${ }^{188}$.

Rispetto a tali problematiche, autorevole dottrina ${ }^{189}$ sottolinea la forte problematicità delle soluzioni di riforma avanzate dalla Convenzione al fine di garantire l'effettiva tutela dei diritti inscritti nella Carta nell'ambito dello spazio giuridico europeo. La Corte di Lussemburgo sarebbe inevitabilmente chiamata a svolgere il delicato compito di garantire i contenuti normativi della Carta dei diritti; né appare proponibile (o auspicabile) l'attribuzione di tale incombenza alla Corte di Strasburgo, ovvero, ancora, ad una Corte appositamente creata, una sorte di 'Corte europea bis' ${ }^{\prime 190}$. Molteplici elementi osterebbero, però, all'efficace svolgimento di tale compito cui i nuovi articoli del Trattato non aggiungerebbero nessuna reale garanzia di miglioramento.

\footnotetext{
${ }^{187}$ Cfr. V. Onida, II problema della giurisdizione ... cit., p. 134.

188 Cfr. M.P. Chiti, "Le norme sulla giurisdizione", in F. Bassanini - G. Tiberi, La Costituzione europea. Un primo commento, Bologna, 2004.

${ }^{189}$ Cfr. L. Favoreu, "I garanti dei diritti fondamentali europei, in AA.VV. (a cura di G. Zagrebelsky), Diritti e Costituzione ... cit.

190 Sulla natura "praticamente velleitaria" del tentativo di pervenire per via ermeneutica a qualsiasi razionalizzazione dei rapporti in essere fra le diverse Corti europee cfr., da ultimo, A. Spadaro, "Una (sola) Corte per l'Europa", in AA.VV. (a cura di P. Falzea, A. Spadaro, L. Ventura), La Corte costituzionale e le Corti d'Europa, Torino, 2003.
} 
D'altra parte, i giudici nazionali, chiamati a fare riferimento alla Carta nell'ambito di applicazione del diritto dell'Unione, non avrebbero competenza per sottoporre al controllo di tutela dei diritti gli atti dell'Unione; le Corti nazionali non potrebbero, quindi che limitarsi al controllo dell'attività degli organi degli Stati membri.

In verità, non manca sul punto chi si interroghi autorevolmente sulla questione se il nuovo ordinamento europeo dei diritti fondamentali non autorizzi gli stessi giudici nazionali, in un controllo che diverrebbe così di costituzionalità diffusa, alla disapplicazione del diritto nazionale in contrasto con quello comunitario nell'ambito della stessa materia dei diritti fondamentali ${ }^{191}$. "Altro è, infatti, - osserva convincentemente Onida - dare la prevalenza a una specifica norma europea su quella nazionale contrastante, per la risoluzione di un caso concreto, altro negare applicazione a una norma nazionale per contrasto con un principio generale del diritto europeo. Parimenti, non si può immaginare che il giudice, invocando tali princìpi, possa negare applicazione a una legge europea ritenendola in contrasto con essi, senza provocare il controllo della Corte di giustizia sulla validità della legge stessa"192.

Negli ordinamenti europei, in tal modo, si dischiude una inedita via a forme di controllo diffuso della costituzionalità delle leggi, "che certamente riceverà un incremento, mano a mano che i magistrati e gli avvocati dei vari Paesi realizzeranno una piena maturazione culturale che li porterà a utilizzare meglio queste tecniche fino ad ora, a mio parere, poco conosciute. In Italia, tale prospettiva è stata recentemente rafforzata, tra l'altro, dalla modifica dell'art. 117 della Costituzione che ha introdotto un primo comma che sembra possa consentire sviluppi di questo tipo, per quanto la giurisprudenza non si sia ancora pronunciata in proposito. Quando le disposizioni del Trattato in preparazione entreranno in vigore, inclusa la Carta dei diritti, queste opportunità probabilmente cresceranno e la prospettiva di sviluppo della giurisdizione costituzionale diffusa potrà probabilmente avere ragione anche della modificazione apportata all'art. 52 della Carta, di cui si è detto sopra. Per non

191 Cfr. A. Pizzorusso, "Una Costituzione 'ottriata', in AA.VV (a cura di E. Paciotti), La Costituzione europea ... cit.; V. Onida, II problema della giurisdizione", in E. Paciotti (a cura di), La Costituzione europea ... cit.

${ }^{192}$ Cfr. V. Onida, "Il problema della giurisdizione ... cit., p. 137. 
dire che, se per avventura tale disposizione funzionasse nel senso di escludere la possibilità di utilizzare le norme della Carta, in loro vece ben potrebbero essere utilizzate moltissime altre norme di carattere internazionale di analogo contenuto che sono comunque in vigore anche negli ordinamenti statali. Ci sono ormai decine di testi internazionali che, in un modo o in un altro, sono stati recepiti nel diritto interno di molti Stati e ciò fa sì che il mondo del diritto sia ormai quasi sempre permeabile a questo tipo di esigenze, per cui le idee che si sono concretizzate in un modo o nell'altro in questi testi hanno grandi possibilità di trovare attuazione soprattutto nella misura in cui esiste una maturazione culturale degli operatori che rende tutto questo possibile (insieme ovviamente con tutte le altre circostanze che si possono presentare nel corso della storia dei singoli Paesi)"193.

Tali autorevoli orientamenti nel senso di un'apertura al nuovo quadro normativo europeo - che continua a restare, per molti profili, incerto e ambiguo per quanto concerne il tema della effettività della protezione giurisdizionale dei diritti pertanto, non fanno che sottolineare, sia pure in modo implicito, il persistente deficit normativo in tema di verifica degli atti dell'Unione e di insufficienza delle vie di ricorso disponibili per far valere i diritti fondamentali. La Convenzione non aveva compiuto grandi passi in avanti sotto questo profilo; non li aveva compiuti il Trattato costituzionale; non li compie l'attuale Trattato di Lisbona. Omologhe osservazioni di tipo problematico si pongono con riferimento alle previsioni in materia giurisdizionale, potendosi sottolineare come il sistema giudiziario dell'Unione richiederebbe una riforma più radicale di quella apportata a Nizza, che pure non è stata irrilevante.

Inoltre, le innovative previsioni dell'art. 6 TUE in tema di portata e di forza giuridica attribuita alla Carta, collocando la protezione dei diritti fondamentali in una posizione indubbiamente centrale, non potrebbe che far propria una mainstreaming clause concernente tutte le altre politiche, interne ed esterne, dell'Unione ${ }^{194}$. Una clausola di tal genere troverebbe un fondamento reale solo se si costituzionalizzasse

\footnotetext{
${ }^{193}$ Cfr. A. Pizzorusso, "Una Costituzione 'ottriata"', in E. Paciotti (a cura di), La Costituzione europea ... cit.., p. 49; M.P. Chiti, "Le norme sulla giurisdizione", in F. Bassanini - G. Tiberi (a cura di), La Costituzione europea ... cit.

${ }^{194}$ Cfr. G. De Búrca, "Fundamental rights and ... cit.; Weiler J.H.H., "A Constitution for Europe: some hard choices", in Journal of Common Market studies, 2002; M. Cartabia, "I diritti fondamentali ... cit., p. 65 ss.
} 
una disposizione che definisse la protezione dei diritti fondamentali come un obiettivo basilare dell'Unione. Sulla base dei trattati dell'Unione attualmente in vigore, tale oggettivizzazione non esiste. Un indizio ancora più importante risiederebbe nella previsione di doveri di protezione e garanzie di effettività dei diritti sociali ${ }^{195}$. Lo sviluppo di una politica dei diritti fondamentali è stato vigorosamente propugnato da parte della dottrina costituzionale e dell'Unione, ribaltando la prospettiva dalla quale comunemente vengono rivolte le maggiori critiche alla tutela dei diritti fondamentali nell'Unione europea, ossia, come si è già visto, quella della tutela giurisdizionale ${ }^{196}$. Si sostiene, in tal senso, che la questione dovrebbe riguardare tutti gli organi politici e amministrativi che operano nell'ambito dell'Unione.

In conclusione, pertanto, se già un'attenta considerazione delle disposizioni della Carta e degli articoli dei nuovi trattati che si riferiscono ai diritti fondamentali rivelano un certo qual 'stridore' fra il riconoscimento alla Carta di forza giuridica equamente ordinata a quella dei trattati e le cautele di cui tali testi vengono circondati con riferimento ai soggetti chiamati a tutelarli e a promuoverli, l'analisi del sistema giurisdizionale solleva perplessità ancora maggiori. Come si fa bene osservare, "Un catalogo dei diritti in assenza di un assetto giurisdizionale chiaro, con una permanente tensione (non risolta attraverso i canali democratici, ma affidata al cosiddetto dialogo fra le Corti) tra competenza statale e competenza comunitaria, caratterizzato per di più da un'incertezza attorno al sistema delle fonti e ai procedimenti di formazione delle medesime, non può che accrescere lo sbilanciamento fra coinvolgimento politico-democratico a livello europeo e ruolo della giurisprudenza comunitaria"197.

195 Cfr. R. Greco, "Diritti sociali, logiche di mercato e ruolo della Corte costituzionale", in Questioni Giustizia, 1994, n. 2-3; A. Di Giovine - M. Dogliani, "Dalla democrazia emancipante alla democrazia senza qualità?", in Questione Giustizia, 1993.

${ }_{196}$ Cfr., fra gli altri, G. Morbidelli, "La tutela giurisdizionale dei diritti nell'ordinamento europeo", in AA.VV. (A.I.C.), Annuario 1999. La Costituzione europea, Padova, 2000; B. Nascimbene, "Tutela dei diritti fondamentali, sanzioni e controllo della Corte di Giustizia. Verso il Trattato di Amsterdam", in Dir. dell'U.E., 1997; P. Caretti, "I diritti fondamentali nell'ordinamento nazionale e nell'ordinamento comunitario: due modelli a confronto", in Diritto pubblico, 2001.

${ }_{197}$ Cfr. R. Balduzzi, "La Carta dei diritti fondamentali dell'Unione europa: un esempio di constitutional drafting?", in Studi in onore di F. Cuocolo, Milano, 2004. 
Tali affermazioni riportano, ancora una volta, alla questione della positivizzazione di adeguate tutele giurisdizionali dei diritti fondamentali, la garanzia dei quali non può che chiamare in causa il livello della Costituzione. Laddove esiste una Dichiarazione di diritti e una Costituzione non può che esistere anche una qualche forma di separazione dei poteri, un regolare circuito democratico, una disciplina degli stessi che si avvalga di strumenti generali e astratti quali le leggi, in breve di quei princìpi strutturali che definiscono tutti i moderni ordinamenti costituzionali. Si ribadisce, in conclusione, come parlare di diritti e di Costituzione nell'ambito dell'Unione europea voglia dire porsi degli interrogativi sulla natura stessa dell'integrazione europea, superando l'approccio funzionalista che l'ha caratterizzata fin dalle origini per ridefinirne le fonti di legittimazione e i valori fondanti (rispettando ed esprimendo realmente le tradizioni costituzionali comuni degli Stati). La garanzia costituzionale dei diritti esige innanzitutto chiarezza sulle responsabilità istituzionali. Le tecniche di garanzia, a loro volta, dipendono irrimediabilmente dalla rigidità ovvero dalla flessibilità del sistema delle disposizioni costituzionali, quindi dalla configurazione del sistema delle fonti, nonché dai poteri riconosciuti in materia agli organi giurisdizionali. In effetti, alla luce della nuova forza giuridica riconosciuta alla Carta, riesce difficile ignorare come sia i valori che gli obiettivi dell'Unione europea abbiano percorso molta strada rispetto alla loro originaria definizione nei trattati fondativi dell'Unione, trasformando radicalmente i contenuti e gli obiettivi. Se non può ancora parlarsi di una 'Comunità di diritti fondamentali', i tentativi per una migliore definizione della tutela di tali diritti sono stati, comunque, molteplici e significativi. In tale ottica, la comunitarizzazione della Carta rappresenta un cambiamento importante, sia nella sua portata simbolica e identitaria ( - i diritti fondamentali assunti come base ed espressione di un ethos e di uno spazio pubblico europeo - ) sia in quella di parametro di interpretazione del Giudice dell'Unione e d'ispirazione per il legislatore europeo; essa pone ancora quesiti e dilemmi sul processo d'integrazione e sulla configurazione ultima dell'Unione europea, soprattutto per quanto concerne l'attuazione di un compiuto 'modello sociale europeo'198.

\footnotetext{
198 Cfr. G. Bronzini, "Il modello sociale europeo e il processo costituente", in http://www. magistraturademocratica.it (2/5/2004).
} 
Le perplessità aumentano se si prova ad intravedere, in un prossimo futuro, il profilarsi di una entità a fini generali che ruota attorno all'obiettivo prioritario della tutela dei diritti fondamentali. Ciò che osta maggiormente alla realizzazione di una simile prospettiva è la considerazione in base alla quale ciò metterebbe in ombra la 'Costituzione dei diritti fondamentali' degli Stati membri. L'introduzione di una 'macro politica' dei diritti fondamentali forte e onnicomprensiva, infatti, verrebbe inevitabilmente ad alterare in modo consistente 'l'equilibrio costituzionale all'interno dell'Unione; si porrebbe in contrasto col principio di sussidarietà e potrebbe attentare alla garanzia dell'autonomia costituzionale come parte dell'identità nazionale"199. Un aspetto, quello dell'impatto dell'adozione della Carta dei diritti sui diritti costituzionali nazionali e sui sistemi di garanzia degli stessi, spesso, non tenuto adeguatamente in considerazione. Si pensi, ancora, alla già richiamata tecnica normativa adottata nella formulazione di molte disposizioni sostanziali della Carta, laddove queste ultime si definiscono come affermazioni di diritti e libertà senza che vengano prefigurate adeguate categorie di limiti suscettibili di essere poi sviluppati dal legislatore - prassi riconducibile, invece, ad una delle più importanti tradizioni del costituzionalismo moderno ${ }^{200}$. Al legislatore europeo, in tale quadro, spetterebbe il delicatissimo compito di decidere sul bilanciamento fra libertà e relativi limiti. Lo stesso potere valutativo della Corte di giustizia risulterebbe accresciuto: come si è già avuto modo di riflettere, infatti, le cautele con le quali vengono circondate le possibili limitazioni dei diritti sembrano rivolgersi più alle autorità giurisdizionali che al potere legislativo. Tuttavia, com'è stato giustamente osservato, la primauté dei diritti fondamentali sulla politica presupporrebbe un consenso solido su valori comuni, ma è quantomeno opinabile il fatto che questo consenso esista già in Europa, se non altro perché i canali democratici esistenti nell'Unione sono ancora insufficienti per offrire una risposta soddisfacente in proposito.

\footnotetext{
199 Cfr. A. Bogdandy, "Comunità di diritti ... cit., nonché dello stesso Autore, "L'europeizzazione dell'ordinamento giuridico come minaccia per il consenso sociale?", in AA.VV. (a cura di G. Zagrebelsky), Diritti e Costituzione ... cit.; M. Cartabia - A. Celotto, "La giustizia costituzionale dopo Nizza", in Giur. cost., 2002; M. Cartabia, "I diritti fondamentali ... cit., p. 64.

${ }^{200}$ Cfr. U. De Siervo, "I diritti fondamentali europei ... cit., p. 266 ss.
} 